\title{
THE INNER SELF- NARRATIVES AND ACADEMIC SELF-PERCEPTIONS OF THOSE WITH LEARNING DISABILITIES IN POST-SECONDARY SETTINGS
}

\author{
by \\ Sofia Alexandra Mendes Bronze, BSW, Ryerson University, 2010 \\ An MRP \\ presented to Ryerson University \\ in partial fulfillment of the \\ requirements for the degree of \\ Master of Social Work \\ in the Program of \\ Social Work
}

Toronto, Ontario, Canada, 2014

(CSofia Alexandra Mendes Bronze 2014 


\section{AUTHOR'S DECLARATION FOR ELECTRONIC SUBMISSION OF A MRP}

I hereby declare that I am the sole author of this MRP. This is a true copy of the MRP, including any required final revisions.

I authorize Ryerson University to lend this MRP to other institutions or individuals for the purpose of scholarly research

I further authorize Ryerson University to reproduce this MRP by photocopying or by other means, in total or in part, at the request of other institutions or individuals for the purpose of scholarly research.

I understand that my MRP may be made electronically available to the public. 


\begin{abstract}
The inner self-narratives and academic self-perceptions of those with learning disabilities in post-secondary settings

Master of Social Work, 2014

Sofia Alexandra Mendes Bronze

Program of Social Work, Ryerson University
\end{abstract}

The purpose of this study was to explore the various disabled identities of those with learning disabilities in higher educational settings, and its impact on academic self-worth. The majority of scholarship has essentialized both disabled identity and academic self-perception, fostering the victimization of those with learning disabilities in the pursuit of their education. This study problematized the medical model, viewing disability as an internal and fixed identity, negatively implicating self-worth. In contrast, this study incorporated a critical disability theory, to highlight the social construction of disability, complimented with a postmodernist lens to appreciate the fluidity of identity and perceptions. A narrative methodological approach was utilized to give voice to the experiences and stories of five self-identifying learning disabled students from Ryerson University. The findings of this research suggest that learning disabled student relate to three different types of disability narratives or identities, implicating their academic worth in many ways. 


\section{ACKNOWLEDGEMENTS}

I found it impossible to fully captivate and express the amount of gratitude I have for everyone that has supported me throughout this exceptionally challenging academic journey. To my family, who has shown nothing but love, enthusiasm and patience in every single academic journey and decision I have made. A deep felt gratitude extends to my loving father, who has always pushed and challenged me to reach the stars, even when I only saw darkness. To my mother who always kept my spirits high, and pushed me to fight even when the going got tough! Thank you both for being my biggest supporters, which gave me the courage to pursue my Masters. To my brothers Ricardo and Jason, for keeping me grounded, balanced and thinking positively. Lastly, to Carlos who always lent a listening ear and knew when to make me smile and laugh. You all have played such an essential part in my academic success; I am not only lucky but privileged to have you all in my life. Thank you!!!

A sincere and special thank you goes to my supervisor Dr. Susan Preston, for her patience, guidance, and continuous encouragement, especially believing in my academic abilities as a student with an LD, which truly gave me the strength to complete this MRP. Dr. Preston has made my time at Ryerson wonderful, I would not be where I am as an academic and social worker without her and I will be forever grateful!

To my entire MSW cohort; what a great journey we all shared and it has been a pleasure learning and developing together! And my research seminar class; I have never felt so much support, understanding and acceptance. I could not imagine completing this M.S W. without each and every single one of you. You are all inspirational and courageous women and it was a blessing to have had the opportunity to share this challenging year with you all. 


\section{DEDICATION}

To anyone who believed in me. 


\section{TABLE OF CONTENTS}

$\begin{array}{ll}\text { Chapter 1. Introduction } & \text { Page 1 }\end{array}$

$\begin{array}{lr}\text { Chapter 2. Literature Review } & \text { Page } 4\end{array}$

$\begin{array}{lr}\text { Chapter 3. Theoretical Framework } & \text { Page } 20\end{array}$

$\begin{array}{lr}\text { Chapter 4. Methodology } & \text { Page } 33\end{array}$

$\begin{array}{lr}\text { Chapter 5. Findings } & \text { Page } 48\end{array}$

$\begin{array}{lr}\text { Chapter 6. Discussion } & \text { Page 83 }\end{array}$

$\begin{array}{lr}\text { Chapter 7. Conclusion } & \text { Page } 112\end{array}$

$\begin{array}{ll}\text { References } & \text { Page } 116\end{array}$ 


\section{CHAPTER 1. INTRODUCTION}

This study intends to describe and explore the academic self-perceptions of postsecondary students with learning disabilities (LD). Positive self-perception and worth is a strong predictor for academic success and achievement (Shany, Wiener \& Assido, 2012). Individuals with LD are more likely to be negatively implicated within academic self-worth domains, specifically in their confidence, esteem and efficacy (Jones, 2012; May \& Stone, 2010; Saracoglu, Minden \& Wilchesky, 2001; Wei \& Merder, 2012). Given the intersection of selfperception with academic outcomes, this study further explores this matter, with a focus on how disability identity may impact academic self-perceptions of post-secondary students with positive academic outcomes. In doing so, this study resists a medical model of disability which has dominated social research understanding of the realities of those with LD; such studies view disability as a fixed element residing with the individual based on biological impairment and as negatively influencing how an individual may perceive the self (Alvermann \& Mallozzi, 2010; Bruzy, 1997; McKenzie \& Thomson, 2005). Such scholarship focuses on impairment as the basis of one's LD identity, undermining the possibilities of multiple truths and perceptions for identities (McKenzie \& Thomson, 2005). Alternatively, a social model of disability views disability as socially created, rather than an internal biological impairment, acknowledging flexibility and external factors in how an individual identifies with disability identity (Green, 2007; Riddell \& Watson, 2003). Along with this social model, postmodernism emphasizes a varied rather than a static and homogenized understanding of identity, stressing that disability identity perceptions vary and do not always reflect a negative self-worth (Savaria, 2008).

Critical disability theory, specifically Hosking's understanding (2008) informs this study, positioning disability as socially constructed, thus acknowledging how discourses of disability 
identity may influence a variety of academic self-perceptions. Critical disability theory is complemented by Foucauldian postmodern perspectives in this study, to shift an analysis from singular truths to emphasizing the diversity of identities and self-perceptions for LD students (Mills, 2003).

This study used qualitative semi-structured conversation style interviews with five individuals who self-identify as having a learning disability and are currently attending a fulltime or part-time graduate or undergraduate program at Ryerson University in Toronto, Ontario. A narrative approach was used to investigate how participants construct and describe their inner self-narrative and academic self-perception. Through a process of restorying and remapping participant's narrated stories, guided by the Three Dimensional Space Narrative Structure (Creswell, 2005), this research identifies and describes commonalities, themes and links within and between participants' stories, to highlight the diverse experiences and academic selfperceptions of those with LD (Creswell, 2013).

\section{Researcher Positionality}

In positioning myself as a researcher with this topic, I reflect on my own identity and history as a learning disabled individual within academia. I was diagnosed at the age of eight and at the time, disability seemed to not impact how I perceived my own intellectual capacity or worth in academia. However, as I grew up, I experienced significant struggles related to my learning. I was advised to not pursue post-secondary schooling, and developed a profound belief that I was not intellectually capable to study at a higher level. At the same time I had a desire to become a social worker and to pursue my bachelor's degree, but assumed that in order to succeed at university, I had to work harder than most students because of my perceived impairment. Once I entered university, I experienced severe anxiety and lacked confidence, 
which impacted my overall wellbeing, my adjustment to university life, and my grade point average; at times I felt that I was not meant to be in academia.

As time passed, with persistence I developed the strategies to succeed academically. I proved to myself that I was intellectually capable, and understood how I learned differently. I recognized that a learning disability can be a stigmatizing label that has been constructed in our society; this label meaningfully constructed who I was in educational contexts (Hosking, 2008). Even knowing the label was socially created I still felt victimized and vulnerable as it framed who I was. I felt this understanding constructed a singular negative disabled identity for all individuals with LD in academia. However, throughout my professional and personal experiences, I began to recognize that not everyone accepted an impairment-based disabled identity, and that some viewed their LD as a place of capability and strength. Through this understanding, I began to consider research to highlight multiple truths related to disability in academia. 


\section{CHAPTER 2. LITERATURE REVIEW}

\section{Introduction}

The identities and experiences of marginalization and exclusion for those with learning disabilities have been explored in various forms of social research, including social work. These experiences are further compounded when those with LD enter educational institutions, perhaps even more so in post-secondary settings (Good \& Orr, 2010; Heiman \& Precel, 2003; Scorgie, Kildal \& Wilgosh, 2010). Given the increasing rate of enrolment of students with LD in higher educational settings, new challenges have emerged highlighting the need for educational institutions and social work to respond (Goodman \& Orr, 2010; Heiman \& Precel, 2003). While there has been some exploration of the academic achievement and experiences of this population, those with LD in higher educational settings are least likely to graduate compared to nondisabled counterparts (Belch, 2004; Goodman \& Orr, 2010; Heiman \& Precel, 2003). Moreover, due to high stress, experiences of academic challenges and receiving poor grades, the persistency of academic effort of those with LD diminishes, hindering academic achievement (Goodman \& Orr, 2010; Heiman \& Precel, 2003). These experiences are magnified by general felt hardship in university life, which includes ableist discrimination, social isolation, barriers to effective supports, and poor academic and emotional adjustment (Heiman \& Kariv, 2004; Saracoglu, Minden \& Wilchesky, 2001, Scorgie, Kildal \& Wilgosh, 2010). Such scholarship paints an exceptionally bleak picture for those with LD in post-secondary settings, filled with negative experiences and reduced likelihood for academic success.

This literature review will explore dominant knowledge related to the experiences of those with learning disabilities in higher-educational settings. Narrowing this review, I will explore academic perception, noting its influence on learning disabled students' overall 
educational experience and success. The components of confidence, esteem and efficacy will be described as fundamental to academic perception. Thereafter, this review will focus on disability and identity informing perception in academia. Dominant theories located in positivist, interpretive and postmodern paradigms each offer unique and contradictory views on disability identity and impacts on perceptions. This review problematizes positivist understanding of disability as a fixed, internal identity based on deficit, negatively impacting self-perceptions and essentializing realities (Alvermann \& Mallozzi, 2010; Newman, 2006). This review posits disability as a social construct, implicating identity in multiple and flexible ways, thus rejecting deficit identities and emphasizing that academic perceptions are interchangeable. I will outline gaps that legitimize my research, noting both problematic substantive knowledge and research processes in current scholarship.

\section{Academic Self-perception}

Understanding the academic experiences of students with LD can be partly understood through self-perception, in how an individual comes to view the self and perceive who they are (Elbaum \& Vaughn, 2001). Sometimes framed as self-concept or global self (De Santos, 2005), self-perceptions guides the processes by which a person thinks, feels and evaluates the total self (Elbaum \& Vaughn, 2001; Wei \& Marder, 2012). Self-perception can be conceptualized within specific contexts, with academic self-perceptions referring only to how an individual evaluates their worth scholastically (De Santos, 2005; Elbaum \& Vaughn, 2001). A positive academic selfperception is a strong predictor for educational success, whereby such individuals are more likely to view the self as academically valuable and competent (Akomolafe, Ogunmakin \& Fasooto, 2013; De Santos, 2005; Shany, Wiener \& Assido, 2012; Wei \& Marder, 2012). 
Signifying the role of confidence, esteem and efficacy as components influencing how LD students come to view self-worth academically, studies suggest that those with learning disabilities across the lifespan are more likely to exhibit overall negative self-perceptions in comparison to non-disabled populations, especially in academic and intellectual domains ( Bear, Minke \& Manning, 2002; Crosnoe, Riegle-Crumb \& Muller, 2007; Elbaum \& Vaughn, 2003; Jones, 2012; LaBarbera, 2008; Paterson, McKenzie \& Lindsay, 2012; Sideridis, 2003; Wei \& Marder, 2012), even more so in higher education settings (May \& Stone, 2010; Saracoglu, Minden \& Wilchesky, 2001; Shany, Wiener \& Assido, 2012; Vaughn, Elbaum \& Boardman, 2001).

Self-confidence. Self-confidences linked to academic self-perceptions, understood as the ways an individual feels and appraises the self, can inform personalized worthiness and abilities (Al-Hebaishi, 2012; Srivastava, 2013). Self-confidence is the overall level of assurance, selfreliance and personalized beliefs in one's own capabilities and the self as a whole, including expected performances and failures (Al-Hebaishi, 2012; Srivastava, 2013). Self-confidence is the most influential variable that impacts learning and academic performance (Al-Hebaishi, 2012). As such, an individual with high self-confidence tends to believe in their academic competencies, and thereby is more likely to experience successful learning (Al-Hebaishi, 2012; Srivastava, 2013). Higher self-confidence is notably valuable for those with LD, as it can assist in alleviating the hardship experienced in academic struggles, ease transition into university life and promote positive socio-emotional abilities (Wei \& Merder, 2012).

However, research concerning the degree of self-confidence for those with LD is contradictory. Some studies indicate that LD students across the lifespan display low levels of self-confidence (Beaty, 1991; Evans, 1998; Heiman \& Kariv, 2004; Jerome, Fujiki, Brinton \& 
James, 2002; Lind \& Bowler, 2009). Meanwhile, Wei and Merder (2012) found learning disabled students do not always display negative self-confidence within academia. Opposing views also exist regarding the stability and conceptualization of self-confidence amongst learning disabled students. Some studies present self-confidence as an either/or reality, emphasizing its fixed nature (as positive or negative). However, Wei and Merder (2012) note the fluidity of self-confidence for LD students, as it shifts over the course of one's academic career.

Self-esteem. In addition to self-confidence, self-esteem is seen as positively informing the self-perceptions of those with LD, particularly in academic domains, with self-esteem understood as "a person's global judgement of competency regarding one's self -worth" (Mohammad, 2010, p. 2474). Self-esteem signifies how an individual feels positively or negatively about themselves and can be manifested in a variety of ways such as pride, shame and self-confidence (Afari, Ward \& Khine, 2012). While self-confidence relates to the assurance an individual has regarding competencies, self-esteem refers exclusively to the total worth perceived by an individual (Al-Hebaishi, 2012; Srivastava, 2013). An individual with high selfesteem is content with who they are as a person, values themselves, recognizes their weaknesses and strengths, and feels comfortable about personalized characteristics and abilities (De Santos, 2005). Those with low self-esteem perceive the self in less favourable means, often fixated on their alleged deficits rather than on their proficiencies (De Santos, 2005).

For student, high self-esteem enhances academic aspirations and willingness to attempt intellectually-challenging tasks, reinforces positive learning experiences, and influences success and/or failure in educational environments, similar to self-confidence (Afari, Ward \& Khine, 2012; Mohammad, 2010; Peixoto \& Almeida, 2010). Such students perceive themselves as active and capable academic agents believe that they have control in scholastically stimulating 
yet difficult situations, and perceive that with investing efforts they can achieve academic goals (Mohammad, 2010). However, scholarship focusing exclusively on self-esteem consistently indicates that learning disabled students are more likely to exhibit lower self-esteem across all developmental stages and age groups, thus potentially impacting their academic self (Bear, Minke \& Manning, 2002; Chapman, 1988; Elbaum \& Vaughn, 2003; LaBarbera, 2008; McKenzie \& Thomson, 2005; Saracoglu, Minden \& Wilchesky, 2001; Tabassam \& Grainger, 2002).

Self-efficacy. Self-efficacy also has been noted for its impact on self-perceptions in learning disabled individuals. Self-efficacy "refers to one's beliefs about his or her ability to successfully perform specific tasks in specific situations" (Hampton \& Mason, 2003, p, 102). Academically, it relates to an individual's assurance and expectations regarding competency, and influences what they think they can or cannot do academically (Lackaye, Margalit, Ziv \& Ziman, 2006). A weakened perception in academic self-efficacy negatively impacts a student's ability to cope in higher educational settings, results in poorer academic performance, and hinders persistency amidst demanding academic circumstances (Hampton \& Mason, 2003; Saracoglu, Minden, \& Wilchesky, 2001). Compared to non-disabled peers, students with learning disabilities have consistently demonstrated lower self-efficacy, especially in academic domains (Frederickson \& Jacobs, 2001; Hampton \& Mason, 2003; Lackaye, Margalit, Ziv \& Ziman,2006; Linnenbrink \& Pintrich, 2003), including those in higher educational settings (Milsom \& Hartley, 2005; Saracoglu, Minden \& Wilchesky, 2001). Some researchers suggest that those with LD may be anticipated to have lowered academic self-efficacy since they have reduced positive efficacy, as they are least likely to experience success (e.g., academic achievement) and are more likely to experience adjustment issues related to disability and social barriers (e.g., rejection by 
classmates) within academia (Hampton \& Mason, 2003). With repeated failure over time, those with LD are thought to internalize a negative belief about their ability to perform academically, thereby weakening perceived efficacy and implicating future academic performances, including willingness to persist (Hampton \& Mason, 2003).

Factors influencing self-perception. There is no denying the role which confidence, esteem and efficacy play in the academic perception of LD students and its ability to dictate academic success. Self-confidence corresponds to the overall assurance in one's skills, as the most influential variable for academic perception; the higher confidence one displays the more likely they are to experience successful learning academic achievement (Al-Hebaishi, 2012; Srivastava, 2013). Self-esteem relates to one's total self-worth, and if developed positively individuals maintain a view as active academic agents, perceive control in demanding scholastic situations, and uphold a belief that with effort they can achieve academic goals. Academic selfefficacy is about one's conviction regarding academic skills, impacting perceived proficiency academically (Lackaye, Margalit, Ziv \& Ziman, 2006). Exploring the self-perception of postsecondary students with LD is essential, given its ability to reinforce positive experiences in higher educational settings and its implications for academic success.

Alongside these individualized aspects of self-perception (including one's confidence, esteem and efficacy), self-perception is influenced by external factors. Individuals who receive parental support, especially acceptance of disability, were more likely to display positive selfperception, enhanced self-worth, and heightened academic achievement (Hagborg, 2003; LaBarbera, 2008; Rothman \& Cosden, 1995). Scorgie, Kildal, and Wilgosh (2010) found that encouragement from family members influenced self-determination in students with LD, assisting in one's ability to cope effectively with learning challenges and positively stimulating 
perceived ability to accomplish educational goals. Keefe and Berndt (1996) emphasized the significance of strong peer relationships in persuading self-perceptions in academia, while others have highlighted the importance of a combination of supportive relationships (peer, family and faculty) accepting disability, whereby students demonstrated enhanced academic performance, perseverance in challenging tasks, and reduced scholastic anxiety (Field, Sarver \& Shaw, 2003; Goodman \& Orr, 2010; Jones, 2012). A strong link between self-esteem and perceived social support from a mix of relational sources amongst those with LD also has been noted (Helsen, Vollebergh \& Meeus, 2000; Quatman \& Watson, 2001; Williams \& Galliher, 2006).

\section{Research Paradigms}

Scholarship has focused on the adverse experiences of those with LD, noting how it relates to their overall negative academic worth, but also acknowledging the role of social supports in mitigating negativity. In examining the literature, several areas seem missing. I question why disability's impact on perception was not explicitly explored. Secondly, given the complexity of humanness, I question why current scholarship homogenizes realities, in ways that victimize disabled individuals in the pursuit of their education. Through my professional and personal experiences I witnessed the fluid and complex nature of identity and its impact on perception. Below I discuss positivist, interpretive and postmodernist disability theorizing, noting differing views on what entails disability and identity (i.e., as an internal impairment, as a socially constructed truth, or as multiple and fluid meanings) and its impact on perception.

Positivist paradigm. A positivist paradigm comprehends that social reality and perceptions can easily be explained in objective and predictable means (Newman, 2006). It values scientific inquiry and value-free science, thus rejecting ideologies, critical thought and the influences of culture or society to explain social life and perceptions (Irving, 1999). Within this 
framework disability has been explored as a predictable, concrete, internal, and individualistic variable influencing social reality (Alvermann \& Mallozzi, 2010; Green, 2007).

In positivist social research, a medical model of disability has dominated explanations of the reality of those with disabilities (McVittie, Goodall \& McKinley, 2008). Within this model, disability is viewed as a loss or impairment of ability; a person is perceived as unable to fully participate in society, with functioning defined as limitations of physical, cognitive, environmental or visual means (Bruzy, 1997; Green, 2007). Disability is assumed to be an intrinsic element, residing within and with the individual, as a reality that can be objectified and generalized (Alvermann \& Mallozzi, 2010). Within understanding disability as impairment, it is outlined as a personalized tragedy or loss within the self, which explains how one perceives reality and the social world; it is posited as creating emotional turmoil or distress, which can included weakened confidence, esteem or efficacy (Bruzy, 1997; McKenzie \& Thomson, 2005; Riddell \& Watson, 2003).

The medical model of disability has been criticized for centering impairment as the sole reality of disabled bodies (Green, 2007). Viewing disability as the problem has been further reproduced by scholarship regarding the negative academic self-perception of those with LD, and undermining resiliency of those with disabilities and ignoring variation in both experiences and identities (Bruzy, 1997; McKenzie \& Thomson, 2005; Riddell \& Watson, 2003). The medical model relies on cause-effect correlations to obtain universalized truth of those with disabilities, homogenizing identities and academic realities (Newman, 2006) of those with disabilities as powerless to alter their predetermined identity, and thus as passive subjects with minimal agency (Tremain, 2005). 
Such scholarship constantly compares disabled against non-disabled individuals, further problematizing their realities. This process structures disability as something to be measured against normative standards (able-bodied), which opposes the celebration of differences and acceptance in the uniqueness of human diversity (Lakkis \& Wehbi, 2010). Lastly, selfperceptions and limitations experienced by disabled individuals are understood to be a direct result of disability (as a problem), based on impairment and consequential emotional distress rather than social, ideological, cultural or external environmental influences (McKenzie \& Thomson, 2005). Doing so denies accountability from society (Lakkis \& Wehbi, 2010) and fosters expectations of failure, inability to learn, and self-blame, thus promoting felt disempowerment in academia (Green, 2007). This approach can hinder educational institutions and the field of social work to fully understand those with $\mathrm{LD}$, as it limits the conceptualization of inability and problematization, ignoring the varying capacities, resiliency and realities of students, and thus the flexibility needed in shaping services (Lakkis \& Webhi, 2010).

Interpretive paradigm. Interpretive scholarship contrasts positivist conceptions, as it foregrounds individualistic and internal subjective experiences in understanding how individuals perceive the self and experience their social worlds (Rubin \& Babbie, 2001). This paradigm values social life, with a primary focus on social interactions and socially constructed meanings related to disability or discourses, seeing the internalized subjective self as a by-product of complex social processes. Social reality is understood as meanings an individual has generated, shaping perceptions (Green, 2007; Newman, 2006). Particular to those with disabilities, interpretive frameworks include social model of disability, labeling theory and social comparison theory (Green, 2007; McKenzie \& Thomson, 2005; Paterson, McKenzie \& Lindsay, 2012). 
A social model of disability discounts disability identity as abnormal, as a defined problem residing within the individual based on permanent deficit (Green, 2007; Riddell \& Watson, 2003), and argues that traditional and positivist disability approaches such as a medical model are based on defective beliefs of impairment as the single disabled experience and basis of identity (Fleischer \& Zames, 2001; Green, 2007; Priestley, 2003). A social model of disability places importance on social, cultural and structural factors that contribute to the negative experiences and disablement of those with disabilities (Green, 2007). Viewing disability as socially constructed, influencing self-perception and impacting how individuals with disability interact and understand the social world (Green, 2007; Riddell \& Watson, 2003), a socially constructed disablement nonetheless reflects the medical model in many ways, and thus maintains its power as a dominant discourse framing the realities of disabled individuals (Bruzy, 1997). The difference between these models is that the "problem" of disability is placed within society and the associated barriers that create disablement (in the social model) rather than the medical model's framing of disabled communities based on biological impairment (Green, 2007).

Labeling theory explains that an individual's self-perceptions are influenced by labels and categories which impact an individual's behaviour. Such labels are usually socially constructed and informed by societal discourses of normality and abnormality. Related to those with LD, individuals take on socially constructed categories of disabled to themselves, usually informed by a dominant discourse of disability based on impairment; this categorized identity often hinders academic success and learning (McKenzie \& Thomson, 2005). Furthermore, such social labels can impact how others in the social world evaluate the individual, including those with LD being perceived as academically challenged or less intelligent (Jones, 2012; May \& 
Stone, 2010). This categorization of identity is perpetuated when an individual experiences academic struggles or is further labeled as an individual with LD within the physical space of academia (McVittie, Goodall \& McKinley, 2008). This process of continued integration of a negative label into an individual's self-perception weakens psychological wellbeing and sense of worth (Paterson, McKenzie \& Lindsay, 2012). A labeling perspective acknowledges cultural and social factors contributing to the person's self-perceptions as an individual with LD, contrary to the medical model's understanding of learning disability as an individualized impairment. Nonetheless, a labeling perspective is problematic as it continues to construct individuals as passive and powerless victims, in the ability to resist labels that influence self-perception (Green, 2007; Tremain, 2005).

Social comparison theory places importance on the role of interactions as informing selfperceptions and one's association with a disabled identity, through a process of downward or upward comparison (Paterson, McKenzie \& Lindsay, 2012). With respect to LD, an individual in academia compares their intellectual proficiency with others, wherein socially constructed labels, like those based on impairment, are managed and resisted through comparison (McVittie, Goodall \& McKinley, 2008). Social comparison theory highlights that disability identity is a social construct, not fixed or static, where LD individuals are not presumed to be passive and helpless victims to labels based on impairment (McVittie, Goodall \& McKinley, 2008).

Postmodern paradigm. Other scholars have highlighted a more dynamic process of identity formation of the inner self, including the self-perception. Some understandings through postmodernism and post-structuralism recognize that social life is fluid, with no concrete predictable pattern within its processes and outcomes, whereby generalizable truths about perceptions or the formation of identities are discounted (Peile, \& McCouat, 1997; Riddle \& 
Watson, 2003). The conceptualization of the inner self for those with disabilities is not an “either/or" phenomenon, but rather multiple in variations and open to many interpretations with diverse implications (McDonald, Keys \& Balcazar, 2007; Peile, \& McCouat, 1997). As reinforced by Riddell and Watson (2003), some postmodernists emphasize that disabled individuals do not possess one fixed identity, but rather individuals consistently negotiate disability identity which can be integrated positively or negatively in multiple means. Although discourses of impairment and deficit hold substantial power and can be challenging to counteract, individuals do resist, although this process is exceptionally individualistic (Savaria, 2008). Furthermore, the process of resistance to or incorporation of disability identity tends to evolve over time and thus is unstable (Savaria, 2008). Therefore, from postmodern perspectives, inner self and identity formation are complex and varied which can differentially impact the ways in which an individual with LD perceives the self and their own worth.

\section{Limitations in Current Scholarship}

Having reviewed above current scholarship relevant to this research, below I will discuss the inherent limitations in the literature, affirming the importance of my research. Issues that will be explored are the incomplete knowledge within the substantive focus of other research and the unrepresentative and biased research processes in current approaches to this research topic.

Incomplete knowledge. Literature that essentializes academic self-perception in negative ways ignores identity as a probable factor requiring exploration. Such scholarship, mostly from a medical model perspective within a positivist paradigm, assumes an automatic and fixed negative identity and perception. Scholarship within an interpretive and postmodernist paradigm views disability as more fluid and multiple in formation, but has not explored identity and 
perception of student with LD at the post-secondary level. Given such limitations within scholarship this research is a needed area of exploration.

The focus of this study is to explore the inner self narratives (disability identity) of postsecondary students with LD, to discover how multiple disabled identities influence academic worth. Self-narratives is a concept devised from critical disability and postmodernist literature that places importance on narratives told by disabled individuals in their own diverse expressions of identities, experiences and perceptions (Green, 2007). The intent is to unearth narratives of post-secondary students with LD to comprehend experiences, contributing to knowledge that denies singular and permanent deficit based identities.

Another knowledge-based limitation is the lack of social work scholarship regarding the academic perceptions and the formation of inner self of those with LD in post-secondary educational settings. Most of the literature drew upon disciplines such as disability studies, psychology and sociology. This gap requires social work's attention, because LD students in post-secondary are actively marginalized and experience structural barriers; often they are unsupported, misunderstood and impacted negatively as it relates to academic achievement, all areas of importance for social work. This research has the potential to provide an alternative critical lens and add to social work scholarship that could potentially improve services and our understanding of those with $\mathrm{LD}$, resisting marginalization and better comprehending the diverse realities of LD students.

Unrepresentative findings and exclusive research processes. This research recruited self-identifying LD students, as the majority of studies have legitimized what constitutes LD (e.g., an official diagnosis), thus silencing particular voices. Other studies excluded some student voices, by recruiting students with only mild to moderate forms of disabilities or only including 
those with dyslexia, dysgraphia and dyscalculia, or excluding those with Attention Deficit Disorder and verbal impairments (Green, 2007; May \& Stone, 2010; Shany, Wiener \& Assido, 2012). Only one study incorporated individuals from a wide spectrum of disabilities (NarioRedmond, 2010), while some excluded participants with LD without medical proof of diagnosis (May \& Stone, 2010; Scorgie, Kildal \& Wilgosh, 2010). This narrowing definition of learning disability in current scholarship is unrepresentative and constitutes disabled identities from the perspective of non-disabled individuals, reinforcing privilege and oppression over disabled communities in social research processes (Fitzgerald, 2004; Stone \& Priestley, 1996).

Traditionally, disabled realities and knowledge have been defined and controlled by dominant groups, typically non-disabled researchers operating within a medicalized model of disability, thus reproducing social and historical domination (Stone \& Priestley, 1996). In doing so, the expert as knower perpetuates discourses of dependence and impairment, as those with disabilities are assumed incompetent to define their identity, further constructing disabled individuals as passive bodies against a normative able bodied standard (Fitzgerald, 2004; Stone \& Priestley, 1996). Recruiting self-identifying (as they determine) individuals with LD acts as process of empowerment, to detract from a medicalized discourse, embrace capability, minimize biased representation, and provide a landscape for inclusion of all experiences (Goodman \& Orr, 2010).

Representation of disabled communities is further biased in current research through problematic data collection tools which ignore the various ways those with LD communicate and process information. In this review, Paterson, McKenzie and Lindsay (2012) and Troiano (2003) were amongst the only researchers that incorporated both written and verbal methods of data collection, combined with repeating questions, providing additional time to process information, 
and permitting participants to tape record interviews, as ways to support diversity in comprehension processes. Researchers that were inflexible with their approach of data collection methods (i.e., only written surveys) noted limitations with regards to uncertainty if participants understood questions and material (Green, 2007). Much of the research reviewed continues to sustain dominant discourses and is misrepresentative of learning disabled communities in postsecondary settings as it relates to academic perceptions and identity, thus limiting the applicability of findings to assist in our conception and the development of appropriate services. This study has offered flexibility in data collection methods to be sensitive to LD communicating and processing styles, to maintain accuracy of data and inclusion of all individuals with LD.

This research intends to explore these gaps in the dominant knowledge and research processes of social research pertaining to disability, identity and academic self-perception for LD students at the post-secondary level. My aim is to contribute to social work literature, by providing critical understandings which may enhance services. Lastly, given the narrow selection of LD students in recent studies and the exclusionary processes of data collection, this research introduces alternative approaches to its processes that can further authenticate data collected and contribute to more comprehensive findings.

\section{Conclusion}

As reflected in this study's literature review, academic self-perception is composed and influenced by a variety of factors. Although a variety of research paradigms have brought forward contradictory and interesting explanations in comprehending identity and perception, many have contributed to essentialization, while those that consider various understandings have limited analysis to students with intellectual disabilities at the post-secondary level. Given the current landscape of scholarship, especially the gaps within, I propose the necessity of this study 
as previously stated. Lastly, the benefits of this study include its inclusive methodological approach that will hopefully bring forth representative findings. The next chapter will outline the theoretical foundation of this study influenced by critical disability theory and postmodernism (Hosking, 2008; Mills, 2003). 


\section{CHAPTER 3. THEORETICAL FRAMEWORK}

Learning disabled studies can be informed by many theoretical approaches and frameworks. This study is informed by critical disability theory (CDT) and postmodernism. Critical disability theory is relevant as it attempts to explain and uncover the negative social realities and positionalities of those with disabilities (Baffoe, 2013), especially as it relates to socially and culturally constructed truths/discourses and assumptions of disability that can implicate learning disabled lives, including social perceptions and identity (Hosking. 2008; Mills, 2003). CDT also considers how language influences the formation of disability and thus acts to categorize disabled individuals (Hosking, 2008). Including this aspect of CDT allows this study to examine the expression of language in how one speaks about identity and inner self narrative. CDT also adds to this study by recognizing the multidimensionality of disabled communities, moving away from homogenizing learning disabled students (Hosking, 2008). Lastly, CDT focuses on self-defined disabled perceptions; this will be critical to my work, as disabled voices are often silenced, thus contributing to faulty generalizations (Hosking, 2008).

Postmodernism is relevant to this study because it acknowledges the formation of identity and perceptions occurs in many ways, countering the dominant homogenized identity as fixed and stable (Mills, 2003; Peile \& McCouat, 1997; Riddell \& Watson, 2003). It still recognizes the power of socially constructed truths but does not accept the truths as factual (Hosking, 2008; McCoute \& Peile, 1997; Mills, 2003). This study will use the following elements of postmodernism: (a) rejection of inner essence of identity, and acceptance of identity informed by discourses; (b) knowledge, truths and discourses as socially created and acting to divide and categorize, operating as power on societal perceptions and individual identity; (c) notions of objectification and subjectivity through power and governance; and (d) power as fluid, whereby discourses can be rejected and resisted (Mills, 2003; Tremain, 2005). CDT and postmodernism 
are used in partnership in this Major Research paper, and complement each other in several ways, which I discuss in detail for the remainder of this chapter.

\section{Critical Disability Theory}

Critical disability theory is an emerging theoretical perspective that studies disability issues (Hosking, 2008). Generally, critical disability theory examines the potential negative social realities of those with disabilities, exploring ways to counteract negative experiences, critiquing dominant norms and discourses (i.e., ableism), and seeking social transformation (Baffoe, 2013). Thus, critical disability theory provides a broad spectrum for understanding and addressing the current multiple realities of those with disabilities (Baffoe, 2013).

Hosking's (2008) unique theoretical approach is different than other approaches to CDT, by incorporating the jurisprudence of disability as a human rights issue, and thus blending critical theoretical traditions and critical legal studies. Given the complexity of Hosking's theory, his theory is informative and thorough, requiring few linkages to other perspectives of CDT.

Hosking's (2008) critical disability theory is an approach for analysis centralizing disability and challenging ableist perspectives that inform society. Hosking draws from traditional critical theory to explain the wrongs of current social order and reality implicating those with disabilities, highlighting ways to contest it towards achievable goals in the quest for social and political transformation for disabled (2008). Hosking's CDT builds from traditional critical legal studies, but given its examination of structural biases (such as the role of identity in society and legal institutions and its inability to respond to certain minority groups), his CDT expands to comprise elements from the family of identity jurisprudence, including seven specific concepts: the social model of disability, multi-dimensionality, valuing diversity, human rights, voices of disability, language, and transformative politics (2008). 
Four of these concepts are particularly relevant to my research. Firstly, the social model of disability views disability as socially and culturally created, which can potentially impact how one views the self (Hosking, 2008). Placing disablement as a dominant socially-constructed discourse allows this study to identify the power and operations of negative dominant truth on social perception and rejects an internal fixed identity. Secondly, Hosking (2008) proclaims language is not a neutral element and can act to divide and label individuals, implicating the social categorization of disability and thus identity. This study examines language as told by learning disabled students to recognize how they relate to their disability. Thirdly, multidimensionality is used to appreciate the diversity of disabled individuals, who may interact with a number of potential identities and social locations (Hosking, 2008). This understanding is utilized to appreciate the complexity of disabled individuals, and thus removes simplistic, fixed notions of disabled realities. Fourth, CDT recognizes that often the voices of those with disabilities are silenced and appropriated by able bodied communities (Hosking, 2008). CDT and this study centralizes the voices and perspectives of disabled individuals in order to challenge dominant discourses of impairment and gain insight that is authentically aligned with learning disabled students (Hosking, 2008).

Hosking's CDT discusses alternative principles such as a focus on human rights, by critiquing methods of unequal participation, exclusion or lack of citizenship in society, whereas CDT places political transformation within such structural exclusionary processes, including systematic responses that do not embody notions of difference (Hosking, 2008). This research is interested in understanding the disabled individual reality (identity) and complexities within at the personal level that influence academic perceptions, rather than overtly analyzing social processes of exclusion and devising alternatives for needed changes (Hosking, 2008). While this is 
important, the focus of this research could be useful for promoting changes in services and supports within academic institutions that affect, comprehend and accommodate disabled individual from an individual rather than a macro level of analysis.

Disability as socially constructed. Traditionally, disability has been regarded as a personalized tragedy requiring prevention and curing of disabled bodies based on medicalized disadvantages, thus framing disability against normality and locating abled bodied at the forefront of acceptance (Hosking, 2008). As an essentializing framework, a medical model views disability as an inherent element within the individual that can be objectified and measured by identifying impairment (Hosking, 2008). Hosking's critical disability theory incorporates a social model of disability in which disability identity is viewed as socially and culturally constructed, rather than as an identity defined by limitations to participation and inclusion in society, or as the consequence of biological impairment (2008). CDT proclaims that disabled realities can be defined by a complex interrelationship an individual forms between impairment, their responses to such impairment and the social atmosphere; the negative social realities of those with disabilities is caused by physical, institutionalized, cultural factors (through socially constructed discourses and truths), that limit those with disabilities and define or inform them as abnormal and thus impaired (Hosking, 2008; Mills, 2003). This social construction understanding provides a starting basis for my work, incorporating an analysis of how those with $\mathrm{LD}$ are potentially perceived by others or themselves and how this may impact one's self-perceptions within academia. This foundation can expose powerful and negative dominant discourses or truths, which de-problematizes disabled bodies based on supposed fixed internal deficit (Hosking, 2008). I will additionally draw on Foucault's knowledge on the operations of discourses, socially constructed truths and power to further CDT's 
understanding related to identity and perception (Foucault, 1979, 1981; Mills, 2003), which I discuss further later in this chapter.

Language. Within critical disability theory, Hosking also focuses on language, particularly how language influences the conceptualization of disability identity and thus acts to categorize disabled individuals (Hosking, 2008). This includes specific words utilized to describe and label disabled bodies and then collectively used to portray disability as a whole (Hosking, 2008). Hosking emphasizes that language is not a neutral element but rather political and perpetuates discourses related to disability; within a medicalized discourse, language negatively defines disabled as incapable and powerless (2008). An examination of language may be useful to comprehend how those with LD describe their disabled identity, in alternative ways (apart from impairment) that may influence perception (Mills, 2003). This CDT understanding of the role of discourses on the formation of identity and perception through communication and language will be complemented by Foucauldian understandings of discourse (Mills, 2003) as discussed later.

Multidimensionality. Hosking (2008) introduces the concept of multidimensionality as an essential element to CBT and our understanding of those with $\mathrm{LD}$, particularly to reflect disabled individuals as a diversified group. Those with learning disabilities may identify with the social positionality of disabled as defined by society; they may also embrace numerous social classifications informed by dominant discourses regarding sexual orientation, class, ethnicity and race, for example (Hosking, 2008; Mills, 2003). Multidimensionality suggests that individuals may interact with a number of potential identities, realities and social locations that could highlight axes of subordination or privilege; these multiple and interconnected memberships, realities and experiences informed by various discourses form the actualized reality of disabled individuals (Hosking, 2008). While important, this study does not intend to explore how various forms of 
identities, such as race, class or gender implicate academic self-perceptions. Rather, multidimensionality is utilized to appreciate the complexity of disabled individuals, moving away from simplistic notions of disabled realities as one fixed truth that perceives the academic selves in one concrete way (Hosking, 2008). This understanding of multidimensionality will be integrated with Foucault's understanding of fluidity in identity and formation (Mills, 2003), as discussed later.

Voice. Given that the voices of disabled individuals are often silenced, critical disability theory foregrounds the stories of disabled individuals (Hosking, 2008). Able bodied individuals have defined and explained disability identity and realities through their ableist viewpoints, usually portrayed as a personalized tragedy and unimaginable suffering, subjected to a life of dependency with little promise (Hosking, 2008). Critical disability theory argues that actively attending to disabled perspectives can educate able bodies that realities of disability does not necessarily mean a life of despair, but rather as a complex life that includes resiliency and ability (Hosking, 2008). This research is interested in placing priority on listening to the stories and voices (narratives) of learning disabled students in post-secondary settings, with the hope to challenge dominant discourses of impairment and the negative academic perceptions as defined by non-disabled communities.

This critical disability theory assists this research by centralizing the tenets of disability as socially constructed, recognizing language as non-neutral, which can help to reveal how one speaks about identity, while also appreciating the multidimensionality of disabled, moving away from simplistic understandings and valuing disabled voices to challenge dominant discourses and produce representative findings (Hosking, 2008). As mentioned, in a collaborative partnership 
critical disability theory complements aspects of postmodernism. I will now discuss elements within postmodernism that interact with critical disability theory.

\section{Postmodernism: Michel Foucault}

Within a postmodernist perspective there are many different approaches that could inform this research, the most appropriate relates to the work of Michel Foucault (Mills, 2003). Foucault (1926-1984) was a French philosopher and historian, who gained a strong reputation as one of the most vital figures associated with critical thought, not only informing postmodernist thinking, but also post-structuralism, post-colonialism and feminism theorizing (Mills, 2003). Foucault's theorizing has received much attention specific to his understanding of knowledge and discourses, and the operation of punishment, power and governance, with an overall focus highlighting social control and the regulation of bodies and identities (Mills, 2003; Tremain, 2005). The thoughts of Foucault have been applied within disability scholarship in interesting ways, to further our comprehension of the regulation of disabled individuals and communities and how they potentially perceive the self (Tremain, 2005). Although his work is extensive, this research will only incorporate four concepts (as discussed below) to further this study's analysis of identity formation, with an aim to understand self-perceptions.

Rejection of inner essence of identity. Of particular importance to this research is Foucault's notion of identity formation. Primarily, Foucault disallowed the idea that an individual has an inherent and fixed identity located within the self (Mills, 2003). The essentialist understanding assumes a fixed and singular identity, and its implicit social positionality regulates and distinguishes who a person is and thus how they must inevitably perceive the self (Foucault, 1972, 1981; Mills, 2003; Tremain, 2005). Foucault and others reject this understanding, positing that perception of identity, including how an individual perceives the self in academia, is based on 
a network of discourses or socially constructed truths incorporated by an individual as expressed through the use of language (Foucault, 1972, 1981). The expressed use of language informs perception at the time of communication, and thus, the method by which an individual expresses (verbally) their identity is discourse, which is continuously shifting and changing (Foucault, 1981).

Foucault describes discourses in complex ways, including its implications for perception. A discourse at times is designated as the general field of statements that includes utterances communicated by an individual that has some type of meaning and specific effect; at other times discourse is seen as an individualizable cluster of statements, which form a collection of meaning, such as a discourse of medical model of disability (Foucault, 1972, 1981). Discourse is a regulated practice that takes into account a number of statements or utterances, which contain unwritten structures or rules that produce particular utterances or statements (Foucault, 1981). In all, discourse can be described as a group of statements which provide a means to mobilize language or communication, to talk about one's identity in a way that represents a knowledge base about that topic from the perspective of that individual (Foucault, 1972, 1981; Mills, 2003). The operationalization of discourses is not simply the use of language as a basis of reality (or the communication of it), but rather that the discourses an individual draws from (such as a medical model of disability) and the regularities and unwritten guidelines within, influence how an individual perceives the self (Foucault, 1981; Hosking, 2008; Mills, 2003). Thus discourses create a lens through which we perceive the world and the self, about identity and social positionality a person has associated themselves with, and provides a means by which to understand one's values and assumptions (Foucault, 1981, 1972; Lambie \& Milsom, 2010; Mills, 2003). This study is interested in the various discourses by which students with LD constrain and 
direct their conceptualized identity (inner self narratives) and its impact on academic perceptions.

Socially constructed truths and discourses. We might assume that discourse(s) and its role on perception suggest an individual is free to choose or can be easily influenced by any discourse at any time, that all discourses weigh the same and hold equal power. Foucault (1979) contests this notion, focusing on how power is played out through knowledge, and especially how it has been used as a method and means to build "Truths" in society. Truths refer to dominant discourses, practices and norms that are freely accepted to be inevitable and thus common sense (Foucault, 1979; Savaria, 2008). For something to be verified as true, other correspondingly valid discourses (or even statements) need to be subjugated as wrong and thus rejected, while those accepted discourses develop into regimes of Truth, socially, culturally and historically created as correct and as common sense (Foucault, 1979; Irving, 1999; Savaria, 2008). Such discourses help to categorize measure or order things such as our perspectives, behaviours and ideas, which in turn impacts individuals (Foucault, 1979, 1981; Savaria, 2008). Understanding knowledge is hierarchically ordered and defined, some knowledge holds prominence (such as disability based on impairment), some none at all (such as disability as strength and capability), and some shift between. Individual identities get ranked and codified as differently located within this hierarchy (Foucault, 1979; Savaria, 2008). This complex order or knowledge impacts identities and thus some individuals (i.e., able bodied) are classified as more vital or essential within society than others (Foucault, 1979; Savaria, 2008).

Foucault provides an analysis of how socially constructed truths and dominant discourses, such as Hosking's understanding of disability, maintain its power within society and can influence the construction of the self-identity for those with disabilities and its potential 
impact on the academic self (Foucault, 1972, 1979, 1981; Hosking, 2008). The disablement produced through the social environment in various forms (as similarly proposed by Hosking), acts as multiple sites perpetuating specific discourses, and thus maintains dominant truths related to disability (Foucault, 1979, 1980; Hosking, 2008). Foucauldian examinations regarding how some identities are ranked, classified or more valuable is prevalent in Hosking's analysis in which disabled are constantly compared against able bodied standards and viewed as less than others or as the problem, rather than being accepted (Foucault, 1979; Hosking, 2008). Hosking offers his critical analysis regarding language as a form of communicating a discourse of disablement to societies and individuals, which sustain its power and maintain Truths (Foucault 1972, 1979, 1981; Hosking, 2008). Hosking informs this research wherein disablement as a discourse is evident, through the social environments and language, whereas Foucault assists to understand how disablement is produced, has maintained its power, and could impact selfidentity (Foucault 1972, 1979, 1981; Hosking, 2008). Perhaps we can comprehend how students with learning disabilities may be influenced by such a dominating discourse, but also how it may be difficult to take on another discourse (i.e., disability as a place of capability ) because such opposing discourses have continuously be subjugated in society (Foucault, 1979; Hosking, 2008; Irving, 1999).

Subjection, objectification and governmentality. Foucault's theoretical understanding of governmentality furthers understandings of how disabled bodies become regulated, objectified and subjected to a dominant disabled discourse (Tremain, 2005). Foucault (1975) examines the nature and operation of discipline and how societies were formed in a disciplinary manner. Understood as part of common and normal processes and events located within various economies, education, politics, sciences and history, discipline is seen as a means to maintain 
order in society, recognizing that any system of power requires an assurance of discipline in order for it to sustain itself (Foucault, 1975).

Foucault coined "governmentality" as the process by which individuals learn to govern themselves to reflect the norms and Truths located within society (1975). Further, the body is seen as a focus of a number of discursive pressures, and thus becomes a site where discourses and dominant truths are sanctioned and disputed (Foucault, 1978). The body is a historical and cultural specific entity, which is experienced, treated and viewed differently depending on the social and historical context of that time (Foucault, 1978; Mills, 2003). Complementing this understanding of the body is the concept of bio-power, as a process of organizing a population (i.e., disabled) for the sake of regulation and corrective mechanisms, and to establish norms (Foucault, 1970, 1977). Within this process, societies introduce a host of practices that act to classify and manage certain individuals until they are divided and thus objectified (Foucault, 1978). Disabled individuals and communities are consistently problematized through language and the social environment, often by attitudes or by exclusion from participation; they are thus divided, usually through essentialist and ableist acts (Hosking, 2008). Foucault would argue that these specific practices of division around a specific norm (i.e., able bodied) act to individualize disabled bodies, whereby people come to view the self along those lines (1978). By objectification, individuals become subjects, such as disabled individuals, and subject both to the control and power within the social environment and to being associated with that identity (disabled impaired) through a process of self-knowledge and self-regulation (Foucault, 1982). Governmentality thus provides this research a foundation by which processes of disablement (Hosking, 2008) are powerful and dictate disabled bodies, substantially influencing identity formation and perceptions (Foucault, 1975). 
Foucault's examination of power is fruitful for this research, to highlight the fluidity of identity formation in its multiple forms. Rather than a simplified understanding of associations between those who hold positions of oppression (disabled) and those who are oppressors (able bodied), power is conceptualized in a chain-like fashion, as a fluid system of relationships that operate throughout societies (Foucault, 1980; Mills 2003). Individuals are not simply the receivers of discourses, but the body is a place where power is enacted and thus a place where it can be resisted (Foucault, 1980). Power is conceptualized as a means of performance on something (the body) rather than a means of absolute accomplishment (Foucault, 1980). Foucault describes the operation of fluidity and complexity of power through discourses as, not once and for all submissive to power or raised up against it... we must make allowances for the complex and unstable process where discourse can be both an instrument and effect of power, but also hindrance, a stumbling block, a point of resistance and a starting point for opposing strategy. Discourses transmit and produce power; it reinforces it, but also undermines it and exposes it, renders it fragile and makes it possible to thwart it. (1979, p. 100-101)

Power is not seen as a means of oppression that ultimately determines identities (as disabled and impaired, for example) but rather is seen as a process of negotiation and performance in which identities can be formed in many ways (Mills, 2003). Additionally, individuals can construct or take on counter discourses, contrary to the normative system of knowledge (Foucault, 1979). This analysis provides an understanding that not all individuals are subjected to a disabled discourse based on impairment that can significantly negatively impact academic perceptions as literature has suggested. Instead, it helps to reveal the multiple ways in which identity is formed and thus the many ways an individual may come to view the self 
academically (Mill, 2003). This notion of fluidity in identity further validates the principles of multidimensionality as proposed by Hosking (2008).

\section{Conclusion}

How I perceive the focus of this research, regarding the complexity of the inner self narratives (disabled identity) and academic perceptions, is guided by critical disability theory and a Foucauldian analysis as detailed (Hosking, 2008; Mills,2003). First, the acknowledgement that disablement has been produced as a dominant discourse and is perpetuated in society through various avenues that may regulate and reduce the self-identification of those with disabilities, helps to understand how it can negatively impact academic perceptions and frame the disabled bodied based on deficit (Hosking, 2008; Tremain, 2005). Second, the emphasis on multidimensionality and fluidity of power and discourse posits that identity and perceptions of disabled individuals is not stable and has variations, rather than determined by a signalised discourse (Foucault, 1979; Hosking, 2008). Lastly, hearing the stories, voices and perspectives of those with disabilities is central to this research as often their realities have been defined by able bodied and appropriated. This research is focused on disabled inner narratives and their academic perceptions, explored from within rather than about the community (Hosking, 2008). In the next chapter, I discuss how I approach this work methodologically. 


\section{CHAPTER 4. METHODOLOGY}

This chapter consists of a detailed discussion and outline of the study's methodological framework. To start, I begin with an introduction to the overall aim, objectives of this research and the research question. The benefits and scope of the methodological narrative approach adopted by this study will be discussed, noting its congruence with the study's objectives, participants and theoretical framework. The second half of this chapter consists of a thorough description of the research design, which includes recruitment, data collection methods and tools, consent processes and data analysis, as informed by the Three Dimensional Space Narrative Structure (Clandinin \& Connelly, 2000; Creswell, 2005).

\section{Aim and Research Question}

This study fused critical disability and postmodernist perspectives as discussed, using a narrative method of data collection and analysis (Creswell, 2005; Mills, 2003; Tremain, 2005). This research is influenced by the substantive gaps in scholarship, combined with my own personal and professional experiences and understandings of disability identity and perceptions as fluid. This study explored the academic self-perceptions of those with learning disabilities in post-secondary settings with a focus on the inner narratives/identities of this population. While not disregarding how the discourse of disability identity related to impairment negatively impacts self-perception, including my own, this study shifted from singular truths to instead emphasizing the diversity of identity and variety of perceptions for students with learning disabilities.

Designed as a small pilot study to potentially inform future research initiatives, this Major Research Paper question is: What are the inner self-narratives of those with learning disabilities in post-secondary settings, and its impact on academic self-perceptions? It seeks to explore the multiple meanings to identity and academic perception. 


\section{Narrative Inquiry}

A narrative methodological approach was utilized within this study to support a story-like structure to data and findings (Newman, 2006). Through narrative inquiry this study examined the ways in which post-secondary students with learning disabilities experienced and framed the self (identity) and their academic worlds or worth. This study describes the lives/experiences of students with LD, through the collection of their stories or narratives. Through a process of remapping and restorying, the study explored individual and common themes and tensions within these stories to understand such experiences as the fluid realities of these students (Creswell, 2005, 2013).

The value of a narrative perspective is the premise that all individuals naturally convey stories or narratives of their lives, realities and experiences, by means of communication, both internally and externally in their everyday interactions within the social world; thus, human beings are story telling creatures and conduct storied existences (Connelly \& Clandinin, 1990; Fraser, 2004). All individuals make sense of randomized experiences or memories or events by installing stories, which also have the potential to reveal the positionality of the story teller (Connelly \& Clandinin, 1990). Human beings utilize narratives to describe and convey their emotions, and how they think, feel or relate to their social world, and this can apply to how one perceives their disabled identity and academic worth (Connelly \& Clandinin, 1990).

Scholars have also highlighted the benefit of a narrative inquiry for providing an efficient lens to examine the expression and formation of identities (self-narratives) and perceptions about themselves in context, such as in an academic setting (Lambie \& Milsom, 2010). A fundamental aspect of a narrative inquiry and this study then is to value and capture all the stories, events or memories, without altering or reducing their narrative-like quality, as it is the foundation to 
interpretation and also maintains the reflection of disabled expressions (Newman, 2006). By capturing the genuine expression of those with learning disabilities through their stories, we can analyze how such narratives have been constructed from the landscape of the story-teller, increasing the credibility of the research data; doing so can also further respect disabled realities and experiences by promoting each individual's representation in the knowledge produced (Riessman \& Speedy, 2007). Additionally, stories are a naturalized element utilized by all individuals, and thus a familiar approach to data collection. Those with learning disabilities are accustomed with and can easily comprehend storytelling, and this research valued a narrative method for its naturalistic approach to research (Creswell, 2005). Since a narrative approach believes stories can be expressed verbally, in written form and through images, it can be inclusive to all individuals who may express themselves in various ways (Creswell, 2005). Lastly, a story telling approach is appropriate because it investigates the direct micro level of experience that is the individualistic stories as told by those with LD, rather than an examination of broad theories, operations of systems or societal customers (Creswell, 2013).

Stories can be understood as discourses as suggested by Foucault, and a narrative inquiry fits well within a critical disability postmodernist lens, to capture the realities from the vantage point of LD individuals (Foucault, 1972, 1981; Lambie \& Milsom, 2010). Disability scholarship operating within a postmodernist framework favours a narrative inquiry as much of their work builds on "disability narratives which explores the sociology of the body and the lived experiences of illness, impairment and disability from the insider's perspective" (Green, 2007, p.329). Narrative inquiry comprehends that describing stories through language is complex and ever changing. When someone describes a story, not all discourses are integrated, only representing their perception at that time; this reflects postmodern understanding of realities as 
never fixed but continuously evolving (Lambie \& Milsom, 2010). Both approaches value the operation of language as something that creates and provides insight into the individual's current reality, which is influenced by history, discourse and culture; it is through the knowledge expressed by language that realities are designed and maintained (Lambie \& Milsom, 2010).

A narrative investigation is further aligned with this study's principles as it highlights the voices of disabled individuals, centering their experience and knowledge, consistent with critical disability theory (Creswell, 2005; Hosking, 2008). The sharing of experiences where voices are heard reinforces that disabled stories are important; story-telling allowed disabled participants to make meaning and connection to this study's focus and their own experience (Fraser, 2004; McEwan \& Egan, 1995). I self-identify as a post-secondary student with a LD and thus was personally implicated within this study; through a narrative approach I was able to become intertwined and self-reflective in the study's plot, where my own voice and life history was incorporated into this research (Newman, 2006). Contrary to positivist research that assumes distance and objectivity, integrating myself in all steps in the research process was understood as a collaborative, empowering process, exchanging knowledge and creating awareness, through highlighting my own voice and the voices of participants (Newman, 2006).

This study collected and retold narratives to reflect the stories of learning disabled participants allowing insight into their historical, social and cultural positions (Clandinin \& Connelly, 2000). In doing so, the research revealed how participants constructed and expressed their inner self narratives/identities and perceptions, and how one located themselves in academia (Lambie \& Milsom, 2010). Below I review the methods utilized to conduct this study. 


\section{Study Design}

Sample and recruitment. Through the use of a purposive sampling, this study recruited five self-identifying post-secondary students with learning disabilities by advertised posters distributed throughout Ryerson University, located in Toronto, Ontario. All potential participants were required to be enrolled full-time or part-time in any graduate or undergraduate program at Ryerson University. Since the focus and research question was based on those with LD and their academic perceptions at the post-secondary level, the described recruitment procedure was appropriate to target the desired population (Newman, 2006). As this study may be used to potentially inform future research, and was small in size consistent with narrative inquiry, five participants was satisfactory for generating findings and discussion as a starting point. Others may build on its foundations, with additional resources to conduct a larger study. Also, given the small sample size of this study, recruitment at one post-secondary institution was sufficient.

Participants potentially represented any characteristic, including a variety of ages, gender, marital status, ethnicity, Aboriginal status and/or income. However, given the research focus all participants were self-identifying individuals with LD (no documented diagnosis required), with various forms of learning disabilities, such as reading, writing, audio and visual impairments. The justification for inclusion of all types of learning disabilities including students who selfidentify as LD was to avoid the appropriation of disabled identity as one that is ascribed by others; anyone who perceived identification with LD, in any way was included, with or without documentation as evidence of their disability.

The recruitment poster was designed to be inclusive to those with various forms of learning disabilities, in terms of comprehension, such as the use of appropriate font size, clear readability, and non-distracting paper color. It concisely outlined the objectives of the study and 
researcher contact information. Once participants expressed interest through email contact, the researcher conducted a brief telephone and/or email screening to ensure participants met the eligibility criteria of the study. Overall, this recruitment method was devised to ensure heightened probability for targeting the study's explicit population, in order to stay within the confines of the research focus and to sufficiently answer the research question (Newman, 2006).

Data collection. This study incorporated one semi-structured face-to-face narrative style interview lasting 1 to 1.5 hours in length (to provide sufficient time) in which participants were asked to engage in a conversation about their experiences as an individual with a learning disability related to their academic perceptions and identity formation. Interviews were held in a privately booked room at Ryerson University or a confidential location chosen by participants; both of these methods were used for accessibility and convenience purposes. Interviews were essential to this research because it placed value and priority on expression of personalized language to data collection, allowing for in-depth development of meaning to various experiences of those with LD and thereby advanced a more thorough understanding in the research focus (Newton, 2010).

A narrative style interview was suitable, as it encouraged participants to tell stories and recall events and/or memories related to the study's focus (Fraser, 2004). With the aim of engaging participants in storytelling, a conversation style was favoured because of its casual, welcoming and friendly approach to interactions, which provided opportunities to construct alternative stories or new memories together with participants, allowing for data to emerge that may not have otherwise seemed pertinent (Fraser, 2004). However, this study incorporated a semi-structured approach to interviewing as it was guided by an interview schedule and demographic questionnaire, to ensure that the questions covered and the flow of conversation 
was relevant and stayed within the confines of the research topic, to promote relevance of data and to answer the research question (Newman, 2006). Semi-structured interviewing allowed a variety of open-ended or probing questions to engage in open dialogue that incorporated active and attentive listening, to uncover elements that could have been significant to the study's focus, but were not covered in the interview guide or demographic questionnaire (Fraser, 2004; Newman, 2006). Interviews were audio recorded and later transcribed, and/or written by the researcher or participant. Providing participants the option to choose one of these two methods of data collection as they preferred enhanced the participation of those with various learning disabilities.

As mentioned, this study incorporated an interview guide and demographic questionnaire. The demographic questionnaire contained identifiable information separate from all other data collected, to maintain confidentiality, and for follow up purposes; information collected pertained to participants name, gender, age, mailing address and telephone number. The interview guide included a variety of closed ended, open ended and probing questions, mostly seeking a response in the form of a narrative related to the study's focus (Fraser, 2004). The interview asked: (1) close ended questions that were unidentifiable information about participants, such as program of study, type of disability and age of diagnosis (2) open ended questions related to identity formation revealing how participants had constructed the ways in which they viewed, perceived and related to their disability identity, and (3) open ended questions on academic perceptions to understand the level of self-worth participants displayed in academic settings. Probing questions were used to further explore stories or responses. The questions were specifically designed to elicit answers that address and answer the research question. Lastly, the interview guide and questions was informed by the Three Dimensional 
Space Narrative Structure, to fully capitalize on the experiences of learning disabled students; details of the framework are discussed in the data analysis section of this chapter. (Clandinin, 2013).

To ensure full consent and understanding of participation, the researcher introduced the research and outlined its purpose, risk, benefits, confidentiality, time commitment and privacy factors, and inquired if participants had any further questions related to the proposed study. For participants that agreed to participate, a consent form was emailed or mailed in advance of the interview to provide sufficient time for participants to review and make an informed decision. Participants brought their signed consent forms to the interview, although consent forms also were available to be signed at the interview. Participants were provided $\$ 20$ cash at the start of the interview, as honorarium but also to cover travel expenses to and from the study location and potentially the cost of something to eat.

As part of a narrative inquiry, stories told by learning disabled individuals were collected and developed into a narrated-like structure to assist in understanding identity formation and its impact on academic perceptions (Newman, 2006). Once the interviews had been transcribed, participants were invited to attend an optional session to review the transcripts for accuracy, both as a reflection of the interview and as an opportunity to revise any of their responses (Creswell, 2013). This process was introduced to promote some degree of a collaborative process and to renegotiate information if needed, both as elements often located in narrative inquiry (Clandinin \& Connelly, 2000).

Data analysis I: The Three Dimensional Spaces Narrative Structure. This study incorporated the Three Dimensional Space Narrative Structure for its retelling and restorying process (structured analysis) as devised by Clandinin and Connelly (2000). This process of data 
analysis was influenced by John Dewey's philosophies towards comprehending individual experiences, realities and perceptions as based on a, "continuous interaction of human thought with our personal, social and material environment" (Clandinin, 2013, p 52). Dewey identified three criteria as necessary to grasp experiences or defined realities - interaction (personal and social) and continuity (past, present and future) which are enacted within specific situations or contexts (Clandinin, 2013). As argued by Clandinin (2013) it is using the three dimensions that individuals recall, express and retell their stories, composing their experiences, which is the basis of a naturally occurring narratively collected phenomenon. The three dimensions proposed by Dewey embody the core concepts of various and recent narrative inquiries towards understanding defined realities, which represents the basis of this research (Clandinin, 2013). Clandinin (2013) proposes these three elements must be explored to fully comprehend experiences as an essential objective within narrative inquiry. Through these influences, The Three Dimensional Space Narrative Structure can be seen as a relevant approach for comprehending experiences, perceptions and defined realities (inner self-narratives and academic self-perceptions) of those with learning disabilities in post-secondary settings (Clandinin, 2013).

Utilizing the Three Dimensional Space Narrative Structure, this study's specific approach to restorying and remapping was to identify/collect three key elements within raw data: (a) interactions; (b) continuity; (c) situation/context, which were later analyzed considering the commonalities, themes and tensions within and across stories (Ollenshaw \& Creswell, 2002). As stated by Clandinin (2013) each dimension has the potential to interconnect and intersect, and does not operate in isolation. Therefore, data analysis and restorying remained sensitive to, and attempted to represent, the complexity of interconnections within and between participant narratives. Each of the three elements are discussed below. 
Interactions. With regards to interactions, this study was attentive to and analyzed both the personal and social conditions of learning disabled participants (Clandinin \& Connelly, 2000). Identification of personal conditions included pronounced feelings, emotions, perspectives, hopes, triumphs, disappointment, values, dispositions, reactions, motives and overall aesthetics (Clandinin \& Connelly, 2000). Chiefly useful through the exploration of personal conditions was the revelation of how participants reacted, spoke about and related to their inner disability narratives (i.e., how they viewed their disability), plus their multiple reflections of academic selfworth (e.g., feelings of stupidity or capability), including how these personal conditions reflected and/or were altered based on social conditions, time and contexts/situation (Clandinin, 2013).

The social aspect of interaction refers to the milieu and condition under which participant's experiences transpired (Clandinin, 2013). Analysis entailed looking at environmental conditions (i.e., academic/institutional, cultural, social, domestic/familial) which included individual interactions (peers, faculty and family members), emphasizing elements such as point of views, intentions, bias, purpose, utilization, influence, significance and impact (Clandinin \& Connelly, 2000). In consideration of social interaction, this study was able to evaluate how environmental elements, including individuals within a particular setting or context, influenced participant experiences of relating to and identifying with their inner self narratives and academic selfperceptions. Analysis of these social conditions and interactions was interlaced with personal elements, time and context (Clandinin, 2013). Overall, the analysis of interaction allowed a turn inward, attending to the personal dispositions of all five narrative accounts, while also examining how these are shaped and informed by outward social/environmental conditions (Clandinin, 2013). 
Continuity. An analysis of continuity entailed identification of stories, events or memories related to the remembered past, present experience, and the predicted potential future, all of which can influence each other (Creswell, 2013). This element reflects an understanding that experiences and defined realities shift through time and are inherently narrative, as individuals constantly revise their autobiographies as they progress through life, which is conversant through interaction and context (Clandinin, 2013). Analysis of continuity was particularly helpful to identify and comprehend the various and often changing (fluid) nature of inner self narratives and academic perceptions expressed and experienced by participants throughout time in their academic career, and potentially influencing their anticipated future. (Creswell, 2013).

Situational/context. Clandinin (2013) posits that an identification of situation/context identifies explicit, concrete and physical landscapes or places, including sequences of places where experiences and events have taken residence in an individual's recalled narrative. These contexts are further interconnected with continuity (time) and may inform and influence both personal and social conditions (Clandinin, 2013). Of particular importance to this study was acknowledging or recognizing that contexts, such as academic settings, can play an exceptional role in informing learning disabled participants inner self narratives and academic selfperceptions.

Overall, this model was appropriate for this narrative research, because in order to explore the experiences, perception or defined realities of those with LD as it pertains to identity and academic self-worth, one must identify the dynamic relations between both the personal and social conditions (interaction) and the impact of past events on current and future experiences or realities, including the context in which interactions or past events occurred. (Ollenshaw \& Creswell, 2002). By attending to the three dimensions, this study was able to examine and 
explore the complexity representing learning disabled experiences and defined reality, both inside and outside, as well as the imagined past, the present and the possible future. (Clandinin, 2013). I argue the comprehensive and dynamic nature of the Three Dimensional Model, which is as robustly present in other forms of narrative methodologies, offered this study a framework to answer to its original question, and also provided additional insightful conclusions due to unique data derived from the three elements.

Data analysis II: Details of the two-step process. Above I noted the structure of the three-dimensional model, which informed how data was collected, organized and analyzed. Consistent with Connelly (2013), my analysis was done as a two-step process. The first step involved restorying and retelling each participant's story from their interview transcript, using the Three Dimensional Model as a structural template to aid this process. In doing so, I framed each participant's story with an introductory description of the participant, followed by presenting their story in small "chapters" which reflected particular concepts and ideas emerging from the interweaving of interactions, continuity and situational/context in the restorying and retelling process. After doing this for each participant, I then moved to the second step of the analysis process, where I began to look for resonant threads that wove between participant stories. While similar to "across-case" thematic analysis in other forms of narrative research (Riessman, 2005), the Three Dimension Model approach seeks patterns in the three elements of interaction, continuity and situational/context, and in the restoryed presentation of participant narratives (Clandinin, 2013). I discuss each of these two steps in detail below.

Restorying and retelling for each participant. The process of data analysis followed many steps. Overall, I analyzed and transcribed data line by line in my own comprehension and words, utilizing retelling and restorying as narrative analysis, leading to a newly created 
individual narrative account for each of the five participants (Clandinin, 2013; Creswell, 2005). Prior to composing each narrative account, I charted and divided field text (participant observation notes and transcribed interview) by identifying the interplay of the three dimensions proposed by Clandinin and Connelly's narrative inquiry (Clandinin \& Connelly, 2000; Creswell, 2005). Doing so helps to uncover untold elements of the experience, and to better understand the interconnection between interaction, continuity and situational/context elements of a person's experience (Clandinin, 2013).

Thereafter, I composed "interim text" as part of the restorying process, by creating "annal sketches" for each participant, still working closely to make sense of the three dimensions located in the field text and chart (Clandinin, 2013). Annal sketches are visual images/diagrams that portray and outline, usually in chronological sequence, a record of events and milestones, as well as themes within the narrative field text, over a particular period. The annal sketches are writings and drawings added to the field text by the researcher, to create a visual aid and assist in seeking a deeper meaning and coherence of field text and charted data (Clandinin, 2013). Moving back and forth, rereading and revisiting field text, divided chart and interim text, was a complex and interactive process towards data analysis, always staying within the confines of the three dimensions (Clandinin, 2013).

Clandinin acknowledges that any narrative analysis, and especially the Three Dimensional Model, can be difficult, as there is no linear unfolding in the process of data collection, data analysis and the writing of final text (2013). Yet this difficulty is also a strength in narrative inquiry, as the analysis process emerges specific to the research question and theoretical framework of the study (Riessman, 2005). Following the annal sketching, I attempted to identify elements in data and devised five narrative accounts as it related to the research question. Final 
accounts must reflect the three dimensions and this was central to my analysis. (Clandinin, 2013;

Creswell, 2005). Restorying is fundamental to narrative inquiry, as often individuals who describe a story may not follow a direct arrangement and thus it may not progress logically, making comprehension difficult (Creswell, 2005). The process of restorying allowed the researcher to uncover commonalities, sequences and casual links amongst concepts, to help make sense of participant experiences (Creswell, 2005).

Second level of analysis: Considering the five narrative accounts. A common second process in narrative inquiry is to code all the data (narrative accounts or written stories) into categories or common themes, which can add a deeper grasp of group and participant realities (Creswell, 2005, 2013; Fraser, 2004). Specific to Clandinin (2013) a second level of analysis requires looking across all five narrative accounts, to investigate what is understood as "resonating threads", or patterns, which are reflected through the three dimensional model. A focus on threads and patterns allows the researcher to follow plotlines that are interlaced and threaded over context and time in each narrative account. This was done by comparing each account alongside one another, and searching for resonances that were consistent across all accounts (Clandinin, 2013). Unlike thematic narrative analysis, it is not so much looking for common themes as it is looking for common elements within stories, knowing that the particularities of each element may differ between participants. For example, "relationship with parents" may be a common element across all participants, but the type, strength and impact of that relationship can vary considerably between participants. Apart from following the general guidelines of this model, the researcher also considered the overall meaning as it relates to identity conceptualization and perception, thus exploring social significance within data (Ollenshaw \& Creswell, 2002). 
Once this study is publically available, participants will be offered a copy of the Major Research Paper by registered mail or email, as a token of appreciation to participation. Lastly, to continue valuing the collaborative process within narrative inquiry, participants will also be offered a follow up session to discuss results (Creswell, 2005).

\section{Conclusion}

This study was intended to identify the inner self narratives (disabled identity) of students with learning disabilities, and its impact on academic self-perceptions. This study recruited five self-identifying individuals with LD from Ryerson University, located in Toronto, Canada. The methodological approach utilized in this research was a narrative inquiry, in order to support a story like structure to data and findings (Newman, 2006). Each subject participated in a one-onone semi structured interview. Through a process of remapping guided by the Three Dimensional Space Narrative Structure, this study explored individual and group commonalities, themes and tensions located within and across stories (Clandinin, 2013). The following chapter presents the findings of this study, consisting of five narrative accounts, ending with a summary of the resonating threads (Clandinin, 2013). 


\section{CHAPTER 5. FINDINGS}

The following presents narrative accounts for each of the five participants with learning disabilities from Ryerson University. The findings are presented and organized in a fashion consistent with the Three Dimensional Space Narrative Structure, incorporating all three elements - interaction, continuity and context/situation - in each narrative account (Creswell, 2005). With the three dimensional model, each narrative account was devised for each participant, to surface and provide a voice for their own individual story (Clandinin, 2013). Remaining true to the study's proposed method means producing lengthy narrative accounts in single-spaced format similar to transcript excerpts, as exemplified in Clandinin's own work (2013). This chapter ends with a review of the resonating threads located across all five narrative accounts.

\section{Five Narrative Accounts}

\section{Narrative Account: Kim}

Kim is a first year undergraduate student enrolled in a non-humanities related program. She identified her learning disability as Attention Deficit Disorder and was diagnosed at the age of 8 .

The remembered past: Exploration, confusion and disability as negative. Kim's journey began with her diagnosis of ADD at the age of 8, "I was young, I didn't really know much about it." Kim felt because of her age she did not quite understand what her disability meant. Her awareness experience of ADD was significantly connected to academia, at the beginning of high school. Her initial reactions were those of shock, followed by a continuous process of meaning making and confusion. "When I was diagnosed I didn't really know much about it. The only time I really noticed that I kinda had it, was like in grade 10 and grade 11. When I started high school and that's when it kinda hit me and it was hard. Cause I was like wow, I really do have ADD. Like I never knew this."

Kim emphasized the realization of her disability impacted her self-esteem and worth and brought forward feelings of shame, embarrassment and disappointment in her academic life. She viewed it as an undesirable identity, rather than something to embrace. "It made me feel scared, it really lowered my self-esteem. So I was like negative about so many things. I had the worse self-esteem issues, I was worried about everything."

Drawing upon dominant cultural assumptions and discourses of disability, Kim identified as intellectually incapable, different and perhaps not normal, as reflected in comments like I was like, okay, wow, I am a complete idiot" and "I was embarrassed by it, like badly embarrassed." 
Kim reinforces how this negative identity situated her within an academic context, "high school was pretty much the hardest time of my entire life because of it [disability]." She also noted the role of her family in how she understood her disability.

The family in making meaning of ADD. Kim's familial story informed her comprehension of her disability throughout the time of diagnosis and increased awareness of ADD, and while in secondary and post-secondary school. The associated familial memories from her remembered past were continuous and influence her present reality. The family unit, physical environment at home and the relationship Kim's parents had with each other informed her disability identity and educational experiences. "I grew up in a very very like tense household. My parents were never really on the same page. I kinda would like, try to zone out and ignore what's going on there. I think that's how I got ADD because I tend to zone out and that really affected me....Zoning out part, just kinda stuck with me... I think that's how like, in class now my imagination would be playing."

The most pronounced familial narrative was Kim's continuous reference to the relationship with her father, as negative and detrimental to her comfort and positive association with disability. "My dad was never really like supportive of it, he would make me feel completely horrible about it. He would continuously bring me down; make fun of me for it, along with his side of the family ... My dad, like, kinda reaction made me feel as if I was stupid."

The relationship with her mother represented a different dynamic, "My mom was more on the supportive side. Like she was trying to help me, and like, make me feel more comfortable with it." While supportive and valuable, the memories and feelings recalled about her father's behaviour appeared to be more influential to her disabled identity.

The start of Kim's post-secondary experience: A difficult transition, with a narrative of incapability and lack of confidence. Kim's stories of academia reflect her disbelief and questioning of her capabilities, and lowered self-confidence and esteem. At the beginning, university represented a negative and frightening learning environment. "My confidence was extremely low, it was like bottom. I was like going to fail this, I am going to get kicked out, and I am going to go on probation. Every single thing that was negative I was thinking, I was going to fail this, why am I here? My confidence was very, very low. The first week of school, that was probably like the most hardest week ever."

An event in class carried her back to her original feelings of ADD in high school suggesting how her past impacts her present reality. In recalling this event, I sensed a great deal of shame and embarrassment.

"I was writing a test and the professor basically screamed out in front of the entire class, "[Kim] are you an access centre student [Access Centre is Ryerson's Disability Support]?" I was like, oh crap; I was like "Yes." He was like "Okay you can forcibly move all the way over there so you have extra time to write your mid-term." I said, "I'm fine here". And he said "No no, no no, you're an access centre student, you have a learning disability meaning you have to go all the way over there." So I had to go on the other side of the room and that made me like, feel completely like back in grade 11 when I felt completely like dumb...It made me feel completely down like I was a complete idiot, like it made me feel like, like, very very negative. Like the entire, entire test, like it would have impacted my own test badly. I sat in the whole test there, like depressed... I was worried what others would like think of me. Cause I didn't want the entire class knowing that. Oh wow she has a learning disability. Wow she must be like dumb." 
Kim also shared stories suggesting her lack of confidence and esteem impacted her perceived ability to complete school work, including overall academic performance. I asked Kim to describe a time she did not feel confident about her academic ability and she stated, "That's actually very very common".

In particular, Kim recalls her perceived struggle and stress when completing assignments.

"Whenever I am doing, like an assignment, I am always thinking, I really hope I am doing this right. I'm not sure, so my confidence goes a bit down... I'm praying that I'm going to pass it. And then you're not really sure of your marks. So the anxiety right there affects my confidence a lot, like badly...Essays I would be like worrying about what to write, or how to write it... then actually being done with it, like at first, I'm like okay that's good and then 10 minutes after...I'm like oh no what if it's wrong? I'm going go back and look through it again, and then when I hand it in its worse. My anxiety is here [hand above head], holy crap, that's not good, what if it's like all wrong? And then I hand it in, and I'm like panicking."

In this story, Kim believes she is not doing an assignment correctly. Later on in our conversation, Kim refers specifically to her disability and completing assignments as the source of academic stress: "I have an assignment due I leave it for the last minute, like for the next day. I would leave it till last minute and I don't know 10 o'clock at night I would be like okay I have to sit here and focus and I wouldn't focus until morning of, when the assignment, homework or the exam is due. It's when I feel stress, like anxiety is through the charts, like whoa. Yeah, it's like crazy and I'm like freaking out and then I'm like I know it's because of my learning disability."

Finding a disabled place, acceptance and understanding. I quickly realized that Kim's narratives were expressed in a way of seeking acceptance, for who she was as a disabled individual with ADD in academia, in both her past and current reality. She seemed to have a desire for individuals such as peers and faculty members to understand her disability, as their opinions were important and mattered. Once Kim felt accepted and understood by other individuals, she appeared to be more comfortable with her disability and confidence. For instance, when I asked Kim if her understanding of her disability changed over time from highschool till post-secondary, she said, "I think my confidence went a little more stronger. Like when I started to make more friends, I started to tell them; yeah I have a learning disability. I didn't think they would react positively... So when I did tell them they were fine. Oh, okay awesome!"

Kim describes a moment when she disclosed her disabled identity to her best friend, noting her fear of being judged negatively: "Recently I told uhh, one of my like best friends here and I really did not know how she would react. We never went to that before, to that point. I didn't know what she would say, cause at times she would say, she would make like jokes about this kinda stuff, like students with disabilities. And when I told her she was kinda like, "Why, like, okay." I was like, "Okay cool, are you going to make fun of me?" And she was like "No, no." I'm like, "Okay that's good."

While Kim comprehends the stigma and negative disabled discourse associated with learning disabilities within academia, she seems to desire resisting such a label through her peer relations. When I had asked Kim how her disability affected her in a positive way, it revolved around being seen as normal by peers and this was a source of strength and support for her in academia: "Knowing my friends here support me and knowing my little circle of friends that kinda understand me and understand that I have ADD and part of the access centre, they helped me a lot. Like not because they feel bad, they don't, they know I am normal, I just have this one 
small thing but they still are really, really caring about it. And if I still ask for help, they will help me out in a friendly way. So it's normal."

Kim also noted the desire for acceptance and understanding from faculty members. She described a story about disclosing her disability to a faculty member, where she felt misunderstood in a negative way which created a barrier to her academic success: "Yeah I was in a lecture class and it was a very important class and it was like right before our mid-term. He was giving us, he wasn't giving us notes. It was like the one class, and he was telling us everything on the mid-term and I was zoning out. I missed pretty much half of what was going to be on the mid-term and then I had to go to him after class and he didn't understand what I was like telling him. And he was like, "Well you're the student and you should have been listening." and then I had to call the access centre to give him the documents. And then he was like,"Oh okay, you could have just asked." So, that was a pretty negative experience. And it made me feel like, okay, I have to do all of this just to get help. I wanted him to know I needed extra time on the mid-term and that I needed help."

Kim stated, "The fact that I am registered with the access centre, they kinda help me get accommodations, which really, really help uh, helps me. I have more time to do things, I have more time in class to finish an in class assignment or like group projects or anything really." I got a sense from Kim that she felt such additional supports increased belief in herself to succeed academically. Kim did indicate that over time, her self-confidence in academia increased. When I asked Kim to describe a recent event when she did not feel confident about her academic ability, she stated, "recently no. I think more like when I started university." In all, her stories represented a journey towards acceptance, understanding and finding her disabled place in academia.

Stories of triumphs and future success, moving forward. Kim's stories also identified moments of academic triumphs, strengths and gaining the skills necessary to thrive, and potential future successes at the post-secondary level.

Kim often questioned her writing ability. She recalls a story towards the end of her first year at Ryerson where she did not feel very confident about the assignment she handed in; her reaction to the high grade received suggests that she not only feels confident, but is optimistic about her academic future. "I thought I was going to get a complete $60 \%$ because I didn't know what I was writing. Today we got it back and I got $100 \%$... I just wrote whatever was in the book and was like okay you know what whatever. .. Now I'm like wow... that's amazing! I'm like, ha-ha I'm passing!"

Kim drew upon stories regarding developing the skills to succeed academically and in particular to work around her disability, ADD, which impacts her ability to concentrate. For instance, Kim refers to her ability to create a study schedule in order to stay on track. Learning to manage her time was a triumph as she struggled with this aspect since high school: "I forced myself to make a schedule, like a planner, from what time to what time, and strangely that really helped me a lot. Yeah, and like I used to never follow any like planner, and that helped me lots, so managing my time, that was my biggest weakness since like grade 9 . And I have finally fixed."

Also, by prioritizing and managing her time, Kim has improved the ability to keep up with academic readings, to be prepared for lectures and to enhance the absorption of knowledge: "When I first came here, I was like okay you know what, it's just a book, it's just a chapter, I can read it when the mid-term comes. That was the biggest mistake I could have ever considered. 
And now I actually read after class, and that way I am on track and I know what's going on and before class."

Kim also refers to the process by which her study habits have improved over time and now in post-secondary represents one of her academic strengths: "studying has definitely improved. Like I did study in high school but like I am actually, like, like focusing a whole lot more and I am actually catching up on my notes. So that is a definite strength."

I sensed that the first academic year was an exceptional challenge for Kim. With time, Kim appears to be moving forward by building the skills to work around her disability, and seems more optimistic about her academic future and comfort with disability. Kim's comfort with disability was illustrated towards the end of the interview as she stated, "I am glad I got to help you and participant in your study, cause I actually, kinda want to start talking about it more [disability] and be open about it."

\section{Narrative Account: Sandra}

Sandra is a fourth year student enrolled in a humanities program. She identifies her learning disability as dyslexia and describes that it is oral based in which she experiences difficulty hearing the sounds of words. She was diagnosed roughly around the age of 8 or 9 , in grade 3 .

The beginning before diagnosis: What's wrong with me? The beginning of Sandra's inner disability narrative, gaining awareness of dyslexia and what that meant, represented a time of frustration and confusion. Her story was connected to the physical space of academia, as she recalls her beginning awareness prior to her official diagnosis in elementary school: "The reason we found out we were doing spelling tests... and my teacher would put our picture on the board if we got perfect and everyone in the whole class got their picture on the board except for me... I just had a really hard time; like we studied for the spelling test and I couldn't do it."

Sandra could not comprehend what was wrong, which was exasperating because she studied hard for the spelling tests yet could not succeed similar to other students. Her first recollection of her disability was based on a direct comparison to her peers, feeling different and potentially not as smart: "I think I was confused, I think I was trying really hard ...I just thought something was wrong with me. I just like didn't think I was very smart."

Along with her personal reactions during this confusing time, Sandra refers to a vivid memory related to her mother's response to her academic difficulties. She emphasized that her mother viewed her academic struggles as negative, potentially against a normative standard: "My mom was like something is obviously wrong cause everything else is fine with me." Further into this academic plot, Sandra recalls the negative experience of conducting a psycho-educational assessment with a school psychologist. This process of being diagnosed was surrounded by a sense of confusion, which further affirmed that something was wrong with her: "I had to do the test to be diagnosed and I remember hating them and thinking what's wrong with me why do I have to do this?"

I could sense from Sandra the beginning of her inner disability narrative was negative. Her stories always referred to how confusing it was and that she did not conform to the standards within academia, and therefore something must be abnormal.

What did dyslexia mean? The stories expressed by Sandra prior to post-secondary presented her learning disability as an undesirable identity. Once Sandra became aware that she had dyslexia after diagnosis, she notes it was, "something definitely negative." When I had asked 
Sandra to share a time she felt her learning disability affected her in a negative way, she immediately recalls being younger, rather than her present reality: "Like when I was younger, making me question my intelligence or my ability to do things. I think it definitely affected my confidence." Her disability was embedded within a dominant disabled discourse related to intellectual impairment, hindering her confidence within academia. For instance, Sandra recalls the year after her diagnosis when she had to do spelling tests (again), in which she continued to struggle: "Even after I was diagnosed, the next year everyone was very into spelling tests and it happened again and I kind of knew what was happening but it still didn't make me feel very good about myself." Within academia her disability affected her self-worth, confidence and academic challenges. Disability was perceived as negative and not a source of pride, strength or ability.

\section{Relationships informing Sandra's understanding of dyslexia prior to post-}

secondary. In forming her disability narrative, Sandra's stories about growing up with dyslexia previous to entering post-secondary were informed by individuals within her social sphere, mostly teachers and peers. For instance, I asked Sandra if the reactions of individuals at the time of her diagnosis impacted her understanding of dyslexia and she completely agreed. Specifically referring to her teacher's lack of understanding, or unwillingness to accommodate her disability within the classroom once Sandra was diagnosed: "I remembered the teacher that I had at the time... she was an older teacher and I don't think she really understood what it meant. Like she didn't change any of her teaching practices... Her reaction was just; it's not my problem."

Sandra stated that her parents, "were obviously trying to find the best way to help me", noting her mother speaking to the teacher who was unaccommodating, "my mom kept being like this is not because she's not trying, and she didn't change." It seemed that the teacher's reaction was very pronounced in her experience, which further impacted Sandra into high school.

Viewing her disability with discomfort and embarrassment, especially within the physical space of academia and in disclosing the diagnosis to her peers, seems a strong feeling, as Sandra said, "I remember when I was in high school, when I had to write my exam in a special room I did not want people to notice, I try to be sneaky, like I wouldn't tell people. Um, like I remember telling a couple of my friends and being embarrassed...I didn't feel like I was as smart as them. Umm, so I think the way it was dealt with, with like the teacher and the students at the time when I was first diagnosed probably influenced that."

Reflecting on Sandra's earlier experiences, through the interactions with others, she believed disability was negative and meant that she was not intellectually capable, influencing perceived capacity in academia. I sensed for Sandra at that time, disability should be tucked away; it mirrors her desire to pass as non-disabled, as what is considered normal and capable in academia.

Stories of growth and comfort with disability, within a discourse of ability: End of

high-school to post-secondary. As I reflect on the stories as expressed by Sandra, I

could clearly identify that her relationship and comfort with disability identity was fluid in nature and changed over time, particularly towards the end of high-school and throughout postsecondary. This was evident the most when Sandra indicated, "I think I identify in a positive way", as opposed to how she perceived dyslexia earlier.

When Sandra identifies positively with her disability, she draws from two sources of experiences that altered her perspective: receiving an education in a humanities-related field, and working directly with disabled individuals. "I think even being in a [humanities related] 
program... I remember even writing my essay to get into the program and it was the first time I wrote about my learning disability... my experience working with other kids and individuals with different types of disabilities changed my perspective on it... I think it's helped me to identify with people...I think it's almost even in my own self-reflection being aware I was embarrassed about it what was it that made me embarrassed." Within the physical space of academia and the program she was enrolled in, Sandra developed a healthy connection with disability. Also important is the influence of those with disabilities with whom she interacted as a service provider; their stories and realities, and how she became personally connected with them based on a shared identity, impacted her own belief system.

Sandra spoke about believing in her capabilities as she progressed through academia. As a fourth year student reflecting back on the overall impact disability had on her perceived capabilities throughout post-secondary, she notes, "it's a small disability... it not really affected me that much in terms of what I am able to do." The theme of capability located within Sandra's stories began to appear in late high-school, particularly when she mentioned a story by which she had to be reassessed for dyslexia: "They brought me in to tell me about the diagnosis I guess... they told me that if I wanted to go to university that they thought at the most I would have to take it part time to complete school. I remember being like what? I feel like I'm the same intelligence level as my classmates and I didn't want to take you know 6 years to do my undergrad. I just remember being really frustrated that they had decided that for me. I kind of wanted to prove them wrong."

This experience was exceptionally profound for Sandra. It exemplified a change in her feelings towards disability within an academic context, particularly when she noted that she was just as intelligent as her peers. The individuals who drew upon assumptions of her disability significantly influenced her; it was a source of strength and determination to succeed and to contest dominant negative disabled labels based on impairment.

Sandra's perspective of her intellectual ability and believing in herself was also noted when I had asked to describe her confidence when starting university. Without referencing her disability, Sandra's concern related to entering a new physical environment, yet she felt confident because of the preparation received in high-school: "In first year I wasn't sure because it was my first time taking university course... I did okay cause I did applied courses in high school. So, I felt kind of prepared...Umm, just cause I thought, actually I guess because I felt relatively confident that I could handle it."

Developing skills over time in academia, learning to learn around disability. Within the physical space of academia and especially the environmental conditions that come along with it (unknown and new), the transition into university for Sandra revolved around adaptation. In her academic stories, Sandra refers to working with and around her disability, both developing an ease with it in post-secondary and enhancing learning strategies for her to succeed and feel confident. Through such experiences in Sandra's academic career, how she relates to dyslexia and the perceptions she holds regarding her capabilities can be understood in the following statement: "I think being okay with my learning disability has allowed me to learn with it. The successes have been learning how to learn better. [Marks received] below, I think happened a lot in first year, I think it was just coming into university and also, learning how to write in a way that's easier for professors to understand."

Sandra expressed struggling academically with regards to writing, which related to her disability. Recalling earlier and more current academic experiences, she notes her gradual ability to write effectively, promoting a positive perception of her capacity. Such stories I sensed came 
from a place of pride and honour: "Well I think this year I felt the most confident...I feel like I finally learnt how to write essays, or how to focus my thoughts like while I'm writing. I think what was kind of difficult was the auditory stuff and also taking my thoughts and putting it on paper was also kind of difficult. I also find... I'm in school more, so because I can't remember how to spell words from sounding them out, I've gotten really good at remember how they look like... So over the course of the past four years now when I write exams, I'm like oh I remember how that word looks so I can write down, whereas before I remember being in exams and having no idea how to write that word and I felt if I wrote it the professor wouldn't know what it is. And I felt like being in school has actually helped me a lot, because it forces me to look at words very often."

Time management was also discussed in terms of the strategies Sandra developed as it relates to working with her disability, further exemplifying comfort and understanding of her learning style: "I think, uh I am now able to understand that it takes me longer to do readings and I have to proof read more. So that's really been helpful and I found over the course of my undergrad I actually been able to adjust, so I actually find that I'm doing a lot better in school because I am allowing myself or think, okay you need more time for this and being okay with it."

There were points in Sandra's stories that exemplified a lack of confidence in certain areas as it related to her disability: "I feel like I'm more confident with assignments because I am able to proof read them. Um, exams umm, I know that I most definitely misspell words and I've had marks off for that... I feel more comfortable with assignments then exams. Especially essays that are in class, I really dislike." Sandra appeared self-reflective regarding such struggles and her lack of confidence. For Sandra, her struggles related to disability acted as a source of strength, determination and motivation, particularly when she made comments such as, "I think I just have to be more confident with myself. I think it's a good thing because it makes me work harder."

Relationships in post-secondary, disability as a place of embarrassment and seeking

understanding. Sandra's disability narrative prior to post-secondary, as being embarrassed, with disability as a place of shame, carried itself through parts of Sandra's postsecondary reality. This is noteworthy as she describes the relationships with peers and faculty, whose opinions are important to Sandra. She describes her current struggle in disclosing her disabled identity: "It's always a little bit difficult to tell people that I was diagnosed, I definitely gotten more okay with it...I find that...Its strange, I had a lot of people that be like they will do something, and be like I'm so dyslexic or something like that. It's just like they are making a mistake...I don't know I find a lot of people say that."

Sandra was significantly aware of the negative stigma and label that comes along with dyslexia or disability in general (as impaired and defective), principally within an academic context. She recalled that some individuals may not necessarily understand what it actually entails: "So, I know, I haven't really told anyone, since first year, I think that was the most recent time I can remember telling someone."

Potentially, Sandra is concerned that such a label will be applied to her academic identity, perhaps leading to misunderstanding by individuals whose opinion she values. In fact, Sandra describes her feelings of sharing her disability with her best friend in first year; it was a good experience because her peer understood and was supportive: "I think it's my best friend who is also in the program we would always edit each other's essays. I had to explain why certain things were spelt certain ways and why I switched up words. I just remember that when I explained she understood why... it's really nice." 
The fear and potential embarrassment or judgment of her disability, and the application of such labels, was present when Sandra interacted with her professors. The process of sharing disability with professors was not a frequent occurrence and exemplified moments of stress and anxiety. Sandra expressed a fear that her professors will think less of her, in terms of academic proficiency: "The access center gave us those papers that you have to give to professors. I remember sitting in class being like oh my gosh, I have to go hand in that paper that says I have a disability and I don't know I was waiting for the right time... I never like said or verbally told a faculty member. I remember feeling really awkward...feeling like I hope they don't think less of me. But then also its kind of nice and hopefully they read my paper and know why I made a mistake."

Passing off as a non-disabled student (out of fear of judgment and misunderstanding) appeared to be an adaptive strategy in order for Sandra to maintain and secure her academic identity and self-worth. Receiving understanding of disability is exceptionally important for Sandra to feel supported in terms of her academic struggles and accommodations.

\section{Narrative Account: Tom}

Tom is a fourth year student, who is enrolled in a humanities related program. Tom identified his learning disability as Attention Deficit/Hyperactivity Disorder (ADHD) and was diagnosed between the ages of 18-19, while he was at the University of Toronto. Tom describes his learning disability impacts his concentration.

Beginning awareness within academia. Source of frustration and confusion.

Resisting disability label. The start of Tom's disability narrative or becoming aware that he indeed had ADHD began when he first started studying at the University of Toronto. For Tom, the new environment and the transition within highlighted that he may have a disability. It was in such a new environment that he was deviating from normality or not fitting in like other students: "The first experience that I had was when I attended the university where the lectures were usually longer then what we attended in the high school... The lectures usually around 1 hour or 1 hour and thirty minutes and then you have a 10 minute break and you can go back to class. So, I found after the first few weeks, after maybe 20 minutes I started to become more irritated, right? Can't concentrate and I couldn't focus. And I just want to take a walk outside, ha-ha...So; I do this every so often... And even sometimes, for example during an exam review where it required lots of attention and to focus on the topic, I find this very difficult for me to sit there for half hour."

The process of becoming aware was gradual for Tom, who felt that the lack of concentration which he experienced within the new academic setting was a typical part of transitioning. Over time, specifically by the end of Tom's first academic year, he felt he was not achieving the academic goals he had imagined. It was clear that Tom took pride in the program he was enrolled in and his inability to adapt and conform was a source of frustration and confusion prior to his diagnosis.

"UofT, which is very competitive and challenging to get in... program is supposed to be one of the most difficult in terms of mental level in North America... Initially I thought maybe I was new to the university and maybe it was more excitement... But after a while, after two semesters I found... it's hard for me to uh, to uh, to concentrate, to achieve what I want in this university". 
During this time, a key player in Tom's disability awareness narrative was a psychologist from whom he received an official diagnosis of ADHD at the University of Toronto. Tom recalls and emphasizes that the psychologist viewed ADHD as normal, and it did not mean anything was wrong with him: "Pretty much she's saying that ADHD is very common in children and adults as well, so there's nothing wrong with it."

I certainly recognized that the opinion of the psychologist was important to Tom. I wondered why and realized that Tom is very much conscious of the dominant negative label attached to disability. For Tom, he desired to disassociate himself from that label. Hence, I learned why the opinion of the psychologist was essential as the psychologist disconfirmed such a label. The operations of how Tom viewed disability in a general sense were emphasized in statements like, "Person has some permanent, incurable, some untreatable mental health disease and you know it's kind of shameful right?"

Along with resisting such a label, Tom struggled to understand what his disability actually meant. He appeared to believe that he could overcome ADHD with practice. His inability to overcome the challenges faced by an individual with ADHD was disappointing: "I thought that ADHD is more like a physical exercise, maybe only lasted for so long, but if you do exercise you will be able to add the 10, maybe 30 . So for me it's more like a mental exercise, say in the beginning I can only concentrate for 10 minutes and then maybe one year after I can concentrate for 15 minutes, and the year after I can concentrate more than 20 minutes. I hoped that this work... Over time yeah, I find that it's not very effective. There was a little bit of improvement, I'd say but not as much as I expected."

Disability for Tom when he was diagnosed was a negative and undesirable identity. Even more so, Tom connected his disability to academia; it was seen as an obstacle and a barrier: "I felt a bit irritated ...I pay lots of money. Right, for the tuition. From my perspective every minute that I spend in the class that's money, right? And if I cannot maximizing or utilize all the knowledge and everything in the class, I'm kinda wasting money."

ADHD impacting academic achievement. Continued source of frustration after

diagnosis. In reflecting the stories as expressed by Tom, a consistent theme that emerged was frustration towards his disability as mentioned. Tom's frustration with disability carried itself from before diagnosis till present day reality and in fact is very much connected and highlighted within the context of academia. Academia was an environment that Tom seeks to achieve and conform in, whereby his disability posed a continuous threat. I was curious to comprehend if Tom associated his disability within academia in a positive way. When asked, Tom struggled excessively, with pause and hesitation to provide an answer and specifically stated, "Okay, that's just hard." I sensed that my question was unrealistic and perhaps obscured, because to Tom it is difficult to find anything positive with a disability.

A source of struggle for Tom and the basis of his frustration is the inability to concentrate, which he believes has worsened over his academic career: "So I feel compared to ah, the time when I was at U of T, I feel that my, the time I can concentrate on a particular subject has decreased. Yeah, that's the major challenge that I have."

Tom drew from a variety of examples of how ADHD impacted his ability to perform academically and continuously expresses his frustration:

"For workshops or for seminars, I want to get all the information, right? I feel really frustrated after maybe 20-30 minutes I can no longer focus on what people were saying... just goes off the track, and then when I realize that probably already 5 or 10 minutes pass, to whatever is original topic was...I feel I miss a lot of information, right?... it's kind of wasting 
time, just sit there and not pay attention and not to grasp the knowledge that is the distress that it's creating... Work on the exam is usually three hours long and with maybe 35 questions, multiple choice, so calculations, and it's really long and really frustrating. The thing that I found is difficult is, is that even though I know the steps of doing self-reflections, I know the formulas, I can't concentrate to compute, to calculate the numbers and that's what frustrates me. Is that I cannot follow the steps, like I know how to do the question, I know which formula to apply, but when I follow the steps and try to do the actual calculations I cannot focus".

Although, Tom had identified and provided a variety of experiences throughout his postsecondary career by which his disability caused frustration and impacted his ability to achieve academically, he indicated that, "I was very confident, I am still very confident now." His statement illustrated that although he found his disability to be a barrier, it did not impact his perceived confidence and worth within academia from the beginning of awareness till present day reality, which demonstrates Tom's persistence and determination over the course of his academic career. An example relates to Toms study habits: "But, what I found was that I probably have to do double my effort because of my disability. Some students may study for four hours and I have to probably study for eight hours."

Hiding disability identity, passing off as non-disabled student. I quickly realized the opinions and point of view of those within Tom's social network; especially how they perceive him academically and in a post-secondary context is imperative. Tom drew upon various stories illustrating his embarrassment and shame of his disabled identity through his social interactions. For the most part, it appeared that Tom had the desire to pass off as non-disabled among peers, family and professors. This was reflected the most when Tom stated he would create excuses to hide his disability from peers: "Use the excuse, like such as language barrier or you know, a physical fatigue, or maybe I just didn't sleep well last night, some harsh things in my family, sort of to cover up the difficulties that I am facing."

I wondered then, if Tom ever disclosed his disability to others - his response: "I never said my attention deficit or ADHD to school, or to peers or to professors, or anything... honestly I don't feel that, like uh, telling anyone." He went on to describe his feelings regarding disclosure, "I don't want to get humiliated... or sympathized or do you need help. Yeah. It's a negative feeling that is attached to the disability that I have." Drawing upon dominant discourses of disability (impairment) Tom feared others would apply such a label to his academic identity. Even more so Tom feared that others would not understand his disability or not take him seriously as an academic: "U of T is very academically focused right, people come to school to study and not planning to party or hang around...they have a very serious attitude towards academic performance... So, if they see me playing video games or watching T.V in the class... they are saying this guy he's probably one of those immature students right? Let's not get too close to him...he's not going to benefit us. If I am an academically focused or outperform student, I would say hey you know what let's be your friend, let's be a study buddies right, and then everybody could benefit from something...they are probably going to say... he doesn't have the same objective and goals as us."

As Tom reflected back into time during his earlier academic career, I learned that peers had judged his academic literacy without an awareness of his disability. This experience was exceptionally influential for Tom. I sensed that disclosing ADHD would further negatively implicate his academic relations and integrity. "We were doing a group project together...there was group members saying that you know what...we will take you as a group, but they won't let me make any serious decisions or... usually divide the tasks for each group members right? 
...They say, you know what [Tom] ... you don't have to do anything... I just felt a little bit isolated...So, they would just say... sorry we don't really trust you... We want a good grade...that's what I call academic isolation."

Tom drew upon a memory desiring to disclose his disabled identity to a faculty member, to explain his behaviour in class as students complained that he was distractive, and thus deviating from typical classroom/academic behaviour. I was curious as to why Tom did not disclose and I sensed that it related to potential misunderstanding, judgment and shamefulness. Tom stated: "I didn't think he wouldn't believe me, and I think he probably maybe see it as an excuse to get away, right? ...I don't really want people to, to, ahh, to see it as my coping mechanism... you know he uses this as an excuse to get away with it and it's really a bad excuse right, so. Yeah, so ah, worry about the humiliation and the distrust."

In all, I gathered that the act of passing off as non-disabled was a source of strength and resiliency for Tom, and a way for him to maintain his confidence and ultimately his academic identity.

Adjusting to ADHD within academia. I realized that Tom's stories during his postsecondary career revolved around successes and overcoming the challenges associated with ADHD in academia. Although Tom perceived his disability as a barrier and obstacle to academic success, he was determined to work with his ADHD and develop the learning skills that were uniquely his. I sensed that this was an exceptional source of strength and resiliency for Tom: "I think of myself that is very... determined, very determined. So when I want to do something I will do it. How long you are going to take, it doesn't matter... I will do it and I make sure to finish it on time...I could overcome majority of the challenges I have...in my persuasion for my degree, and you know my future."

Later on, Tom describes the unique learning model he adapted that was tailored to his ADHD: "I cannot concentrate and learned my own learning models. So basically every 20 to 20 minutes I go, I dunno, listen to music, I go to watch an episode on the YouTube, just to you know relax a little bit. But yeah, so this is my learning strategy right, it takes a long time but, let's say if I fully focus on something for 1 hour I feel exhausted. Let's say if I do the switch model, study for 20 minutes, go play for 10 minutes, study for 20 minutes. I do that for two or three hours I should be okay."

For Tom, developing a unique learning model separated him from other students in a positive way, as it relates to his academic identity and ability, which was a source of pride. Interestingly, he associated this strategy as a place of unique capability which was developed because of his disability and thus counter-acting dominant disabled discourses of impairment: "Right now I can... shift my attention pretty quickly, from one thing to another, and switch back and forth right. Right?..I find is a very unique skill that I have and not many people are willing or could do it, you know?"

\section{Narrative Account: Samantha}

Samantha is a fourth year student enrolled in a humanities related program and was diagnosed with a learning disability between grade 4 or 5 . She defines her disability as, "I don't think it pin points one specific area, um, my motor skills are kind of slow...umm my processing is slow and retention."

The beginning: Lack of understanding and embarrassment, embedded within a discourse of inability. The beginning of Samantha's awareness of disability began in 
grade 3, and was connected to academia. Samantha notes that her behaviour in an English academic setting was not typical and something was wrong with her. Her disability was framed against normality: "I was in French emersion and they were switching me into English and then noticed something was wrong... something was off compared to how they expected me to act, so I started getting just tests done... I wasn't officially diagnosed till maybe grade 4 or 5."

Samantha accentuates the difficulties experienced adjusting to disability, because she lacked a comprehension of what it meant due to her young age: "It was pretty hard because... I was probably 9 or 10 , grade 4 or 5, around that. So you don't understand what that means."

As time went on, Samantha described developing a negative understanding of disability, perceived as a source of impairment and embarrassment. Samantha felt uncomfortable disclosing her disability within the contexts of academia: "It meant that I was dumb and stupid; it meant that I had this big secret that I couldn't let out...peers I kept it from them. No one really did [know] so I just kept it to myself."

Disability was a foundation of frustration within elementary school, as a disadvantage to succeeding academically: "Things were harder for me...it meant I took a lot more time doing homework and still not seeing the results that other people would see...It just meant a lot of work; it was a lot of work."

Family in making meaning of disability. For Samantha the family unit was vital, particularly in forming her comprehension of disability and academic proficiency. The family as support to Samantha evolved in gradual stages from the beginning of diagnosis, through elementary and high-school, to present day reality.

In earlier stages, Samantha describes feelings of confusion towards LD and this was partially attributed to her parents, as they lacked a clear comprehension of what her disability entailed. Thus, they were unable to support and assist her to understand how it impacted her. "They are very liberal and supportive and understanding ... there was confusion about trying to understand what it was because my parents didn't know how to explain it or how to help, like I said they were struggling to support me so I was struggling to figure out what this was and what it meant to me and how it affects me."

The stories of consistent support received from her parents throughout elementary school assisted Samantha to gradually view disability within academia more positively, as capable and proficient. "Like most parents, as long as you try they are proud of you and they will be your biggest fans and cheerleaders... [because of their support she learned] it wasn't my fault, it wasn't something I could control... it didn't mean...I was stupid and dumb...you associate your understanding with everyone, so being told its okay, your just different and all that stuff, sometimes you accept it and sometimes when your hard on yourself you don't."

The relationship between Samantha's siblings played an essential component in interpretation of disability, especially in regards to her academic ability. She reflects on growing up in a family setting that consistently compared grades. In contrast Samantha's non-disabled siblings regularly received higher grades; these memories were profound and reflected how perception of academic ability was influenced by comparison against normativity: "I have two younger brothers and they were always brilliant at school so of course they would always compare... getting something like a 70, which is basic but it was great for me. And they were like oh we got an $80 \ldots$ That just sticks with you."

An empowering moment was when Samantha indicated that although she appreciated her parents support, she needed to take accountability for her own learning as it related to her disability. This new framework of thought appeared around the beginning of high-school and 
continues in her current reality. To Samantha there was and is a great sense of pride to independently tackling the challenges associated with her disability: "Your parents have to stop advocating for you.... You know at some point you have to grow up...I'm just taking it on myself, so I know when I get my marks or when I succeed in a job, I know that I did that on my own...There's a sense of pride with how much you overcome and what you challenge yourself with, it was a challenge. It's just, that's how I see it, and I'm challenged, because I learn a little bit differently... I'm not going to fail I refuse to do that."

Transitioning to comfort with disability, and the importance of context to success in

academic perceptions. High school represented the beginning point of Samantha's transition and independent searching for what disability meant and how she perceived herself within academia. Her disability began to shift from incapable to able. Samantha's disability narrative represented itself as a gradual process of change, informed by a variety of experiences within the context of academia. The consistent themes that emerged exemplified ownership for her learning and comfort with disability.

"I think my perspective changed when I went into high school and actually later in high school...I really started to own up to my disability...you really have to own it... I think it's also the mind set when you're in elementary school you think of all the little small traits add up to be you... at some point that just disconnects or unravels and you're just like no, no no I'm me and all these things are just aspect about me. So somewhere that clicks, so my understanding yeah it used to be wow I'm stupid, I'm slow, I'm different in negative way. "

The educational environment mattered in terms of how Samantha understood her own disability and academic self-worth. Samantha's elementary school stories referenced the detrimental effects of the environment and the limited practices within education to assist with her disability, such as segregation and lack of resources. Within this context, Samantha felt abnormal; this contributed to her academic struggles, isolation and reaffirmation that she was incapable.

"Teachers want to help because they feel sympathetic but they have a classroom of you know 30 kids they can't sit down, work one on one with you or anything like that... I could tell I was different from everyone else cause I would go to the resource centre, you know and get extra help and be separated from the class...the overall impression was um, that I couldn't do school quote on quote normally, or as compared to other kids."

Samantha began to view her disability in a positive fashion at a time when she entered a new inclusive academic environment. She started to feel comfortable with disability, allowing her to advocate for her learning needs and therefore enhancing perceived academic ability: "I went to ah, a private school at the beginning for grade 9 or 10, didn't get support, I was really embarrassed and I changed to an arts school, so it was a different environment, it was more accepting... So it was just the environment that was easier, to be my own advocate and to say something."

Samantha attended a university prior to Ryerson; she recalls the lack of support and understanding received regarding her learning needs, negatively impacting her academic confidence and association with disability. Afterwards, Samantha attended a college that was supportive and aligned with her learning style; in this context she thrived and displayed heightened self-assurance academically.

"I found challenge at the first university... I found lack of support, um with the writing centre, with what they just had to offer when I went to their disabilities centre we worked on ...Things I already knew. I didn’t get help with my actual courses I found that this, the 
professors weren't really understanding. .. So, I had a rude awakening my first time at university and I actually just passed...I had such a hard time and then I went to college... college was hands on, and I was like okay this more me."

Samantha decided to return to university (Ryerson) after her positive experiences in college. She indicated experiencing some anxiety and felt possibly not intellectually capable enough for university; such perceptions were connected to her first university experience: "I was confident because I had... done a diploma program... So I knew what I was getting into and I had done that with flying colors...the past anxiety of, because I did so poorly the first time I went to university .... Wondering is that still me? Is that university and is that what university is going to be like for me? So basically can I do this? Am I smart enough to do university?"

Samantha had established herself within the supportive and understanding context at Ryerson and did exceptionally well academically. Because of this she feels a great sense of selfworth and capability intellectually, impacting her current perspective: "I feel confident all the time now. I think so after I started the program I understood, like I got a better understanding that this was for me and I could do it, even though this was university."

Comfort with disability through disclosure and creating awareness - relationships. Samantha's stories mainly while attending Ryerson were expressed in a way of utter comfort, and confidence towards her disability and academic capability, which was particularly evident in her social interactions, desiring for others (teachers, peers and the public) to accept and understand LD. The process of creating awareness through social interactions was vital for Samantha's disability narrative, as her actions challenged a disabled label based on impairment, an identity that she refused to accept, instead seeing her disability as representing a source of empowerment and a way to ensure academic success and maintain comfort with disability: "Not only just understanding your learning disability, or how you are different, but understanding why that's okay and advocating for that... How do I deal with it, how do I manage and how do other people see me...I talk about it all the time."

A profound moment was when Samantha reflected back into time, recalling a negative experience that occurred in grade 9. This experience taught her to be open and comfortable discussing disability in order to succeed academically and feel competent in the work she does. She reflected on the shame she maintained with disability and her desire to ensure teachers comprehend the struggles she experiences, therefore assisting her to thrive in her own unique way: "In grade 9 and I was writing an English test... I have 20 minutes and I have not gotten to the essay. And I just started crying ... It takes me 20 minutes to think of the outline of an essay and I just gave up. I remember seeing the teacher ...I told him, I have this learning disability and I needed a computer and... ...I realized how I have to start advocating for myself. But that was the first time bringing it to someone else and being worried, and maybe worried about how they were going to react and why didn't I talk to him before? So most likely ashamed of being ashamed of it."

As informed by previous experiences, when Samantha attended Ryerson, she expressed incredible comfort disclosing disability to professors, which is a source of strength in terms of her ability to succeed, feel confident and maintain academic integrity. Important to her is that professors understand that she is able and learns in a different way. "I went to the guy's office hours, my professor and I introduced myself... I have a learning disability and actually from that week on, I would meet him in his office hours for at least an hour... I've almost done that at least, at the beginning of every semester to every professor... so they know why I'm struggling... again I'm not asking for any special treatment...don't lower your expectations... 
help me understand what you're asking for... I think I felt proud because in my head it was like yeah way to go your sharing this and this is good.... So, um I guess it's always nice to get the understanding back. And to actually have an open conversation about it."

Ease disclosing learning disability appeared in Samantha's interactions with peers. She recalled a powerful memory challenging a peer's assumption of those with LD as academically incapable. As she told her story, I felt how strong her conviction was towards her own academic proficiency and desire for individuals to understand that those with disabilities are capable in academia similar to non-disabled students. Samantha's disability narrative was embodied by advocacy and awareness, for herself and LD individuals in general: "I was in a psychology class...I heard the girl after class, saying I don't think anyone in there has a learning disability cause you couldn't make it into this class, it's a fourth year class... So I tapped her on the shoulder and said actually me and the girls I sit beside, we both have learning disabilities. It felt good because I was saying it on behalf of other people who may have been in that class and was embarrassed, or you know felt affected because they had a learning disability and maybe they can't speak up or anything."

Samantha's disability advocacy and believing in the capabilities of those with learning disabilities extends to her involvement in public education, such as speaking on a panel to parents who had children with LD and her professional work assisting students to achieve and adjust academically. For Samantha these experiences, "help you understand yours more...feel validated and I guess accepted." Creating awareness and engaging with other individuals aided Samantha to challenge negative perceptions of disability and boost her confidence within academia: "It's taken me a little bit to get through school, which is sometimes a struggle in my inner dialogue there, it's a little hard, to admit that... So I think it allowed me to take those negative perceptions that I had...To be like actually I'm using those for a good thing right now and helping other people...It just took a lot of the negative components that I associate with my learning disability, with university and post-secondary and the fact that it takes me longer to do things and spin it in a more positive way."

Developing strategies for academic success in post-secondary. Moving forward past

challenges. A consistent element in Samantha's stories while attending Ryerson revolved around the development of effective strategies to succeed academically, allowing her to work around challenges related to disability, increasing her confidence and belief in her capabilities: "With me I just found ways that work. I couldn't even tell you what specifically I'm supposed to be working on with my processing, or retention, what's like specifically housed because I just found coping mechanisms."

Samantha was exceptionally self-reflective and acknowledged that everyone has challenges within academia. Although she experienced difficulties, so did everyone else and some more than others; this understanding placed her within normalcy and represented a typical part of the post-secondary experience. This was apparent when Samantha discussed writing papers, "I think everyone is at different levels, some people can whip it up in the night and some people work on it over a month. Like so I think I fall within quote on quote normal or average range with everything."

In particular to academic challenges, Samantha stated, "balancing everything. Um, multi-tasking everything... Challenges is sometimes keeping up with the work load... not letting my anxiety get the best of me, cause when that happens that's when you just shut down." She reflects on developing multi-tasking strategies, representing a current strength and source of confidence in academia, "challenging aspect is shrinking... I think at the beginning of my 
university career it was hard to balance everything... but now it's my strength because, it's just become a part of my life...I'm always on top of my stuff. I know when things are due."

One of the major academic challenges for Samantha is the ability to complete multiple choice exams, believing it is connected to her disability; however, she never understood how and is not entirely sure if it is. Given such lack of understanding, Samantha describes ways of coping and developed a strategy over time. This not only highlights her drive to achieve academically, it indicates that her disability or perceived incompetence is a source of determination: "So there has never been support on how to fix the issue that I have to do a multiple choice test ... why specifically I can't do them. I assume it's my learning disability in some aspect, but I don't know for sure and that's why I get freaked out about them all the time...I do the oddest things...so yeah crossing out, eliminating um circling or underlying the words and if I'm really stump ill circle the number and come back to it... that's how I try to deal with it."

\section{Narrative Account: Elizabeth}

Elizabeth is a second year student enrolled in a humanities related course and identifies her LD as Attention Deficit/Hyperactivity Disorder as non-verbal. Elizabeth does not thoroughly comprehend her disability.

The beginning: Disability as confusion and difference. Elizabeth was diagnosed with a learning disability in grade 2 . The beginning of her disability awareness was centred within academia, spanning throughout elementary school. LD meant she was different, potentially abnormal and was perceived negatively: "grade 2 was when I realized I was different... I felt different but like in a bad way."

When Elizabeth was asked to define what disability meant to her during elementary school, she struggled to provide a clear definition, which may be due to her young age at that time. Disability was part of her identity within academia, in a way that meant confusion and lack of clarity, negatively impacting her self-worth: "I don't think it meant anything, because I was really young. I was very confused; I didn't really get it... I didn't really know...I remember being umm, sad a lot because I was like, ugh I don't really know what's going."

Overall, within the space of academia Elizabeth sensed frustration and felt academically challenged, potentially incapable: "Frustrated with the whole situation... I thought something was wrong with me... School was always challenging for me."

Segregation: difference and confusion. Elementary school. Elizabeth continuously made reference towards her experiences of segregation in elementary school and it represented a source of perceiving disability as an element of difference: "Grade 2 was when I realized I was different from everyone because they like separated the classrooms."

She refers to being placed in a special educational classroom and in this environment Elizabeth felt that in order to be there you are incapable and something was different about you as a student. Elizabeth indicated that she felt out of place, that she was not incapable but was able. She sought to disassociate from such a context; it appeared that there was a desire to reject the label highlighted in that context: "In grade 6 I got put into a class, a regular classroom and they were like...we're going to put her in this other classroom that's like, umm like, it wasn't special education, but it felt like special education. Because it was very... like basic, so I was not feeling good in that environment... and I'm like oh my god, like I'm not stupid... why am I here?...I was like hoping to go back into the regular class." 
Even more frustrating for Elizabeth, she lacked stability in terms of the education she received, as she was continuously tossed between special educational and regular classrooms. For her it meant even more confusion towards comprehending what her disability or learning needs meant in academia: "I was moved around all the time and I hated grade 6 because of it really... no one really explained to me why."

Given such a confusing and degrading academic contact, Elizabeth positively notes the support and understanding she received from her grade 6 teacher: "My grade 6 teacher just didn't seem different at all... she was the only real person that stuck out to me...like believed in me... really helped me get through that year because it was really, really, really hard... she really helped me...cope with everything that's going on."

I sensed this teacher was incredibly important towards informing Elizabeth's association with disability and academic self-worth. This teacher believed in her capabilities, and validated that Elizabeth was not different, in a negative way, as a student. This teacher represented a source of reassurance particularly in that academic context as Elizabeth was constantly reminded by segregation that she was abnormal.

Furthermore, Elizabeth shared that she wished someone would have explained what disability meant at that time and at a comprehension level that she would be able to understand. However, the support she received from her grade 6 teacher: "was the beginning of figuring out my learning disability.” Thus, Elizabeth's teacher was exceptionally intertwined in her beginning process of comprehending disability.

High-school, disability as incapable informed by context and relationships. Highschool was an important time in Elizabeth's life, as it relates to association with disability and perceived competency within academia. It is during this period, informed by the context and the absence of appropriate support that Elizabeth's disability narrative transformed from confusion and lack of understanding to impairment influencing feelings of difference and impacting her self-worth in academia. I asked Elizabeth to identify moments when her understanding of disability altered. She noted the physical context of high-school, being marked as a special educational student and again segregated to only applied classes (lowered academic standards), and it was then she felt stupid: "Um I was marked as a SPED, special education person... So that was cool...that was sarcasm by the way... I didn't have the option of doing academic... I was in the applied, special whatever classes...It was good in some senses because I had cheat sheets and I had extra time, and I had like somebody to help me... But on the other hand I felt...stupid."

Her feelings of incompetency were also affirmed by teachers: "I felt really stupid because people were treating me like I was." Recalling specifically a math teacher who was unsupportive and made her feel incompetent, Elizabeth noted one specific event where he recommended staying away from math; this narrative impacts her perceived ability today: "He gave us our assignments... And he goes, "I would advise you to stay very far away from math because you're not very good at it." ...I hated this teacher. Umm, so yeah I took his advice and I stayed away from math, cause I'm bad at it... That conversation with that teacher impacted my whole life... I stay away from math even now... and I'm never going to be good at it."

Post-secondary journey. Disability as impaired and deficit. School just isn't for me.

Lack of confidence: I just can't. Elizabeth's post-secondary journey was certainly a negative one, specifically when she attended university prior to college and Ryerson. As Elizabeth reflects back to her personal feeling based on the experiences at the first university attended, she learned and believed that, "university isn't for me; maybe school isn't for me." 
Evidently, academia was a place she did not fit into, which was an accustomed reality during her earlier academic life.

As the conversation moved forward, Elizabeth's conviction that university was not a place for her, was associated with a variety of factors: "Well I didn't do well in school... I was not motivated, um, and I was not really engaged... Being with my friends, and talking about assignments and talking about exams...I felt like behind them, I felt like... Not as good... Not really equal."

Elizabeth's mention of the lack of academic accomplishments and engagement, including feelings of incapability especially in comparison to peers within the space of university, infers that Elizabeth carried an impairment discourse, which significantly impacted her academic confidence and how she associates herself in academia. In academia there is no disabled place and no place for her. Because of her earlier post-secondary experiences it impacted her selfesteem once she began studying at Ryerson: "I was very nervous about going into university again because my first experience wasn't good."

I had asked Elizabeth to describe a time when she felt her learning disability affected her in a negative way. Although not a current habit, her response authenticates how powerful her perceived incapability was and how her internal dialog (self-talk) influenced her confidence to complete course work: "I understood my learning disability that it was a difference ... something like holding me back... I guess I had a very negative like inner critic...I don't do it as much anymore, but I used to put myself down a lot... had to do with my learning disability... I start writing a sentence, and then read the sentence and I would be like oh my god that's so stupid ...I was the bully to myself... it definitely hurt my confidence, it definitely made me feel like shit..I would go to bed upset or cry and I'm really glad I don't do that anymore."

Moving into Elizabeth's time at Ryerson University, her narratives were told in a way that she appeared to lack a concrete belief in her academic capabilities in numerous areas, and this was particularly true at the beginning of enrollment: "reading, writing, exams and assignments those were the things I was very like nervous about. Not confident at all, um going into it."

Throughout the interview Elizabeth would often use the words, "I can't", which speaks volumes, indicating that she potentially still carries a discourse of incapability. For instance, Elizabeth utilized the academic supports at Ryerson; they encouraged her to work independently but she believes she unable to do so, “It's not that I'm dependent on them; I just feel ...I can't. I don't know if it's a competence thing, I don't feel like I can all the time."

When I had asked Elizabeth to identify an area of particular academic strength, she struggled to answer. When she excelled academically she was remarkably self-critical. Elizabeth recalls a story receiving $98 \%$ on a paper and believed it was an error: "I'm very hard on myself when it comes to getting my grades back because I always wish I would do better... a paper that I wrote... I ended up getting 98, which is like the highest grade I've ever gotten in my life, ever...I was like whoa, wow, like I was so surprised... I think I was in shock...I thought there was a mistake... like I've never, never, never, ever, ever been like a top person in my class, ever."

Stories of acceptance and understanding towards feelings of competency. An important element to Elizabeth's stories was searching for acceptance and understanding of her disability within academia; such stories were consistently replete with examples given within the physical environment, or through faculty and peer relationships. It is then that, Elizabeth feels 
comfortable, safe with her disability and more confident in who she is in academia. It appeared that Elizabeth is seeking to find a disabled placed in academia.

What I sensed from Elizabeth is when she is positioned in an environment that does not mesh well with her learning style; she does not feel comfortable and supported. Context is important for Elizabeth's perceptions and academic success. An example is when Elizabeth discusses taking an online course at the first university she attended: "Where you can watch the class...they stream it live... and it didn't work for me... I ended up dropping the class... I wrote the exam and I failed the exam... because I wasn't in class, like I can't learn through watching on a video like it just doesn't work for me."

Elizabeth moved ahead in time, to her studies at Ryerson University. She describes a narrative where she was unaware about an in-class exam, and was unable to write in an alternative room (as part of her accommodations), leading to extreme anxiety related to perceived inability to complete the exam. This environment was unsupportive towards her disability: "An exam and we thought it was an in class assignment ... I went to my prof, and said I'm having a lot of anxiety right now ... she let me bring a desk outside, and like put a chair just right outside the room.. I didn't know where to go and I didn't feel like I had enough information, like I wasn't prepared, I wasn't going into this thinking I was writing an exam or an essay, I wasn't given enough time... I was in a hall way, so there were people coming in and out, I was distracted...had I known this was an exam and I could have prepared myself..You know booking and like whatever, it would have been a lot different."

Elizabeth references her ability to access accommodations and resources from both college and Ryerson. Through such resources and accommodations in the physical space of academia, Elizabeth feels safe, included and supported, increasing perceived academic capability. "Because in college... they were very supportive... like there is a centre for those with learning disabilities, and here it's the access centre... the resources I have been able to access ...like the accommodations...were and are so helpful... can't imagine not being able to write in like a smaller classroom... exams like where there is a lot of writing, to get more time to write ...I don't process that fast... like I just need to think about things... I have that space to like take my time and also like with my assignments to get an extension on an assignment."

Being supported in her learning needs was and is important in Elizabeth's faculty relationships and towards feeling capable in the work that she produces at Ryerson. An academic challenge is Elizabeth's writing ability, and at times she requires extensions in order to produce a scholarly paper. Asking for extensions is a source of stress as Elizabeth fears that faculty may judge or misunderstand her: "Like, sometimes it's really hard for me to ask for an extension, um, actually not sometimes, all the time. ...I'm always thinking oh, like what are they thinking about me, or like they are probably expecting so much more now because I have more time." She recalls a moment emailing a professor to request an extension; the professor was understanding and this was vital for Elizabeth to feel accepted as a disabled individual in academia: " Um, but it's always like a nerve wrecking experience and to get that positive like thing back, it's just really good, like it feels nice so."

A profound moment in Elizabeth's narratives was when she described a story where she had a pop-up quiz, resulting in anxiety corresponding to her perceived inability to write it. Elizabeth recalls her personal feelings towards the professor's actions (allowing her to write the exam at an alternative location and date), and how she not only felt supported towards her learning needs but also confident in her ability: "she took it so well... she was fantastic and super accommodating. Because I didn't know her, like I didn't know how she would respond or I 
didn't know if she would judge me. But when she like validated my feelings, I was...like I don't need to be scared like she gets it...I didn't feel like she saw me any differently after that."

Elizabeth's desire to seek acceptance and understanding extends to her peer relationships, as an integral part of her academic identity and receiving support towards her academic achievements. Elizabeth comprehends the potential stigma associated with disability and this impacts her comfort to disclose. Elizabeth recalls a time when she accidently revealed her disability to peers; this made her feel vulnerable and potentially misjudged: "I was angry because I was like why did I just disclose that information... I don't know how they are going to perceive me, or take that information or use it against me...I was like oh my god I just outted myself... I felt really, um vulnerable." She notes the importance of the acceptance and understanding she receives from close peers related to her academic accommodations, "they are not judgemental or anything."

Understanding learning towards competency and developing skills and strategies

for academic success. Moving forward. Throughout the conversation I noted exceptional progress in terms of Elizabeth gaining a deeper understanding the way she learns and her disability, increasing self-assurance towards academic ability, including developing the strategies that lead to success, Elizabeth states: "I'm more aware of myself and of my learning." Her disability narrative is slowly transforming from confusion, imbedded within a discourse of impairment towards acceptance and comfort.

A noteworthy moment in her narrative was being re-evaluated for LD. Her reassessment allowed her to comprehend her mathematical challenges, which was a source of confusion and misunderstanding. Elizabeth found comfort in comprehending her mathematical struggles through such awareness: "My first year of university I got like, um re-evaluated...they said that like my learning disability was like, like hugely on math and then I was like oh it makes sense! Because I didn't know... math was actually my learning disability, I just thought I was so bad at it. ...seeing it on a piece of paper... it was just like it makes sense."

There was a further sense of comfort in re-diagnosis, particularly in Elizabeth's ability to gain access to resources, learning that she required them because of her LD, to enhance achievement and feel competent in her ability: "like having not been diagnosed I wouldn't have had those option because they are specifically for, umm people, like there is a centre for those with learning disabilities."

Aligned with Elizabeth's sense of understanding disability and challenges, she developed academic strategies to work with disability, such as accessing resources and asking for help. This was a source of confidence to ensure academic achievement: "I know if I need help or support I will ask, I'm good at asking...like that wasn't always the case; I wasn't always good at asking for help or wanted to acknowledge that I needed help."

Elizabeth struggles with writing; her ability to seek out assistance has been influential to developing skills and confidence within that area: "learning strategist has really helped me figure out how I learn and figure out how it works... Writing support person I've been seeing... and she is fantastic ... Through those resources is I'm seeing...writing differently. I think I have come a long way when it comes to paper writing ... Is I think organization of ideas umm... when I read my paper and it doesn't flow, I can catch it, whereas before my paper would be all over the place ...I'm starting to get it; like I'm starting to kind of get the whole process." 
Having provided narrative accounts for each participant to surface their stories, the next step in Clandinin's (2013) approach is to examine resonating threads, similar to some forms of across-case narrative analysis.

\section{Resonating Threads}

\section{The Complexity of Disability Identity: Fluid in Nature}

Resonating across all participant narrative accounts emerged three types of disability discourses that influence inner narratives and ultimately academic self-perceptions: (a) disability as confusion, lack of clarity and difference; (b) disability as impaired and incapable, (c) no dis in disability, embracement and comfort. Utilizing the Three Dimensional Space Narrative Structure, the element of personal condition allowed this study to identify the three different disabled narratives, particularly through expressions of participant feelings, reactions and dispositions regarding how they perceived their disability, which included to a certain degree their own academic self-worth (Clandinin, 2013). Secondly, the element of social conditions assisted to highlight cultural and social narratives, norms and assumptions of what entails disability that influenced how participants perceived their inner self narrative (i.e,. disability as a basis of abnormality or impairment). Furthermore, the means by which a disability discourse was taken on as an identity varied considerably with each individual throughout any one's academic career, including shifting back and forth between discourses or perceptions of disability within any given period for any individual. Such an analysis was surfaced by Clandinin's element of continuity, referring to the past, present and potential future (2013).

Through the complexity of the Three Dimensional Model, this study located additional resonating threads/findings that exemplify the ever-changing nature with inner narratives of each participant, including academic self-worth (Clandinin, 2013). Primarily, the dimensions of 
context/situational and social condition allowed this study to uncover that participant experience of developing and forming disability narrative was partially influenced by the physical and social environmental context of academia. Through analysis of social interaction dimension within participant stories, it appeared that individuals (family, peers and faculty) played an essential role towards developing one's inner self narrative (Clandinin, 2013). Lastly, the dimension of continuity helped to specifically identify that participants drew on stories, memories and events related to developing skills and competencies over time, altering their inner narratives (Clandinin, 2013). These resonating threads will be discussed in detail below.

Disability as confusion, lack of clarity and difference. This discourse represented itself as confusion and lack of clarity towards disability and learning. A few participants with an official diagnosis said they lacked an understanding, such as Tom and Elizabeth; they felt different, in a negative way, and that something was wrong and potentially abnormal with them in academia. This discourse was frustrating and irritating, because they are unable to comprehend how they learn and thus unable to find a disabled place in academia; it also influenced their perceived capability and self-worth. Therefore, awareness or full understanding of disability does not need to be present; it was more about perceiving the self-outside the confines of abnormality, representing a dominant social and cultural norm and assumption.

Across all participant narrative accounts, each had experienced and expressed such a discourse. Each participant had articulated it at the beginning of building their awareness of what disability entails for them, and specifically within the physical space of academia. Although this discourse was mostly at the beginning of disability awareness, and generally at a young age, it was also evident in later accounts specifically for Elizabeth, who stated that she does not 
thoroughly comprehend her disability as her current reality even though she was diagnosed in elementary school.

Most participants indicated that because of their age they were unable to wholly comprehend what disability meant; however they felt different from others, and this aspect contributed to their confusion in the physical space of academia. For instance, Samantha recalls, "I was probably 9 or 10 , grade 4 or 5, around that. So you don't understand what that means" and Kim recalls, "I was young, I didn't really know much about it.” This lack of comprehension was seen as a source of aggravation and stress, with Elizabeth indicating her transition into academia and understanding her learning would have been easier if someone had explained disability at a comprehension level she understood.

Two participants expressed confusion and frustration within elementary school, noting how she felt different which impacted her perceived ability academically, as less intelligent (Sandra) and feeling something was abnormal about the way she learned, which impacted her perceived ability (Samantha). For Tom, at the beginning of his disability awareness he could not comprehend why he was struggling academically, and this impacted his academic identity negatively. He viewed it as something he could overcome with time, which was even more frustrating when his understanding about ADD made him realize this was not something physical to be healed: "There was a little bit of improvement... but not as much as I expected..."

Disability as impaired and incapable. This discourse is characterized by a deep belief that one is unable, and has a personalized deficit or impairment in learning, significantly connected to dominant social cultural truths. For participants, they have attached comprehension and meaning to their learning disability, rather than lack of confusion or misunderstanding within the confines of difference or abnormality. This discourse was detrimental to participants' 
association with disability, negatively impacting their overall academic self-perceptions. All five participants, at one time or another, displayed aspects of such a discourse. Interestingly some participants had operated within it, yet they still expressed confidence academically; they exhibited self-determination and persistency to overcome their academic challenges to succeed. The operation of such a discourse was noted specifically when participants stated, "I can't", or "I am stupid", "I am dumb" and so forth. When participants referenced how it impacted them academically they would often express anxiety, fear of or not believing in their abilities in certain areas.

Two participants maintained an impairment discourse from high-school often referencing a lack of academic confidence, including experiencing extreme anxiety and disbelief in their capabilities. As noted by Kim, “ [Beginning of University] My confidence was extremely low...I was like going to fail this; I am going to get kicked out......The first week of school that was probably like the hardest week ever." Sandra similarly notes "[Disability was] something definitely negative. Like when I was younger, making me questions my intelligence...I think it definitely affected my confidence."

Other participants referred to a sense of shame within an impairment discourse. However, Tom's shame was tempered by his confidence. "It's a negative feeling that is attached to the disability that I have...You know this person has some permanent, incurable mental health disease...it's kind of shameful. I think of myself that is very...determined......I could overcome majority of the challenges I have... in my persuasion for my degree...I was very confident, I am still very confident now." Tom's commitment, determination and persistence counteracted the effects of an impairment discourse on his academic identity. 
No dis in disability, embracement and comfort. This discourse is characterized by comfort and embracement of disability; it is seen as a place of capability and strength, with little to no shame or embarrassment within the context of academia. Such a discourse is exceptionally liberating and empowering for students with learning disabilities and has positive implications to academic self-worth and confidence. Such a discourse directly opposes dominant cultural and social assumptions of disability based on impairment or abnormality. Majority of participants had, at one time or another (towards the end of their studies) exhibited such a counter-discourse. It is important to note that some only showed a slight expression of it, suggesting that they are gradually learning to accept and take on such a discourse to their identity and potentially moving back and forth between discourses. As it will be discussed later, this discourse is highly determined and influenced by other factors such as relationships and academic context.

Both Kim and Sandra are gradually becoming more comfortable and accepting of their disability, informed by supportive relationships and context, including developing skills to learn with disability. Kim stated: "I actually, kinda want to start talking about it more (disability) and be open about it." Sandra minimized impairment related to her disability: "It's a small disability... it not really affected me that much in terms of what I am able to do" and notes how confident she felt when she started post-secondary. However, at times I sensed that Sandra felt lack of confidence and exhibited an impairment discourse, reflecting the fluidity of selfperception and identity. Similarly, Samantha, who is not confident in her writing ability because of dyslexia and is exceptionally self-reflective of this, also sees it as a source of determination and strength to overcome her negative perception: "I think I just have to be more confident with myself. I think it's a good thing because it makes me work harder." 
Tom and Samantha both expressed a sense of comfort and ownership about their disability. Citing the powerful hold an impairment discourse has for those with disabilities, Tom resisted such a label by turning his disability into a capability. "Now I can...shift my attention pretty quickly, from one thing to another...I find is a very unique skill that I have and not many people are willing or could do it" Samantha resists an impairment discourse by acknowledging that everyone within academia faces challenges, like she does, which provides a sense of normalcy and equality: "I think I fall within... average range with everything".

\section{The Importance of Context}

Academic contexts played an exceptional role influencing participants' inner disabled narratives, impacting their academic self-perceptions. Across all five narratives, participant learning disabilities were mostly highlighted in the physical and social environment of academia. Within these spaces participants expressed their disabilities being seen as abnormal and thus impaired. In fact, it is within such spaces that majority of participants recognized that they had a LD and began their disability narrative, usually negatively. Take for instance Elizabeth who stated: "Grade 2 was when I realized I was different from everyone because they like separated the classrooms." Within educational environments that were not inclusive, understanding and supportive of participant's learning disabilities, they felt much more shamed and incapable academically, impacting their confidence academically. Participants described their disability as a barrier towards their success, particularly for Tom who was unable to concentrate during lectures: "if I cannot maximizing or utilize all the knowledge and everything in the class, I'm kinda wasting money." Participants who found themselves in supportive, inclusive and understanding spaces expressed significant comfort and less shame with their learning disability and increased confidence within academia. 
Unsupportive, exclusive and lack of understanding. For Samantha, context was exceptionally important, as she reflects back to her elementary school and also the first university she attended. Within such environments she not only took on an impairment and incapable abnormal discourse, she also lacked confidence. In fact, the lack of support from the first university Samantha attended impacted her perceived ability to re-enter university later (Ryerson). "I found challenge at the first university... lack of support... first time at university and I actually just passed...the past anxiety of, because I did so poorly the first time I went to university .... Wondering is that still me... Am I smart enough to do university?"

Both Samantha and Elizabeth specifically reference the impact segregation had on their association with their disability and worth within academia. For example, Elizabeth noted: "I was marked as a SPED, special education person...because I have an IEP...So that was cool...that was sarcasm by the way...so in grade 9 it was like I didn't have the option of doing academic, it was nope, you don't do academic your SPED... Um, and so I was in the applied, special whatever classes...I felt...stupid."

Inclusive, supportive and understanding. Kim and Elizabeth specifically noted how the resources offered for those with disabilities were beneficial for feeling included, supported, and capable, and finding a disabled place within the school. Kim recalled that, "The fact that I am registered with the access centre they kinda help me get accommodations, which really, really help uh, helps me. I have more time to do things, I have more time in class to finish an in class assignment or like group projects or anything really." Elizabeth similarly noted, "I think like the resources I have been able to access ... are so helpful. Like, I just can't imagine not being able to write in like a smaller classroom... I don't process that fast... I have that space to like take my time and also like with my assignments to get an extension." 


\section{Disability Identity Informed and Supported by Relationships}

Relationships with family, peers and faculty/teachers played an exceptional role to influencing the inner narrative of participants and their academic self-perceptions. The more participants expressed and received non-judgement and were included, and they felt support and understanding of their learning disability, the more they felt comfortable with their disability and competence academically. And on the other hand, if participants were excluded, felt judged as incapable and misunderstood, or lacked support from their relationships, they maintained a negative association with their disability.

Family in making meaning of disability. As it relates to family, their support and understanding of a participant's disability, particularly as being capable, was important to developing inner narratives especially in elementary school and high-school; this may be related to also being the time span when participants were learning about and growing a concrete awareness of what their disability entailed.

Recall Kim's reactions to her father's beliefs towards her disability, which informed and maintained a negative impairment association with her disability when she was young: "My dad was never really like supportive of it, he would make me feel completely horrible about it.... My dad, like, kinda reaction made me feel as if I was stupid." Samantha indicates her parents did not comprehend her disability, hindering their ability to support her, which negatively impacted Samantha in terms of understanding her disability and comfort with it in academia: "my parents didn't know how to explain it or how to help... so I was struggling to figure out what this was and what it meant to me and how it affects me".

Peer relationships. Peer relationships within the physical space of academic were vital in all five narrative accounts. Particular to peer relations, participants were continuously aware of 
the stigma and label associated with their disability, and felt ashamed and embarrassed to disclose their identity to a peer at some point or another, which assisted to maintain their negative relation with disability. Those that were comfortable, or developed a comfort with disclosing to a peer, exemplified a healthier association (as capable or normal) and received support and understanding towards the way they learned.

Both Kim and Sandra noted the stigma of disability and concerns about disclosing to their peers. However, they both shared positive experiences with peers. Kim notes: "I think my confidence went a little more stronger...I started to tell them; yeah I have a learning disability. I didn't think they would react positively... Knowing my friends here support me and ..... they helped me a lot. Like not because they feel bad, they don't, they know I am normal, I just have this one small thing but they still are really, really caring about it." Sandra recalls that when she did disclose to a peer in academia she felt comfortable and understood in regards to her dyslexia: “It's...difficult to tell people that I was diagnosed... It's strange; I had a lot of people that be like they will do something, and be like I'm so dyslexic or something like that. It's just like they are making a mistake...I don't know I find a lot of people say that...my best friend...we would always edit each other's essays. I had to explain why certain things were spelt certain ways... I just remember that when I explained she understood why...it's really nice”

.One participant, Elizabeth, noted both positive and negative associations with her relationships with peers, regarding her disability. Her fears to potentially being misunderstood and judged from peers make her feel vulnerable: “I don't know how they are going to perceive me, or take that information or use it against me". However, she also notes the importance of the acceptance and non-judgement she receives from her close peers, as a place of comfort: "Even to 
my close friends, they know, like because usually I'll say like oh I got an extension or... and they are not judgemental or anything".

Faculty and teacher relationships. Across all five participant narrative accounts, the paramount social relationships to informing inner narratives are the ones maintained with educational professionals like professors and teachers, potentially because it is within the physical space of academia. Such stories were referenced throughout the individual's educational career.

Elizabeth recalls the relationship she had with teachers in high-school and how it impacted her negatively: "I felt really stupid because people were treating me like I was..." The most profound story was when her grade 9 math teacher advised her to stay away from math because of her incapability to do it, which was part of her learning disability. Elizabeth describes her feelings to his disposition: "That conversation with the teacher impacted my whole life...I didn't ever think I would be or like get it, math was this concept that I was like I don't want to go near."

In post-secondary a professor was judgemental of the impacts of ADD on Kim's ability to pay attention during lecture; when she went to him for notes, he resisted assisting her, and according to Kim, he stated: "you're the student and you should have been listening." Kim had to obtain advocacy from the university's disability support in order to receive the notes she required. Her feelings about this experience were: "And it made me feel like, okay, I have to do all of this just to get help." To Kim, within academia, the lack of understanding and support towards her disability impacted her positive association with it and continued to reinforce her impairment and inability to succeed. 
Samantha notes specifically how empowering it is to disclose her disability to professors and receiving understanding, accommodations and support related to her disability:

"Proud...way to go your sharing...this is good.... So, um I guess it's always nice to get the understanding back. And to actually have an open conversation about it... so they know why I'm struggling... just help me understand."

Some participants appeared to be fearful about the potential application of impairment labels from educational professionals, as they saw it to impact their academic identity within (generally) the physical space of post-secondary. It appeared to be an adaptive strategy, to ensure they maintain their academic self-worth; however, their association with disability was one of shame. Thus, there is no denying the importance of understanding and acceptance. For instance, this was relevant to Sandra who stated, "I never like said or verbally told a faculty member.[Other than handing in an accommodation form] I remember feeling really awkward...feeling like I hope they don't think less of me.". She notes her positive feelings when professors understand her dyslexia: “it's kind of nice and hopefully they read my paper and know why I made a mistake." Tom notes an event where he did not disclose his disability to a faculty member because: "I don't really want people to, to, ahh, to see it as my coping mechanism...you know he uses this as an excuse...it's really a bad excuse right, so. Yeah, so ah, worry about the humiliation and the distrust." His ability to pass of as non-disabled was source of strength, to maintain his academic identity and also confidence.

\section{Working with Disability Over Time at the Post-secondary Level: Developing Skills and Strategies}

Across all five narrative accounts, participants expressed stories of academic triumphs, successes and a more positive outlook in terms of their academic identity, ability and 
competency, including the relationship they had with their learning disability. This is predominantly true for participants who had been in academia at the post-secondary level for longer, such as Samantha, Tom and Sandra, and thus time appeared to be a factor. For example, Sandra described her confidence in her academic ability when she began university: "In first year I wasn't sure because it was my first time taking university course.” Throughout post-secondary, participants (some more than others) had expressed a heightened understanding of what their disability entailed (how they learned) and what does it mean and look like; they also noted how they then developed the skills and strategies over time to work with it for academic success. The more participants felt comfortable and comprehended their unique learning style and their disability, they felt more self-assured to work with it, to complete their coursework and succeed academically.

Kim struggled throughout her first year university, as it pertains to her comfort with her disabled identity and academic competency. However, recalling her narrative account she drew upon various stories regarding academic successes and triumphs, developing skills and strategies, particularly related to time management and concentration. "Yeah, studying has definitely improved...focusing a whole lot more...I forced myself to make a schedule, like a planner, from what time to what time, and strangely that really helped me a lot...so managing my time, that was my biggest weakness since like grade 9. And I have finally fixed."

Similar to Kim, Elizabeth is gradually comprehending her disability and unique learning style and needs within the physical space of academia. Presently she indicates that she does not thoroughly comprehend her disability and what it actually entails or how it impacts her academically. However, over the course of university thus far, she has slowly become more aware of herself and the way she learns, which has acted as an incredible source of strength to 
her academic success and developing competency. "I know if I need help or support I will ask... I wasn't always good at asking for help or wanted to acknowledge that I needed help." She adds: "I think I have come a long way when it comes to paper writing ... Is I think organization of ideas umm... when I read my paper and it doesn't flow, I can catch it, whereas before my paper would be all over the place, and I think that comes with practice... writing... I'm starting to kind of get the whole process."

Samantha (a upper year student) indicated that adjusting to university was a challenge; moving forward she has significantly developed effective skills and strategies to work with and around her learning disability within academia. She not only illustrates comfort with disability as capable, but also shows confidence in her abilities. Samantha appears to be in tune with her academic strengths and challenges, and is continuously open about it and often seeks out assistance, particularly from her professors. She notes her academic triumphs she has obtained throughout her academic career, including overcoming and minimizing her learning challenges:

"[The beginning of university]was trying to figure out the transition to my next level of education and I did it, because now I'm on the dean's list and I'm doing research ... With me I just found ways that work...I just found coping mechanisms... [Consulting with professors] I've almost done that at least; at the beginning of every semester to every professor...help me understand...challenging aspect is shrinking because I think as I get older and more mature, um there are more strengths, because I think at the beginning of my university career it was hard to balance everything... but now it's my strength ...I'm always on top of my stuff. I know when things are due...There's a sense of pride with how much you overcome and what you challenge yourself with...It's just, that's how I see it, and I'm challenged, because I learn a little bit differently... I'm not going to fail." 


\section{Conclusion}

Drawing on Clandinin's approach to narrative inquiry (2013), full narrative accounts of each participant were outlined above, to give a sense of the experience of being a student with a learning disability in a post-secondary setting, from the perspective of each participant. A second level of analysis was used to seek resonant threads across the experience of some participants. Complementing the notion of fluidity, these resonating threads, or common themes, were experienced in both similar and different ways by participants. The next chapter explores those themes more fully, in answering this study's research question. 


\section{CHAPTER 6. DISCUSSION}

\section{Introduction}

As a learning disabled individual, who is personally implicated within this research, I reflect on the findings of this study and was amazed by the complexity and diversity amongst all narrative accounts/participants. Specifically, I was interested in how participants spoke about their disabled identity in interesting and alternative ways, including how they perceived themselves within academia. This chapter will begin by answering the research question with a discussion exploring the inner-self narratives expressed by participants, highlighting elements that also influence the conceptualization of one's identity. In doing so, I reference context, relationship and the notion of time, consistent with the Three Dimensional Model (Clandinin, 2013). An attempt will be made to identify how the conspired inner self-narrative influenced the ways in which participants perceived the self academically. As informed by participant accounts, I also will note unanticipated findings that appeared to impact academic self-perception. Thereafter, the limitations of this study will be discussed, including lack of generalizability, potential researcher bias and inability to fully implement the original research design. I then will offer insight into the strengths, rigor and credibility of this study, including methodological congruence and responsive interview design. To end this chapter, in line with the findings, limitation and credibility of this research, I will outline implications for practice, at the direct, policy and research level, to enhance our comprehension of learning disabled students and to support them in inclusive ways.

\section{Answering the Research Question}

The aim of this study was to explore and answer: What are the inner self-narratives of those with learning disabilities in post-secondary settings and its impact on academic self- 
perceptions. As discussed in the findings chapter and consistent with many forms of narrative analysis (Clandinin, 2013, Connelly \& Clandinin, 1990; Riessman, 2005), the first step in answering this question was to surface the individual stories of each participant, which was done through a restorying analysis process, resulting in a narrative account for each participant. Specific to the Three Dimensional Model (Clandinin, 2013), the second step was looking for resonant threads across these stories, as a way of analyzing commonalities relevant to the research question.

Across all five narrative accounts emerged four resonating threads: (a) complexity of disability identity; (b) importance of context; (c) influence of relationships; and (d) developing skills and strategies over time. Each participant noted the complex and non-static nature of disability identity, with varying effects to academic self-worth. The other three resonating themes indicated factors that shape one's relationship with disability and their academic selfperception. Reference was made to the importance of context influencing one's association with disability, including the role of relationships. Lastly, all participants expressed stories corresponding to the development of skills and strategies to work with and around their disability, altering their inner disability narrative.

Inner self-narratives as fluid and complex. The first portion of the research question, identifying the inner self-narratives, was most prevalent in the findings of this study, specifically, how participants spoke about and perceived their disabled identity. Contrary to scholarship that assumes a fixed identity for disabled (Alvermann \& Mallozzi, 2010; Bruzy, 1997), there were multiple expressions of participants 'relationships with disability, with three different inner narratives most commonly expressed: confusion, impairment, and capacity. 
All participants expressed that disability and learning represented a place of confusion, as a lack of clarity on what disability entails, with most participants noting it appeared towards the beginning of $\mathrm{LD}$ awareness or immediately after diagnosis. Within a framework of confusion, disability was perceived to be negative and embodied by difference and/or potential abnormality, particularly within the physical atmosphere of academia. In such a narrative, it appeared that due to the lack of disability comprehension, how one learns and how to strategize around LD for academic success, disability was negative and a barrier in academia, perceiving it as different and abnormal due to the inability to conform or succeed. While the abnormality and non-conforming experience is consistent with both other research (Heiman \& Kariv, 2004; Saracoglu, Minden \& Wilchesky, 2001; Scorgie, Kildal \& Wilgosh, 2010) and more positivist understandings (Alvermann \& Mallozzi, 2010; Bruzy, 1997; Green, 2007), the source of these perceptions is not particularly informed by categorization or labelling. Within this inner narrative, comprehension of disability is not developed into dominant discourses that reflect "either/or" confines of impairment or capability (McDonald, Keys \& Balcazar, 2007; Peile, \& McCouat, 1997); rather, the difference is based on confusion and lack of clarity, leading to perceived difference within academia. Interestingly, and contrary to other understandings (Bruzy, 1997; Green, 2007; McKenzie \& Thomson, 2005), abnormality was applied to this discourse without any reference to impairment or deficit.

Current scholarship does not reflect an identification of disability within a framework of confusion. The conceptualization of abnormality as a result of lack of comprehension towards disability may be a new understanding, although the concept of abnormality itself is not. Hosking (2008) reminds us that while the idea of abnormality is aligned with aspects of socially constructed truths of disability, whereby disability is framed against normality, it can be done in 
a way that locates disabled bodies as acceptance. However, although not presented as a form of impairment, the inner self-narrative of confusion seems to borrow from some elements located in a medicalized model of disability, most notably that of abnormality. Foucault explains that perception of identity is complex and often can be based on stringing together elements from various discourses (1972, 1981). Regularities located in specific discourses (i.e., medical model) can be borrowed and drawn into one's perception (Mills, 2003), even when one's "self" is more informed by other discourses (i.e., social construction). The inner self narrative of confusion about disability from these participants reflects how powerful dominant truths are in the lives of those with learning disabilities, even in partial form (Hosking, 2008; Mills, 2003). Given such findings, the link between confusion and abnormality as a discourse of disability possess as an area for further exploration; potentially indicating that LD students may benefit from comprehension of their disability as a means of moving away from perceived abnormality.

Another inner self-narrative consistent across all five stories was disability as a place of impairment and deficit in learning, reflecting dominant social and cultural perceptions of disability located within a medical model (Bruzy, 1997; Green, 2007; Hosking, 2008; Riddell \& Watson, 2003). Within this narrative, disability carried the meaning of stupidity in learning. This narrative was viewed as a negative and powerful identity that is undesirable, signifying a place of shame and embarrassment in academia. Once again, the notions of difference and abnormality were predominant within this narrative, but here disability has been given a concrete meaning. The distinction of this narrative is comprehending disability as impairment or deficit, rather than a lack of clarity about disability. This impairment focus mirrors more positivist and medicalized notions of disability (Alvermann \& Mallozzi, 2010; Bruzy, 1997; McVittie, Goodall \& McKinley, 2008), although as discussed below, it is informed particularly through language. 
Consistent with both scholarship and the theoretical underpinnings of this study, participants operationalized this inner self narrative through language reflecting dominant socially constructed knowledge related to disability (Green, 2007; Hosking, 2008; Savaria, 2008). A social model of disability references disability as impairment and deficit, as a place of abnormality constructed by dominant cultural and social norms (Hosking, 2008); we see this reflected in the ways learning disabled participants perceived the self and expressed their identity as noted in the Findings chapter. These findings also mirror labeling theory, with individual selfperceptions influenced by labels that are informed by dominant cultural and social ways of knowing (McKenzie \& Thomson, 2005); this is especially evident, for example, when participants reference themselves as "stupid" or "dumb", using language that represents and reproduces socially constructed labels of deficit. There is no underestimating the power and prevalence of this discourse on the social perception of LD students.

I was astonished by the power this inner self narrative (as a dominant Truth) maintained with the perceptions of participants, who appeared to be subjected to it (Mills, 2003). Knowledge as represented by language becomes hierarchical, where some terms and ideas dominate (such as disability framed as impairment/abnormality), while other terms and ideas (such as disability framed as capability or normal) are subjugated at the bottom of the knowledge hierarchy. Identities are thus ranked and classified (Foucault, 1979; Hosking, 2008), and we can see this, for example, in Tom's narrative about his diagnosis being framed as "normal" by his psychologist but his enduring sense of shame about his disability. Even the language of "normal" was not sufficiently powerful to counter the dominant discourse of impairment and abnormality regarding disability. 
In these examples, we see how learning disabled individuals become subjected to this inner self narrative by their association with an impairment discourse, through a process of selfknowledge, language, and regulation, dictating their disabled bodies and identity perception (Foucault, 1982). We can see that those with LD may be more influenced by such an inner self narrative as it may be difficult to resist or take on an alternative inner-narrative.

Lastly, another narrative that was expressed by all five participants in various degrees was disability as a place of capacity and strength. This narrative was most dominant in later academic careers, at times appearing in high-school, and gaining strength towards the end of post-secondary. An identity of being "different" was noted, but contrary to notions of deficit and abnormality (Alvermann \& Mallozzi, 2010; Bruzy, 1997; Green, 2007), difference was not perceived as negative. Instead, the differentiated self was embraced with comfort and pride, including an enhanced confidence with this identity. This narrative was liberating for students with LD in the physical realm of academia. An inner self narrative expressed as capable and as a place of strength and embracement, names disability in language outside the dominant discourse hierarchy (Foucault, 1979), and frames disability outside the confines of a medicalized model (Hosking, 2008). This contrasts most scholarship, which discusses the detrimental effects of an impairment discourse on disabled social reality, contributing to essentialization and framing disability as undesirable (Alvermann \& Mallozzi, 2010; Bruzy, 1997; Green, 2007; McKenzie \& Thomson, 2005; Riddell \& Watson, 2003). Few, if any, studies evaluate how disability identity can be shaped and informed in ways alternate to socially constructed truths. Given this research finding that there is strong positive association with disability, I suggest this as an area of further exploration given the positive perception it promotes for LD students within academia. 
In light of the short comings of scholarship, postmodernist theorizing on identity conceptualization assists to comprehend how LD students in this study produced their inner self narrative within a place of capability, strength and embracement (Riddell \& Watson, 2003). Individuals can navigate, work around and resist an impairment discourse informing their perceptions. Contrary to much of the current scholarship, learning disabled students are not uniformly oppressed bodies awaiting subjection to an impairment discourse. The body is a place where power is dynamic and identity is fluid, where dominant truths may be reinforced (such as adopting an inner narrative on impairment) but also where it can be resisted, which was demonstrated across all five narrative accounts of participants. This finding reinforces Foucault's (1979) position that individuals can construct or take on counter discourses contrary to the normative discourse of disability, as we see in these five participants who reflected inner self narratives based on capability.

In reflection of these three inner self-narratives - confusion, impairment, and capacity identity is not singular but multiple and represents diverse and complex meanings, signifying that the association with disability is not fixed and permanent but rather is fluid in nature. Within all narrative accounts, participants had operated at one time or another within all three discourses, to different degrees (i.e., some related to impairment discourse more than others). This is consistent with postmodern understandings that we draw from many discourses in constructing our innerself (Mills, 2003). We also see that at certain periods individuals can move back and forth between identities. For instance, an individual may take on an impairment discourse towards learning; however, they also expressed a gradual comfort and ownership of who they are as a disabled individual. The inner self narrative related to disability is not a singular entity, but one which varies across and between individuals. 
The medical model of disability and positivist scholarship predisposes disabled identity as a singular and fixed element, located permanently within the individuals; such understandings regrettably dominate explanations for learning disabled students (McVitte, Goodall \& McKinley 2008). This perspective has been countered by the findings of this study, which acknowledge the fluid and non-static nature of perception and identity, whereby resiliency and capability is an achievable identity. The findings of this study reaffirm both an interpretive approach acknowledged specifically by CDT (in a social model of disability) and a postmodernist lens (reflecting fluidity and resistance); in doing so, I argue that traditional disability scholarship reproduces defective beliefs that impairment is a signalised and negative identity (Fleischer \& Zames, 2001; Green, 2007; Priestley, 2003). The participants in this study are multi-dimensional, and although disablement/impairment is a powerful social and cultural construct that can influence identity formation, it is not an inherent fixed identity that precludes perceptions (Hosking, 2008; Mills, 2003).

Inner self-narratives informed by context, relationships and time. The fluidity and complexity of relating to a disability narrative was different for each individual, as noted above. These differences were informed in various ways, by academic contexts, relationships and time, consistent with Clandinin's (2013) understanding of narrative. Depending on such factors over the life-span of those with learning disabilities, the association with disability is vast, given the intricacy of each factor and the interplay between them. Each of these is discussed below.

Academic contexts were influential for all participants, throughout all levels of one's academic career. Academic contexts that were inclusive, supportive and accommodating to diverse ways of learning and disabilities promote a healthier disabled identity, with students moving away from narratives of confusion and/or impairment. Meanwhile, contexts that were 
unaccommodating, designed only for able bodied individuals, or those which actively exclude or segregated participants promoted a negative association with disability, based on confusion and impairment. Within inclusive and supportive contexts, participants not only better comprehended their disability and learning needs (e.g., utilizing disability services), it enhanced their comfort with, and embracement of, their disability and perceived capability. Students also referred to a gained a sense of normality in such inclusive contexts, rather than abnormality as informed by exclusive contexts that consistently remind and compare disabled individuals against able bodied standards.

Drawing from CDT (and a social model of disability), unaccommodating, exclusionary and ableist academic contexts socially construct and produce an impairment discourse by limiting learning disabled students, defining them as impaired and thus abnormal (Hosking, 2008). The learning disabled body becomes a site where these dominant negative discourses are reinforced (Mills, 2003). Foucault (1982) would argue that academic contexts revolving around ableist norms individualize and objectify learning disabled students, where they come to understand the self in these ways, as they become subjects to the control and power within such environments (1982). As seen in this study's findings, processes and practices of disablement are powerful and dictate learning disabled bodies in academia, substantially influencing identity formation (Foucault, 1975). However, contrary to social constructions of impairment and deficit, participant experiences suggest that academic contexts that are inclusive and supportive inform identities of capability and strength. In this way, while recognizing the power of academic contexts and recalling the negative identities within ableist environments and discourses, I suggest that inclusive academic contexts can counter dominant discourses of disability as abnormality. Hence, as discussed later in this chapter, shifts in academic practices may, in turn, 
also shift student identity formation and self-perception, which can also enhance academic achievement.

In regards to relationships informing inner narratives, three main sources appeared to be the most influential: family, peers and educational personnel. The role of the family is exceptionally important during elementary school and high-school, coinciding with when an individual gains an awareness of what their disability means (usually after diagnosis). Family assists in meaning making: the more family comprehends what disability means and entails (i.e., how an individual learns differently), and are supportive and understanding (including viewing disability as capable), the more enhanced an individual develops their understanding of disability (away from confusion). This enhanced understanding also produces a stronger belief towards capacities and comfort with, and embracement of, disability. Scholarship notes the role of parental support, for accepting and embracing learning disability, influencing positive selfperceptions, and enhancing both worth and academic proficiency (Hagborg, 2003; LaBarbera, 2008; Morvits \& Motta, 2001; Rothman \& Cosden, 1995). The findings of this study are consistent with this literature, but advances knowledge by focusing on the influence of family relationships overall (including siblings), noting the long-lasting impressions from negative parent associations with disability, as well as the impact on identity formation for post-secondary students.

In terms of relationships with peers, individuals are both aware of the cultural and social stigma and labels associated with disability (within a medicalized model), and fearful of how such a label could be applied to their identity by peers, through judgement and misunderstanding. Recalling interpretive scholarship, labeling theory suggests that individuals apply socially constructed truths to the self, in particular when they are additionally labelled by others within 
the social environment; as such, experiences of being labeled by peers (as noted by some participants) further integrates a negative self-perception, weakening psychological health and total sense of worth (Paterson, McKenzie \& Lindsay, 2012), which can then hinder academic achievement. Conversely, participants noted that once they felt accepted and understood by peers, their inner self narratives were much healthier, reflective of a place of embracement of their disability, and capability and normalcy as a student.

Participants consistently referenced developing one's inner self narrative through relations with educational personnel throughout one's academic career. Similar to family and peer relationships, academic professionals who are accommodating, inclusive and supportive, and did not view disability as impairment or a deficit, influences healthier inner-self narratives. Educational personnel who lack to accommodate, promote judgement and exclusivity, and treat disability as a deficit assist to preserve negative disabled narratives based on a medicalized discourse. Consistent with the influence of peers, while this finding may reinforce labeling theory understands of the impact of labels and categorization (McKenzie \& Thomson, 2005; Paterson, McKenzie \& Lindsay, 2012); it counters singular labels of disability as a deficit. In other words, students with LD may embrace labels of capability and normalcy when such categorizations are reinforced by peers and personnel in academic realms.

The degree and intimacy between all social relationships varies for each learning disabled individual, which exemplifies how the conceptions of inner narratives are conspired differently. Depending on the personal connection an individual has between family, peers and teachers, some may value the support and opinion from one network over another. In all, such findings suggest that the more supportive and understanding one's social network of relationships is, especially viewing disability as capable, the more it influenced inner self-narratives in positive 
means. In addition to informing inner narratives, the more an individual is able to openly discuss disability with their social networks, particularly peers and educational personnel, the more they displayed a positive association with disability. This is a specifically relevant finding to this study, representing itself as an alternative or new knowledge not present in current scholarship, and thus requires further exploration.

Lastly, an alternative and important factor that can shape and inform inner self-narratives particularly in positive ways was the notion of time. For all five participants, entering postsecondary required adaptation in order to succeed academically. Over the course of academia, students with LD develop strategies, models and skills that enhanced their academic proficiency and success. Through this means, individual learn to work with and around disability, thus turning academic barriers and struggles into capacities and strengths. Because of this process, individuals gain a heightened understanding of what their unique learning style entails, which increased comfort, capacity and embracement. This new and unexpected finding fills a significant gap in current scholarship, as previous research has ignored the role of time and the development of skills influencing inner narratives in academia. As such, I suggest that this focus could be fruitful for future exploration and for our understanding of learning disabled students.

Inner self-narratives impacting academic self-perceptions. In reference to the second part of the research question, identifying the impact the three inner self narratives had on academic self-perceptions, specifically elements of confidence, esteem and efficacy, was not as prominent in the findings of this study. However, the link between inner self-narratives and academic self-perceptions was present to some degree, which I discuss below.

Working within a narrative based on confusion about disability, embodied by feelings of difference in academia, appeared to be frustrating for individuals, in terms of fulfilling their 
academic requirements and obtaining their goals. The lack of comprehension of the ways one learns and the inability to locate a positive disabled place in academia (which maintains negative difference) appeared to hinder perceived academic ability. Self-efficacy has previously been noted in scholarship, as playing a role in framing one's academic perception, with respect to an individual's assurance regarding skills and one's belief in what they can or cannot do academically; this perception also impacts overall academic confidence, as it corresponds to one's validation of their capabilities and self-worth (Al-Hebaishi, 2012; Lackaye, Margalit, Ziv \& Ziman, 2006). This study's findings suggest that an individual carrying a disabled discourse based on confusion seem more likely to be susceptible to reduced assurance in their academic competencies; they do not comprehend how they learn differently and thus cannot strategize for success through individual skill development, potentially implicating academic efficacy and confidence as well as academic achievement.

The most common negative inner self-narrative that influenced academic self-perception was one based on beliefs of deficit in learning. At times participants stated that inner selfnarratives such as feelings of stupidity obstructed confidence and esteem within academia. This negative self-perception, which is reinforced through dominant discourses of impairment and labeling of difference as abnormality (Hosking, 2008; McKenzie \& Thomson, 2005; Tremain, 2005), heightened academic anxiety and fear, and diminished believing in capabilities within the physical space of academia. Such findings are reflected in current scholarship. All participants at one time or another illustrated a negative academic self-perception (influenced by an impairment discourse), confirming other research demonstrating a lowered self-worth in academic domains for student with LD, perhaps more so than non-disabled students (Jones, 2012; LaBarbera, 2008; Paterson, McKenzie \& Linday, 2012). Secondly, participants demonstrated that students with LD 
can take on socially constructed truths of disablement, which influences one's self-worth both academically and more generally. This finding is consistent with interpretive scholarship that notes socially constructed truths based on impairment have negative implications to not only how one views themselves as a disabled individual, but also their self-worth and confidence, in a general sense (Bruzy, 1997). Interestingly, in this study (and missing from other scholarship), individuals who maintained determination, persistence and commitment to achieve academic goals expressed self-confidence within, suggesting that such personality characteristics acted to counteract the potential negative effects of an impairment narrative. This preliminary and somewhat unexpected finding warrants further investigation.

The inner self-narrative based on capability, comfort and embracement of disability seemed to be liberating and empowering with regards to academic self-perceptions. The operation of such a discourse heightens academic confidence and proficiency. Dominant scholarship presents the academic realities (confidence, esteem and efficiency) of those with LD in essentializing and negative ways, victimizing them as helpless, passive agents filled with negative academic self-worth (Hampton \& Mason, 2003; Jerome, Fujiki, Brinton \& James, 2002; LaBarbera, 2008; Lind \& Bowler, 2009). The findings in this small study oppose such assertions, suggesting that individuals with LD can have a positive self-worth, achieve academically and enjoy their educational experience at the post-secondary level. I argue that individuals maintain this more positive discourse by actively resisting cultural and social assumptions of impairment and deficit in learning, in a variety of ways.

Participants altered their disability and learning challenges into capabilities and strengths, such as acquiring unique strategies or models that capitalized on or worked around their disability. They also minimized perceived difference by acknowledging that all individuals have 
academic strengths and weakness, thus situating challenges related to disability into a place of normalcy in academia. Lastly, demonstrating an increased commitment and self determination to overcome and triumph academic obstacles lead to perceived academic proficiency.

In addition, supportive, inclusive and non-judgemental educational contexts and relationships play important roles influencing academic self-perceptions, including the ways students with learning disabilities develop understanding of disability, and the skills and strategies to work with it for academic success over time. While not explicitly explored in this study, participant narratives illuminate that such factors enhance academic self-confidence, which leads to an increase perceived academic ability and proficiency. These preliminary findings suggest the need for further exploration of such factors on academic self-confidence of students with learning disabilities.

In summary, there are diverse means by which the participants in this study expressed relationship with disability (inner self-narrative), with three common inner narratives: confusion, impairment and capacity. These inner self narratives exemplify that identity is not singular but is multiple and diverse, with various meanings; as such, one's association with disability is not fixed and permanent. Support, understanding and inclusion received from academic contexts and various social relationships played a strong role in promoting a healthy capability inner-self narrative amongst participants. Another factor that shaped inner-self narratives positively was time; as students develop strategies and skills to work around disability and enhance their academic success over time, they displayed healthier inner self narratives. Identifying the impact of the three self-narratives on academic self-perception represented itself as less prominent in the findings. However, there is a potential that supportive contexts and relationships, including 
developing skills over time to work around and with disability, could be influential factors to informing academic perceptions.

Having explored this study's findings in response to the research question, the remaining sections of this discussion chapter will review the limitations and rigor of the study and implications for practice.

\section{Limitations of Study}

This section will outline the limitations of this study. As a researcher, I was attuned to the potential problems in this study. According to Creswell (2005) limitations is a common occurrence in both qualitative and quantitative research designs, and issues may correspond to data collection tools, recruitment, sample size and loss or withdrawal of participants, some of which arose in this study. One limitation of this study relates to the lack of generalizability of findings. Issues also arose from the study's inability to conduct secondary interviews. Thirdly, as part of the data analysis process indicated within the Three Dimensional Narrative Space Structure, I was unable to co-create findings with participants, implicating authenticity of data which was further hindered by potential researcher bias in data interpretation (Clandinin, 2013). Lastly, there may be concerns of potential bias in findings regarding my social positionality. I discuss each of these points below.

Findings of this study are not generalizable, due to the qualitative approach itself and the limited sample. Generalizability relies on statistical probability, which (mostly) requires a representative sample and numerical forms of data, consistent with quantitative studies (Newman, 2006). This study was qualitative in nature, and as such did not use or generate numerical data or use probability sampling to generate a representative sample. Generalizability also requires large sample sizes, and given that small sample sizes are used in most qualitative 
research, the ability to generalize findings to the demographic under study diminishes or disappears (Creswell, 2005). Based on the small sample size of five participants, recruited through non-probability sampling, the findings of this major research paper cannot fully reflect the experiences of students with learning disabilities in post-secondary settings. A larger sample group would have elicited a broader range of perspectives, as would engaging participants from more than one educational setting. While these two limitations are essential to note, the intent of this Major Research Paper was not to produce generalizable findings, but instead to offer findings that are both preliminary and transferable. As noted throughout this MRP, there are several areas for future research, informed by the preliminary findings of this study. As evidenced by the rigor of this study (discussed later in this chapter), there is merit in the transferability of this study's finding. Additionally, seeking knowledge about this study's topic, from a critical, interpretive perspective, through quantitative means and with a larger representative sample, is an area for further investigation.

A second limitation relates to conducting only one interview with each participant. In narrative inquiry, the use of more than one interview per participant is a common data collection method, and was noted in the Three Dimensional Space Narrative Structure (Clandinin, 2013). Further, engaging in a second set of interviews could have created richer data for this study, including allowing follow up to the original interview points after review (Clandinin, 2013). However, the conducted interviews were lengthy and in-depth, in part to compensate for this limitation, allowing for the production of generous and rich data (Boyce \& Neale, 2006).

Thirdly, following the original principles of the Three Dimensional Narrative Space Structure, participants should have been given the opportunity to cooperate in the creation of their own narrative accounts as part of the data analysis process (Clandinin, 2013). Given the 
limited time for this short study, this process was not followed, which could hinder the authenticity of the interpretation of findings, depending on this researcher's ability to analyze and comprehend data without misrepresenting and or mislaying what participants had actually intended to express. This limitation is a prevalent issue with time-sensitive graduate research. The Research Ethics Board at Ryerson University advised against follow-up with participants due to time limits, but it none-the-less represents itself as a clear limitation to this specific narrative approach.

Lastly, I also recognize that my social positionality as a learning disabled student may be reflected in the findings and could have potentially influenced the data analysis process and the presentation of findings. However, as noted earlier in the MRP, my positionality also allowed me to engage in the research process in a more collaborative way than might have been possible if I were not a learning disabled student.

The limitations of this study have provided further insight into improvements for future research projects; this will be discussed in the implication section of this chapter. It is important to note, however, that this study strived to be both rigorous and credible in its process and outcomes, which is discussed in detail below.

\section{Rigor and Credibility of Study}

To maintain the credibility of findings and rigor of this study, this researcher was cognizant to following all the steps outlined in the research design, and was attentive to issues related to enhancing authenticity and trustworthiness of the outcomes. I discuss these various elements in detail here.

The researcher engaged in a systematic and intentional sampling method, to ensure that recruited participants fit within the demographic required for this study. The researcher explicitly 
recruited at Ryerson University and engaged in an email and telephone screening to determine eligibility. These methods are common measures to maintain the rigor and credibility, as it corresponds to upholding and following the steps of the research design and systematic sampling (Newman, 2006).

Throughout the interviews, the researcher attempted to sustain authenticity of participant's responses by incorporating a variety of methods, including flexibility in the timing and order of questions, and being attentive to potential hesitation of participants to disclose sensitive information; participants also were given the option to decide the time and location of interview, to enhance ease and comfort. Secondly, the researcher was aware that those with LD may express and communicate in various ways. To ensure accuracy of data and for participants to best describe their thoughts and feelings they were offered two means by which they can communicate, written or verbal. Participants were informed that they can skip questions, request to stop interview and pause if they desired, and the researcher attempted to provide time to reflect on answers and freedom to speak in-between questions. Lastly, the researcher engaged in a conversation style interview in the hopes to enhance authenticity, comfort and casual conversation by which participants may be more responsive (Newman, 2006). In all, such interview tactics helped to enhance the credibility and trustworthiness of participant responses, such as promoting freedom and control of participants to navigate the interview and researcher flexibility (Creswell, 2005, 2013). The interview questions were specifically designed and tailored to encourage the respondents in their answers to assess and explore the research question. The researcher stayed within the confines of questions throughout all five interviews conducted. This study followed the approach of the Three Dimensional Space Narrative Structure, focusing on identifying three elements, interaction, continuity (time) and context, 
which directly informed the interview questions (Clandinin \& Connelly, 2000), as a further example of this study's methodological rigor.

Recalling this study's review of current scholarship, various research processes have misrepresented and appropriated the experiences and realities of students with learning disabilities. Narrow definitions of what constitutes LD (May \& Stone, 2010; Scorgie, Kildal \& Wilgosh, 2010; Shany, Wiener \& Assido, 2012) and inflexible data collection methods that are inconsiderate of various communication and processing styles (Green, 2007) are two examples of the questionable rigor of other studies of this topic. An element fundamental to this study's design was to be sensitive, reflective and accommodating to these various mechanisms within the data collection process, which in turn heightens the likelihood of authentic data that represents the participants, and offers insight that is not present within current, dominant research. To enhance the accuracy of data, interviews were audio-recorded and transcribed verbatim. Careful attention was given to the transcription process, which included observational notes, non-verbal actions/words and pauses (Creswell, 2005). To further this, the researcher offered a follow up session with participants to review transcribed data to assess if data was truly reflective of what they had expressed.

To enhance the likelihood that each narrative account was a reasonable illustration, I had maintained enough time to read, review, chart and analyze data. Considering that I was very much implicated to this study, I used processes to minimize misrepresentation or biased interpretation of data, such as the ones stated above. Even more so, throughout data analysis, I had given myself time away from the text. There were periods when data brought forward memories of my own past, and this I acknowledged was emotionally heavy and could construe 
data, I therefore accredited the time away as needed. This reflexive and time-rich process is consistent with confirmability standards for qualitative research (Lincoln \& Guba, 1985).

To advance the credibility of the findings, I engaged in a process of data driven analysis as an inductive process, allowing the findings to emerge from the frequent and dominant themes that were naturally located within raw data (Thomas, 2006). The analysis naturally occurred from the stories as expressed by participants, which fit into the three dimensional model that acknowledges all narratives are told within the confines of interaction, continuity and context (Clandinin, 2013). This process allowed exploration of the intrinsic and inherent structure of data (stories), followed by finding resonating threads across all narrative accounts (Clandinin, 2013). The benefits of such an approach allowed this study to condense raw data into a finalized summary, with clear linkages to the overall research objectives and findings. It assisted to develop and form a discussion of the underlying elements of participant experiences that were clearly evident in data (Thomas, 2006).

The credibility and rigor of this study is further reflected in my commitment to following the research processes as close to originally outlined as possible. As mentioned, I engaged in the original recruitment process that was designed to target the intended sample group. Each participant successfully completed a screening prior to interviews. Upholding the methodological narrative approach, I conducted all five-one-on-one conversation/narrative style interviews, guided by the specific and original interview protocol that allowed participants to reflect and respond in narratives/stories based on their experiences (Creswell, 2005). Along with the methodological approach, I carefully analyzed and charted each transcribed interview by following the Three Dimensional Space Narrative Structure as intended, locating themes related to the three elements (Creswell, 2005; Ollenshaw \& Creswell, 2002). Common to narrative 
approaches, I created narrative/story-like accounts for all participants, to maintain the story-like structure from the original raw data (Clandinin, 2013). Careful analysis was done, moving back and forth between all narrative accounts finding commonalities, known as resonating threads (Clandinin, 2013). Lastly, as part of the collaborative process as originally outlined in this research, I committed to connecting with all participants to follow up and review transcripts, which includes my intent to later offer to review findings and send the final report to each participant.

By utilizing purposeful and comprehensible planning this study was able to enhance methodological congruence. By ensuring that the narrative approach was reflected in the interview protocol and process, the analysis of data and the representation of findings, this study sought to answer the research question authentically and maintain its credibility (Thurston, Cove \& Meadows, 2008). I was committed to follow all the steps in this research, with respect to recruitment, data collection and analysis/interpretation. Trustworthiness of interview responses was heightened by introducing sensitive and adaptive tactics and strategies that kept participants needs and comfort at the forefront. The interview protocol maintained credibility as it was designed to explore the research question and aligned with the structural framework of the narrative model utilized, maintaining methodological congruence. Time played a factor contributing to credibility of the findings, related to analysis and time spent away from, and reflecting on, sensitive data with which I was personally connected. Following a data driven, inductive process ensured that findings emerged from themes that naturally occurred and were located in data (Thomas, 2006). As discussed in detail above, I argue here that the study demonstrates strong credibility, authenticity and confirmability, as indicators of the rigor of this research. 


\section{Implications for Practice}

Here I outline suggestions and implications drawing from the fundamental findings of this research project, including its limitations. Propositions are made to potentially improve educational approaches, practice and disability services, as well as policies, with the aim to better support those with LD. Lastly, I have delineated areas of future research in the hopes to improve the substantive knowledge base on this study's focus and topic, in our quest to better comprehend LD students and support them educationally. To improve the dynamic of research with those that have learning disabilities and further explore this research topic, methodological recommendations also are provided. Finally, the role of social work in its various forms related to this research is noted.

Many school settings provide support services to students with learning disabilities. However, these supports focus exclusively on the student, outside of any relationships that may be critical in how a student understands their LD. School social workers and educational personnel are recommended to create and implement an educational program to all students (disabled and non-disabled) about disability and inclusion, promoting a narrative of capability and understanding, to minimize felt embracement and shame related to disability and to promote student body cohesion and support. Secondly, peers and non-disabled students need to become integrated into service and supports offered to those with learning disabilities, at all levels of education. Suggestions include, one-on-one peer support, study groups and mentorship programs. While peers and faculty may be important, given the importance of family members in meaning making of disability, they should be included in any support processes (with the student's consent). This process may happen in elementary and perhaps also secondary level education, but seems missing from post-secondary settings, likely due to their adult education 
context. However, given the value of positive family associations, this option could be offered to every student seeking support with their LD.

With respect to practice within educational contexts, student services for those with learning disabilities could be enhanced to promote healthy associations with their disabilities from the beginning of diagnosis. Such programs should be maintained throughout all levels of education, and can be incorporated by one-on-one or group work in elementary, secondary and post-secondary settings. From my personal experience, disability supports focused on learning skills, models and strategies to gain academic competency to work with and around one's disability can be effective. Services that focus on positive discourses of LD could promote narratives of capacity, embracement and strength, which challenge negative cultural and social assumptions based on impairment and or deficit. It is essential for services to place importance on the impact of identity on academic self-perceptions, in terms of sustaining student emotional wellbeing and confidence, and success in academia. School social workers and disability advocates alike have an important role in the implementation of services, through direct practice, policy alterations, continued research, advocacy to promote increased funding, and facilitation of training workshops within schools.

Developing the skills and strategies for students entering post-secondary settings ought to be incorporated as early as possible (i.e., at time of offer of admission rather than at start of academic year), then emphasized during their primary year and maintained consistently throughout one's academic career. In the promotion of skill development and support, there lacks a continuity of supports between the various levels of education. There is continuity when a learning disabled student transitions from elementary to secondary education, through their Ontario Student Record and other sources, whereby needs are noted and supports continued. But 
a similar process appears to be missing in the transition from secondary to post-secondary school. Considering the lack of congruency of services and supports for LD students while transitioning into post-secondary, social workers and disability advocates must engage in recommendations of policy changes, and lobby directly with the Ministry of Education and the Ministry of Training, Colleges and Universities in Ontario, for example. This includes enhancing collaborative efforts with various levels of education to ensure that students ease into the next level of education and receive continued support to develop skills and strategies.

A fourth recommendation would be for educational settings, especially at the postsecondary level to challenge the operations of cultural and social assumptions of disability based on impairment, through its institutional practices, policies, teaching mechanisms and overall educational approach; school social workers can play an essential role as they are responsible to support students who can potentially become marginalized or excluded. This can help to facilitate an atmosphere of understanding, non-judgement, inclusion and support influencing educational personnel and other students/peers. It is suggested that disability be normalized and embraced, whereby academia moves away from tailoring to able bodied students.

Given the scope of this study, it is recommended that future research be conducted to examine and evaluate how educational contexts can improve their practices, policies and teaching mechanisms in order to promote an inclusive and non-judgemental approach, embracing disability within a framework of capability. Below are some specific suggestions:

- Introducing inclusion practices, rather than segregationist approaches.

- Engaging educational professionals in workshops and mandatory training to become aware of the dynamics of disability, and to learn how best to encourage healthier 
disability perceptions based on capacity and support LD students to build skills for academic success.

- Implementing accountability policies for educational staff, regarding LD awareness.

- Challenging stigma of disability through student educational initiatives.

- Developing peer integrated programs.

In addition to these practical recommendations, I offer both substantive and methodological research recommendations arising from my experience conducting this study. Recognizing the current focus on scholarship informing practice (and thus potentially the perspectives of many students with LD), there is a clear need to enhance the link between identity in its various forms and its influence on academic self-perceptions. It is recommended that a shift in theoretical perspectives of identity be introduced, including its influence on selfperceptions, by moving away from the detrimental medicalized framework that dominates scholarship and practice approaches, and embracing an interpretive and postmodernist lens. Current scholarship that solely focuses on academic perceptions engages in essentialist assumptions that homogenize the realities of disabled students into one and depicts them as helpless victims in the pursuit of their education. Such scholarship assumes students will inevitably experience lower self-confidence, continuous academic struggles/underachievement and heightened anxiety. These understandings in current scholarship must be challenged, and conducting research that counters this knowledge is one way to do so.

Secondly, engaging in a theoretical shift from a medicalized model will help to alter our comprehension that those with LD are not helpless and doomed to a fixed identity based on deficit in learning. Instead, scholarship from a more critical postmodern perspective can emphasize the possibility for fluidity and change, and that capability, strengths and perceived 
embracement is a possibility and can be developed. Such understandings can acknowledge that those with learning disabilities in educational settings do not necessarily need to expect, nor have a struggle or negative experience, but with the right perspective and support, such students can begin to find a disabled place in academia and feel confident about who they are and how they understand themselves.

The following represents recommendations for future research initiatives:

- Shifting theoretical approaches from a medicalized/positivist approach, to interpretive and postmodernist lens.

- Exploring the link between identity and academic self-perceptions amongst learning disabled students at all educational levels.

- Exploring the correlation between confusion/lack of clarity towards disability and viewing the self within the confines of abnormality and negative difference.

- Identifying how disability identity can be perceived outside socially constructed representations of disability.

- Examining the dynamic and elements of educational contexts and relationships towards identity formation and academic self-perception.

- Evaluating how educational contexts can improve their practices, policies and teaching mechanisms, to promote inclusivity.

- Assessing the role between one's ability to disclose and discuss their disabled identity and how it promotes a positive association with disability and potentially a healthy academic perception. 
- Developing research that pin-points what skills, models and strategies LD students develop to work around their disability, which enhances their academic proficiency.

- Examining the link between personality factors of self-determination and persistency in the formation of disability identity and academic perception.

In addition to these substantive recommendations, to further explore this research focus, future studies may find the following methodological recommendations fruitful. Given the limitations of this small study, a larger sample size and expanding recruitment to include participants from a variety of post-secondary institutions could generate broader results. This also includes expanding the sample demographic to students at all levels of education.

In reflecting on the narrative approach of this study, I learned that participants appreciated the ability to communicate their experiences through stories. Participants noted their comfort with it, triggering positive responses and reflections, and thus a narrative approach appears to be a suitable. In particular, the use of the Three Dimensional Narrative Structure (Clandinin, 2013) could be useful to future research in this area, as it allows findings to emerge naturally from raw data maintaining its authenticity (Thomas, 2006). Second, because of the complexity of this approach, acknowledging interaction, continuity and context, this study derived unique findings that would have otherwise been unacknowledged (Creswell, 2005). Further, as part of a narrative approach future studies would benefit to involve participants in the co-creation of data and findings (Creswell, 2005). Traditionally those with disabilities have been further subordinated and oppressed in social research by able bodied social inquiries who maintained their dominance in all processes (Stone \& Priestley, 1996). By including them in 
knowledge creation it can challenge impairment discourses and create knowledge that is truly representative (Potts \& Brown, 2005).

Lastly, social researchers must remain sensitive to their participant's unique characteristics while conducting interviews, to enhance rich data collection and thus further authenticate findings. Future studies must incorporate various ways to collect data given the complexity of how learning disabled individuals communicate and process information. Participants should be given the option to respond in written, verbal, pictorial and arts-based forms and researchers must follow the cues of participants with regards to needed breaks and time in-between responses. This means avoiding assumptions and not limiting options for participants, and being open to any means of communication should be of upmost importance, to avoid promoting a culture that supports only able bodied participants.

\section{Conclusion}

This discussion began by exploring how the findings of this study answered the research question. In addition to noting the specific responses related to inner self-narratives and academic self-perceptions, the prevalence of responses related to the first part of the research question, regarding inner self-narratives was noted. As a means of evaluating the credibility of this study, limitations were explored, but also were framed within the context of conducting graduate-level research. The rigor of this study was highlighted, with particular attention to methodology. Finally, implications for practice were noted, with many recommendations for practice and policy changes, as well as suggestions for future research. 


\section{CHAPTER 7. CONCLUSION}

The intent of this study was to explore and describe the academic self-perceptions of students with learning disabilities in post-secondary settings. Recalling that a positive academic self-perception is linked to emotional wellbeing, achievement and success within academic (Shaney, Weiner \& Assido, 2012), this study sought to discover how disability identity implicated academic self-perceptions. This research was necessitated by the gaps located within both substantive and theoretical scholarship. Current substantive knowledge regarding the academic self-perception of learning disabled students depicts their educational realities in essentialzing, negative and fixed means, stigmatizing and marginalizing them as they enter post-secondary education. Learning disabled actualities in academia were further negatively portrayed by positivist scholarship focused on a medicalized model of disability. Interpretive scholarship that identified fluidity and complexity towards disability identity and perceptions was limited for this population. This study sought to answer two questions:

- What are the inner self-narratives of students with learning disabilities in post-secondary setting?

- What is its impact on academic self-perception?

This study capitalized on the stories/narratives of five student participants from Ryerson University who had learning disabilities. To centre a valuing of their participant voices and perspectives, the commonalities and resonating threads discussed in this study are steeped in the responses of participants as articulated in each expressed narrative. I purposefully decline to offer conclusive findings that essentialize academic experiences, perceptions or identities for students with learning disabilities in general. Instead, consistent with narrative inquiry, I allowed the findings to speak for themselves, and representing only the participants in this study. In this study, 
I explored the variations of identity and academic perceptions, noting the exceptional individualistic experiences within academia and each person's single reality, seeking to not make assumptions and replicate findings informed by internal impairment and deficit as portrayed in much of the current scholarship.

The following will synthesize the findings to answer the study's research questions based on all five narrative accounts. In relation to the inner-self narratives, there were three common ways in which participants had expressed their association with disability: confusion, impairment and capacity. Relating to these three inner-self narratives, identity is not singular but represents diverse meanings, whereby the relationship with disability is non-static. This fluidity was seen in how some participants took on different identities or assumed a similar identity to others, but to a higher degree, while at other times shifting between identities. Further, the association with an inner self narrative was deeply informed by context, relationships (with peers, family and educational personnel) and time.

The impact of the three self-narratives (confusion, impairment and capacity) on academic self-perceptions, as related confidence, esteem or efficiency, was not a prominent finding. However there was some insight relating to the three inner self narratives. Disability based on confusion and difference can lead to aggravation for students, in completing and fulfilling academic goals. Lack of understanding and inability to find a disabled place in academia appeared to hinder perceived academic capacity. Disability based on impairment seemed to be the most influential narrative to affect academic perception negatively. This corresponds to feelings and expressions of stupidity, low self-esteem and confidence, and academic anxiety. Disability based on capability presented as a liberating and empowering identity positively influencing selfperceptions. Although not specifically explored in this study, supportive, inclusive and non- 
judgemental educational contexts and relationships, and developing understanding of disability, including effective learning skills and strategies, appeared to positively influence academic perceptions.

The positivist medicalized notion of disability identity as a singular, deficit and fixed element located within the individual that leads to emotional distress and potential negative selfworth, is countered by the findings of this study (Bruzy, 1997; McKenzie \& Thomson, 2005; Riddell \& Watson, 2003). This study was influenced by principles of critical disability theory and postmodernism, as reflected in the understanding that identities and perceptions are everchanging and thus not static. The experience of LD students in post-secondary settings does not preclude misery, emotional turmoil and academic failure, but it also is one where capacity and resiliency is an actualized possibility. The importance of this study is recognizing that disablement is a powerful and dominant social construct that can (but not always will) implicate identity and perceptions in a negative way (Hosking, 2008: Mills, 2003). Deproblematizing learning disabled students in post-secondary settings and shifting responsibility from individualized change to institutional change at educational institutions, the field of social work and society in general have a responsibility to create and promote spaces and social/cultural atmospheres that embrace and construct disability for all its forms and complexities.

The findings of this study have implications for the field of social work and educational institutions at the direct level, and in policy and research. As detailed in the discussion chapter, implications at the direct level include incorporating peers and family into services/supports, creating services that promote healthy narratives of disability, integrating disability support at all level of education, particularly during times of transition ( i.e., secondary to post-secondary), and challenging impairment discourses in the overall educational approach. 
Given the recommendations listed above, policies will have to be altered to support such accommodations. One fundamental need places social work and disability advocates at the forefront to address issues, such as reviewing and altering policies in educational contexts to promote ability and inclusion. With respect to research, recommendations include adopting an interpretive theoretical perspective to resist a medicalized/positivist model in disability studies, exploring the link between identity and academic self-perceptions at all educational levels, as well as the role of relationships and academic context in contributing to identity formation. Additionally, future research should incorporate narrative approaches to promote comfort during data collection processes, along with data collection methods that are sensitive to and inclusive for learning disabled individuals.

As I reflect on my own personal experiences as a learning disabled individual in academia, I encountered ableist discrimination and assumptions through various avenues (i.e., individuals and the social environment) that negatively implicated my relationship with disability and perceived academic proficiency. I learned over time that my biggest obstacle was not because I could not achieve academically due to my learning disability, but rather I maintained a concrete belief that I was not smart or capable enough: this is a clear distinction and I hope this research helps to make it known. It took me a very long time to realize this, to challenge the operations of an impairment discourse on my own identity and perceptions and at times I am still impacted. I hope that we can begin to acknowledge, and take ownership and accountability for how we (social workers, educational institutions and society) perpetuate discourses of impairment, and then begin to shift into a promotion of disability as capability. The utmost goal is for students with learning disabilities to embrace their identity as disabled, believe in their academic ability and find an inclusive space in academia, increasing their academic success. 


\section{References}

Afari, E., Ward, G., \& Khine, M.S. (2012). Global self-esteem and self-efficiency correlates: Relations of academic achievement and self-esteem among Emeriti students. International Education Studies, 5(2),47-49.

Akomolafe, J.M., Ogunmakin A.O., \& Fasooto, M.G. (2013).The role of academic self-efficacy, academic motivation and academic self-concept in predicting secondary school students' academic performance. Journal of Education and Social Research, 3(2), 117-129.

Al-Hebaishi, M. S. (2012). A comparison of learners' achievement between blended learning and distance learning. International Journal on E-Learning, 11(4), 373-382.

Alvermann, D.E., \& Mallozzi, C.A. (2010). Interpretative research. In A. McGill-Franzen \& R. L. Allington (Eds.), Handbook of Reading Disability Research (pp. 488-498). New York, NY: Routledge.

Baffoe, M. (2013). Stigma, discrimination \& marginalization: Gateways to oppression of persons with disabilities in Ghana, West Africa. Journal of Education and Social Research, 3(1), 187-198.

Bear, G. G., Minke, K. M., \& Manning, M. A. (2002). Self-concept of students with learning disabilities: A meta-analysis. The School Psychology Review, 31, 205-242.

Beaty, L. A. (1991). The effect of visual impairment on adolescents' self-concept. Journal of Visual Impairment and Blindness, 85, 129-130.

Belch, H. (2004). Retention and students with disabilities. Journal of College Student Retention, 6, 3-22. 
Boyce, C., \& Neale, P. (2006). Conducting in-depth interviews: A guide for designing and conducting in-depth interviews for evaluation input. Pathfinder International Tool Series, monitoring and evaluation -2 . Retrieved from http://www.pathfind.org/site/DocServer/m_e_tool_series_indepth_interviews.pdf?docID $=6301$

Bruzy, S. (1997). Deconstructing disability the impact of definition. Journal of Poverty, 1(1), 8191.

Chapman, J.W. (1988). Learning disabled children's self-concepts. Review of Educational Research, 58, 347-371.

Clandinin, D.J. (2013). Engaging in narrative inquiry. Walnut Creek, CA: Left Coast Press Inc.

Clandinin, D. J, \& Connelly, F. (2000). Narrative inquiry: Experiences and story in qualitative research. San Francisco, CA: Jossey-Bass Publishers.

Connelly, F.M., \& Clandinin, D.J. (1990). Stories of experience and narrative inquiry. Educational Research, 19(5), 2-14.

Creswell, J. (2005). Educational research: Planning, conducting and evaluating quantitative and qualitative research. Upper Saddle River, NJ: Pearson Education Inc.

Creswell, J. W. (2013). Qualitative inquiry and research: Choosing among five traditions (3rd ed.). Thousand Oaks, CA: Sage Publications.

Crosnoe, R., Riegle-Crumb, C., \& Muller, C. (2007). Gender, self-perception and academic problems in high school. Social Problems, 54 (1), 118-138.

De Santos, M. (2005). Negative self-perceptions among students with learning disabilities. (Published Master's Thesis). California State University, Fullerton. 
Elbaum, B., \& Vaughn, S. (2001). School-based interventions to enhance the self-concept of students with learning disabilities: A meta-analysis. The Elementary School Journal, 101, 303-329.

Elbaum, B., \& Vaughn, S. (2003). Self-concept and students with learning disabilities. In H.L. Swanson, K. R. Harris, \& S. Graham (Eds.), Handbook of learning disabilities (pp 229241). New York, NY: Guilford Press.

Evans, D. W. (1998). Development of self-concept in children with mental retardation: Organismic and contextual factors. In J. A. Burack, R. M. Hodapp,\& E. Zigler (Eds.), Handbook of mental retardation and development (pp.462-480). Cambridge, UK: Cambridge University Press.

Field, S., Sarver, M., \& Shaw, S. (2003). Self-determination A key to success in postsecondary education for students with learning disabilities. Remedial and Special Education, 24(6), 339-349.

Fitzgerald, T. (2004). Powerful voices and powerful stories: Reflections on the challenges and dynamics of intercultural research. Journal of Intercultural Studies, 25 (3), 233-245.

Fleischer, D., \& Zames, F. (2001). The disability rights movement: From charity to confrontation. Philadelphia, PA: Temple University Press.

Foucault, M. (1970). The order of things archaeology of the human sciences. London, UK: Tavistock.

Foucault, M. (1972). The archeology of knowledge. New York, NY: Harper Collins.

Foucault, M. (1975). Discipline and punishment, practices and knowledge. Panopticon. New York, NY: Random House, Inc.

Foucault, M. (1977). Discipline and punish: The birth of the prison. New York, NY: Pantheon. 
Foucault, M. (1978). The history of sexuality, Vol. 1. New York, NY: Pantheon.

Foucault, M. (1979). The order of things: An archaeology of the human sciences. New York, NY: Random House, Inc.

Foucault, M. (1980). Power/knowledge: Selected interviews and other writings 1972-1977. London, UK: Harvester.

Foucault, M. (1981). The order of discourse. In R. Young (Ed.), Untying the text: A poststructural anthology (pp. 48- 78). Boston, MA: Routledge \& Kegan Paul.

Foucault, M. (1982). The subject and power. In P. Dreyfus \& P. Rabinow (Eds.), Michel Foucault: Beyond structuralism and hermeneutics (pp. 208-226). Brighton, UK: Harvester.

Fraser, H. (2004). Doing narrative research: Analyzing personal stories line by line. Qualitative Social Research, 3(2), 179-201.

Frederickson, N., \& Jacobs, S. (2001). Controllability attributions for academic performance and the perceived scholastic competence, global self-worth and achievement of children with dyslexia. School Psychology International, 22, 401-416.

Goodman, N., \& Orr, A. (2010). "People like me don’t go to college": The legacy of learning disabilities. Journal of Ethnographic \& Qualitative Research, 4, 213-225.

Green, S. (2007). Components of perceived stigma and perceptions of wellbeing among university students with and without learning disabilities. Health and Sociology Review, $18,328-320$.

Hagborg, W. (2003). Sources of school belonging for students with learning disabilities. Paper presented at the meeting of the American Psychological Association, Toronto, ON, Canada. 
Hampton, N.Z., \& Mason, E. (2003). Learning disabilities, gender, sources of efficacy, selfefficacy beliefs, and academic achievement in high school students. Journal of School Psychology, 41(2), 101-112.

Heiman, T., \& Kariv, D. (2004) Manifestations of learning disabilities in university students: Implications for coping and adjustment. Education, 125(2), 313-323.

Heiman, T.,\& Precel, K. (2003). Students with learning disabilities in higher education. Journal of Learning Disabilities, 36(3),248-258.

Helsen, M., Vollebergh, W., \& Meeus, W. (2000). Social support from parents and friends and emotional problems in adolescence. Journal of Youth and Adolescence, 29, 319-33.

Hosking, D. L. (2008). Critical disability theory. A paper presented at the 4th Biennial Disability Studies Conference at Lancaster University, UK, Sept. 2-4, 2008.

Irving, A. (1999). Waiting for Foucault: Social work and the multitudinous truth(s) of life. In A. Chambon, A. Irving, \& L Epstein (Eds.), Reading Foucault for social work. (pp. 27-50). New York, NY: Columbia University Press.

Jerome, A.C., Fujiki, M., Brinton, B., \& James, S.L. (2002). Self-esteem in children with specific language impairment. Journal of Speech, Language, and Hearing Research, 45, 700-714.

Jones, J. (2012). Factors associated with self-concept: Adolescents with intellectual and development disabilities share their perspectives. Intellectual and Development Disabilities, 5(10), 31-46.

Keefe, K., \& Berndt, T. J. (1996). Relations of friendship quality to self-esteem in early adolescence. Journal of Early Adolescence, 16, 110-129. 
LaBarbera, R. (2008). Perceived social support and self-esteem in adolescents with learning disabilities in a private school. Learning Disabilities: A Contemporary Journal, 6(1), 3344.

Lackaye, T., Margalit, M., Ziv, O., \& Ziman, T. (2006). Comparisons of self-efficacy, mood, effort, and hope between students with learning disabilities and their non-LD matched peers. Learning Disabilities Research \& Practice, 21, 111-121.

Lakkis, S., \& Wehbi, S. (2010). Women with disabilities in Lebanon: From marginalization to resistance. Affilia, 25 (1), 56-67.

Lambie, G., \& Milsom, A. (2010). A narrative approach to supporting students with learning disabilities. Journal of Counseling and Development, 88, 196-203.

Lincoln, Y., \& Guba, E. (1985). Naturalistic inquiry. Newbury Park, CA: Sage Publications.

Lind, S., \& Bowler, D. (2009). Delayed self-recognition in children with autism spectrum disorder. Journal of Autism \& Developmental Disorders, 39, 643-650.

Linnenbrink, E. A., \& Pintrich, P. R. (2003). The role of self-efficacy beliefs in student engagement and learning in the classroom. Reading \& Writing Quarterly, 19, 119-137.

May, A., \& Stone, A. (2010). Stereotypes of individuals with learning disabilities views of college students with and without learning disabilities. Journal of Learning Disabilities, 43(6), 486-499.

McDonald, K.E., Keys, C., \& Balcazar, F.E. (2007). Disability race/ ethnicity and gender: Themes of cultural oppression, acts of individual resistance. American Journal of Community Psychology, 39, 145-161.

McEwan, H., \& Egan, K. (1995). Narrative in teaching, learning and research. New York, NY: Teachers College Press, Columbia University. 
McKenzie, K., \& Thomson, R. (2005) What people with learning disabilities understand and feel about a learning disability. Learning Disability Practice, 8 (6), 16-19.

McVittie, A., Goodall, K., \& McKinley, A. (2008). Resisting having learning disabilities by managing relative abilities. British Journal of Learning Disabilities, 36, 256-262.

Mills, S. (2003). Routledge critical thinkers: Michel Foucault. London, UK: Taylor \& Francis Group.

Milsom, A., \& Hartley, M.T. (2005). Assisting students with learning disabilities transitioning to college: What school counselors should know. Professional School Counseling, 8(5), 436-441.

Mohammad, A. (2010). Relationship between self-esteem and academic achievement amongst pre-university students. Journal of Applied Sciences, 10, 2474-2477.

Morvits. E., \& Motta, R. (2001). Predictors of self-esteem: The role of parent child perceptions, achievement and class placement, Journal of Learning Disabilities, 25(1), 72-80.

Nario-Redmond, M. (2010). Cultural stereotypes of disabled and non-disabled men and women: Consensus for global category representation and diagnostic domain. British Journal of Social Psychology, 49, 471-48.

Newton, N. (2010). The use of semi-structured interviews in qualitative research: strengths and weaknesses. Exploring Qualitative Methods, 1(1), 1- 11.

Newman, W.L. (2006). Social research methods: Qualitative and quantitative approaches (6th ed.). Toronto, ON: Pearson Education Inc.

Ollenshaw, J., \& Creswell, J. (2002). Narrative research: A comparison of two restorying data analysis approaches. Qualitative Inquiry, 8(3), 329-347. 
Paterson, L., McKenzie, K., \& Lindsay, B. (2012). Stigma, social comparison and self-esteem in adults with intellectual disabilities. Journal of Applied Research in Intellectual Disabilities, 25, 166-176.

Peile, C., \& McCouat, M. (1997). The risk of relativism: The future of theory of knowledge development in social work. British Journal of Social Work, 27, 343-360.

Peixoto, F., \& Almeida, L.S. (2010). Self-concept, self-esteem and academic achievement: Strategies for maintaining self-esteem in students experiencing academic failure. European Journal of Psychology of Education, 25, 157-175.

Potts, K., \& Brown, L. (2005). Becoming an anti-oppressive researcher. In L. Brown \&S. Strega (Eds.), Research as resistance (pp. 255-286) Toronto, ON: Scholars' Press.

Priestley, M. (2003). Disability: A life course approach polity: Cambridge, UK. Disability Studies Quarterly, 23 (2), 1-5.

Quatman, T., \& Watson, C. M. (2001). Gender differences in adolescent self-esteem: An exploration of domains. The Journal of Genetic Psychology, 162, 93-117.

Riddell, S., \& Watson, N. (2003). Disability, culture and identity. Harlow, UK: Pearson/Prentice Hall.

Riessman, C. (2005). Narrative analysis. In N. Kelly, C. Horrocks, K. Milnes, B. Roberts \& D. Robinson (Eds.), Narrative, memory and everyday life (pp. 1-7). Huddersfield, UK: University of Huddersfield.

Riessman, C. K., \&. Speedy, J. (2007). Narrative inquiry in the psychotherapy professions: A critical review. In D. J. Clandinin (Ed.), Handbook of narrative inquiry: Mapping a methodology (pp. 426-456). Thousand Oaks, CA: Sage Publications. 
Rothman, H.R., \& Cosden, M. (1995). The relationship between self-perception of a learning disability and achievement, self-concept and social support. Learning Disability Quarterly, 18, 203-212.

Rubin, A., \& Babbie, E. (2001). Research methods for social work (4th ed.). Belmont, CA: Wadsworth.

Saracoglu, B., Minden, H., \& Wilchesky, M. (2001). The adjustment of students with learning disabilities to university and its relationship to self-esteem and self-efficacy. Journal of Learning Disabilities, 22, 590-592.

Savaria, E. (2008). "If only I had known...": Young people's participation in the construction of their learning disability. Unpublished Masters of Arts in Early Childhood Studies, Ryerson University.

Scorgie, K., Kildal, L., \& Wilgosh, L. (2010). Post-secondary students with disabilities: Issues related to empowerment and self-determination. Developmental Disabilities Bulletin, $38(1 \& 2), 133-145$.

Shany, M., Wiener, J., \& Assido, M. (2012). Friendship predictor of global self-worth and domain specific-concepts in university students with and without learning disabilities. Journal of Learning Disabilities ,46(5), 444-452.

Sideridis, G. D. (2003). On the origins of helpless behavior in students with learning disabilities: Avoidance motivation? International Journal of Educational Research, 39, 497-517.

Srivastava, S.K. (2013) To study the effect of academic achievement on the level of selfconfidence. Journal of Psychosocial Research, 8(1),41-51.

Stone, E. \& Priestley, M. (1996). Parasites, pawns and partners: Disability research and the role of non-disabled researcher, British Journal of Sociology, 47(4), 699-716. 
Tabassam, W., \& Grainger, J. (2002). Self-concept, attritional style and self-efficacy beliefs of students with learning disabilities with and without attention deficit hyperactivity disorder. Learning Disability Quarterly, 25, 141-151.

Thomas, R. (2006) A general inductive approach for analyzing qualitative evaluation data. American Journal of Evaluation. 27(2), 237-246.

Thurston, W.E., Cove, L. \& Meadows, L.M. (2008) Methodological congruence in complex and collaborative mixed method studies. International Journal of Multiple Research Approaches, 2(1), 2-14.

Tremain, S. L. (Ed.). (2005). Foucault and the government of disability. Ann Arbor, MI: University of Michigan Press.

Troiano, P. (2003). College students and learning disability: Elements of self-concept. Journal of College Student Development, 44 (3), 404-416.

Vaughn, S., Elbaum, B., \& Boardman, A.G. (2001). The social functioning of students with learning disabilities: Implications for inclusion. Exceptionality, 9(1), 47-65.

Wei, X., \& Marder, C. (2012). Self-concept development of students with disabilities: Disability category, gender \& racial differences from early elementary to high school. Remedial \& Special Education, 33(4), 247-257.

Williams, K.L., \& Galliher, R.V. (2006). Predicting depression and self-esteem from social connectedness, support, and competence. Journal of Social and Clinical Psychology, 25, 855-874. 